\title{
Development of a Corrosion Monitoring System for Molten Salt Reactors
}

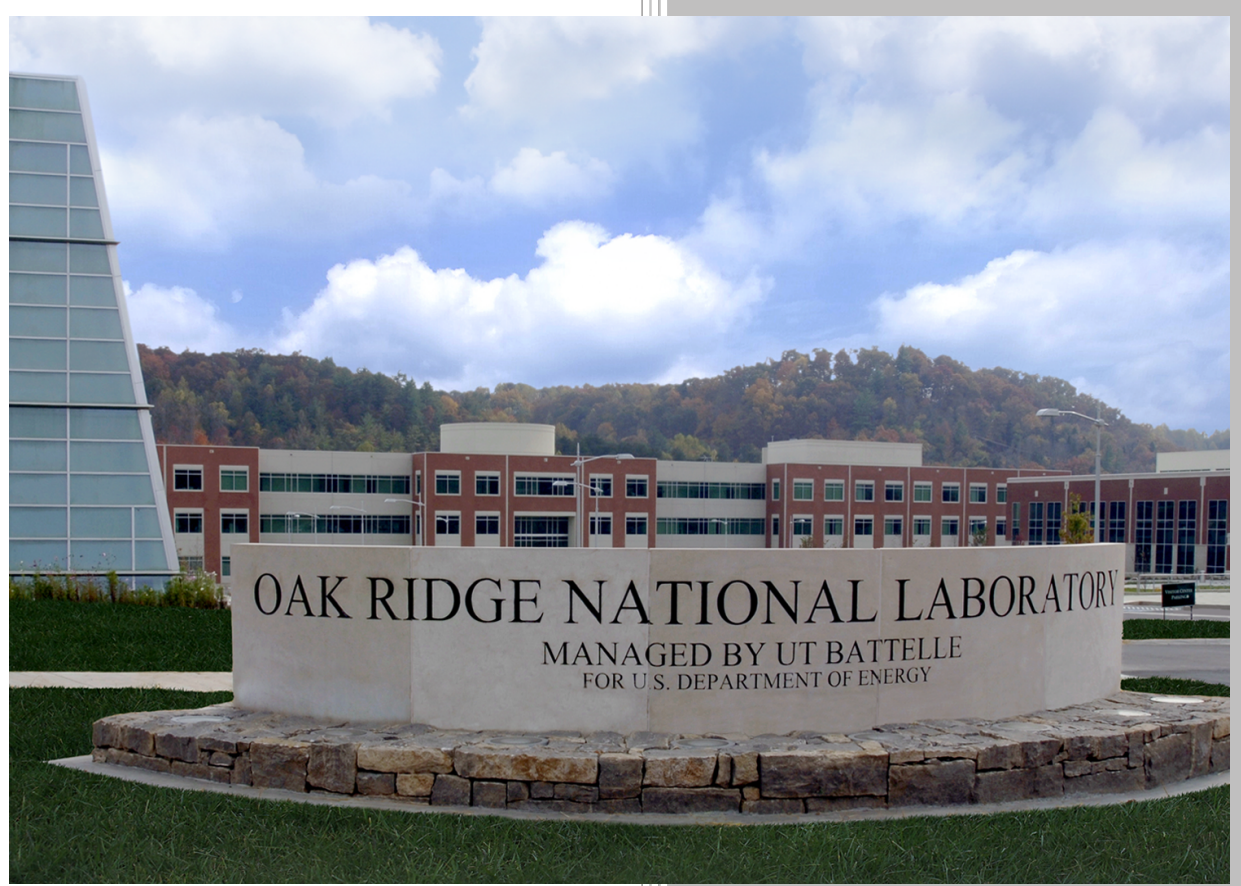

Approved for public release. Distribution is unlimited.
N. Dianne Bull Ezell

Roger Kisner

Nicholas Russell

F. Kyle Reed

Patrick Champlin

James Keiser

Alex Martin

David Holcomb

August 2019 


\section{DOCUMENT AVAILABILITY}

Reports produced after January 1, 1996, are generally available free via US Department of Energy (DOE) SciTech Connect.

Website: www.osti.gov/

Reports produced before January 1, 1996, may be purchased by members of the public from the following source:

National Technical Information Service

5285 Port Royal Road

Springfield, VA 22161

Telephone: 703-605-6000 (1-800-553-6847)

TDD: $703-487-4639$

Fax: 703-605-6900

E-mail: info@ntis.gov

Website: http://classic.ntis.gov/

Reports are available to DOE employees, DOE contractors, Energy Technology Data Exchange representatives, and International Nuclear Information System representatives from the following source:

Office of Scientific and Technical Information

PO Box 62

Oak Ridge, TN 37831

Telephone: 865-576-8401

Fax: 865-576-5728

E-mail: report@osti.gov

Website: http://www.osti.gov/contact.html

This report was prepared as an account of work sponsored by an agency of the United States Government. Neither the United States Government nor any agency thereof, nor any of their employees, makes any warranty, express or implied, or assumes any legal liability or responsibility for the accuracy, completeness, or usefulness of any information, apparatus, product, or process disclosed, or represents that its use would not infringe privately owned rights. Reference herein to any specific commercial product, process, or service by trade name, trademark, manufacturer, or otherwise, does not necessarily constitute or imply its endorsement, recommendation, or favoring by the United States Government or any agency thereof. The views and opinions of authors expressed herein do not necessarily state or reflect those of the United States Government or any agency thereof. 
Reactor and Nuclear Systems Division

\title{
DEVELOPMENT OF A CORROSION MONITORING SYSTEM FOR MOLTEN SALT REACTORS
}

\author{
N. Dianne Bull Ezell \\ Roger Kisner \\ Nicholas Russell \\ F. Kyle Reed \\ Patrick Champlin \\ James Keiser \\ Alex Martin \\ David Holcomb
}

Date Published: August 2019

\author{
Prepared by \\ OAK RIDGE NATIONAL LABORATORY \\ Oak Ridge, TN 37831-6283 \\ managed by \\ UT-Battelle, LLC \\ for the \\ US DEPARTMENT OF ENERGY \\ under contract DE-AC05-00OR22725
}





\section{CONTENTS}

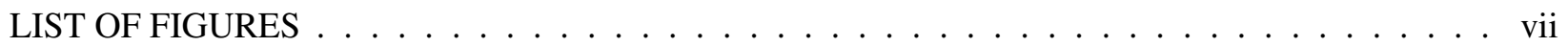

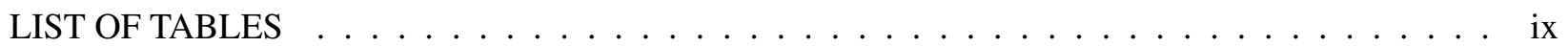

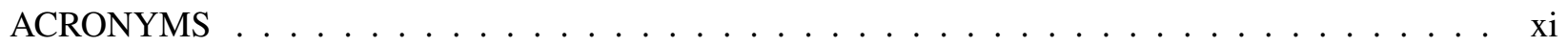

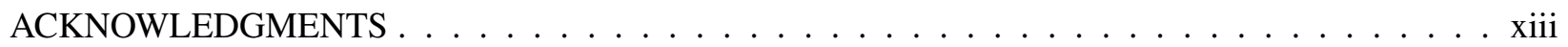

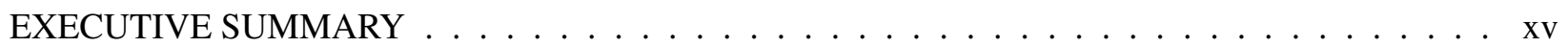

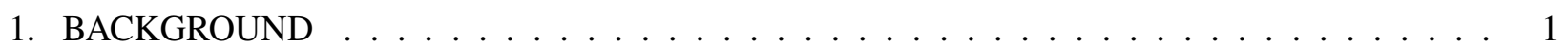

2. DESIGN GEOMETRY AND MATERIAL SELECTIONS $\ldots \ldots \ldots \ldots$

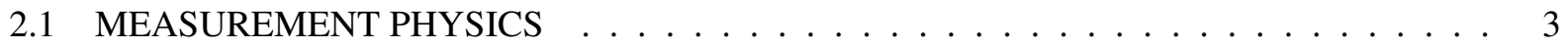

2.1 .1 Eddy Current Loss Discussion $\ldots \ldots \ldots \ldots \ldots$

2.1 .2 Field Saturation Concepts _. . . . . . . . . . . . . . . . . . 5

2.1.3 Permeability of MSR Structural Alloy Changes as Constituent Ratios Change . . . . 8

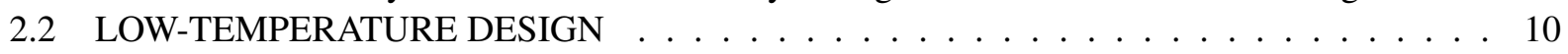

2.2.1 Measurement Apparatus to Observe Permeability Changes. . . . . . . . . . . . . . . 11

2.2.2 Apparatus Using Independent Primary and Secondary Coils Provided Significant Insight . . . . . . . . . . . . . . . . . . . . . 12

2.2.3 Measurement Sensitivity Improvement Using LIA $\ldots \ldots \ldots$

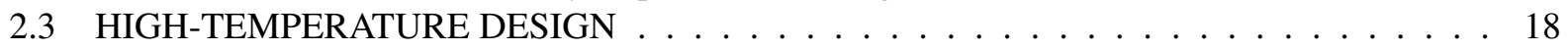

2.3.1 High Temperature Core Alloy . . . . . . . . . . . . . . . . . . . . 18

2.3.2 Test Apparatus Using Hiperco ${ }^{\circledR} 50$ Core Material . . . . . . . . . . . . . . . . . . . 19

2.3 .3 High Temperature Sensor Build . . . . . . . . . . . . . . . . 20

2.3 .4 Hysteresis Loss Discussion . . . . . . . . . . . . . . . . . . . . . 25

2.4 MODELING AND SIMULATION OF HIGH-TEMPERATURE

DESIGN/ELECTROMAGNETIC PERFORMANCE . . . . . . . . . . . . . . . . . 28

2.4.1 Verification of Model Theory . . . . . . . . . . . . . . . . . . . . . 29

2.4.2 Verification of Model to Experiment . . . . . . . . . . . . . . . . . 30

2.4.3 Optimization of the Core with a Corroded Tube . . . . . . . . . . . . . . 35

3. EXPERIMENT TESTBED DESIGN AND IMPLEMENTATION $\ldots \ldots \ldots \ldots$

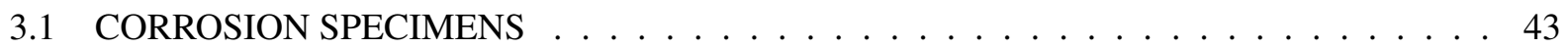

3.2 REFERENCE USED TO COMPENSATE FOR TEMPERATURE EFFECTS . . . . . . . . 46

3.3 ELECTRONIC PACKAGE SELECTION . . . . . . . . . . . . . . . . 47

3.4 TESTBED DESIGN FOR HIGH-TEMPERATURE CORROSION SENSOR . . . . . . 50

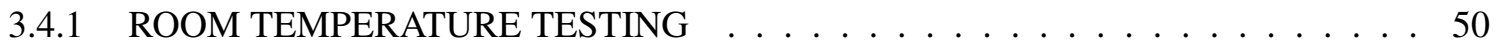

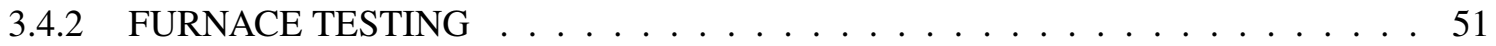

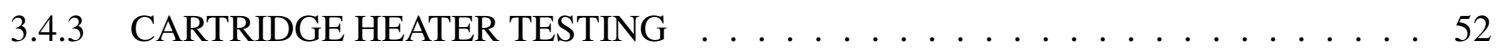

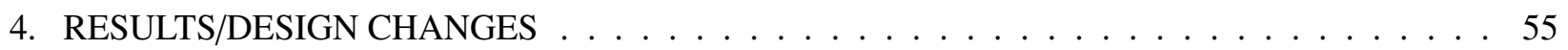

4.1 ROOM TEMPERATURE TESTING . . . . . . . . . . . . . . . 55

4.1.1 Comparing Annealed and Unannealed Hiperco ${ }^{\circledR} 50$ Core Materials . . . . . . . . . 55

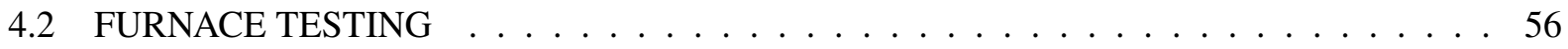

4.2 .1 System Verification . . . . . . . . . . . . . . . . . . 56

4.2.2 Temperature Compensation Reference Verification . . . . . . . . . . . . . . . 57

4.2 .3 Possible Current Drive Implementation . . . . . . . . . . . . . . . . . . . . . . 58

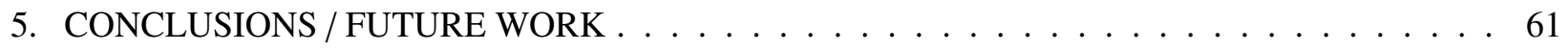

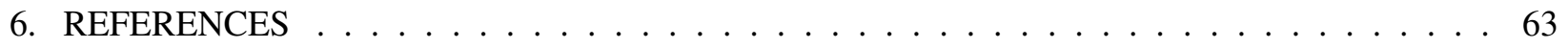





\section{LIST OF FIGURES}

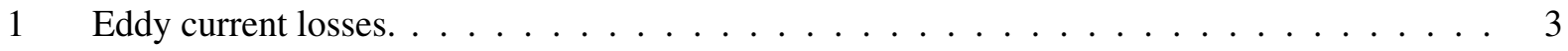

2 Eddy currents develop in the corrosion zone of the pipe wall. . . . . . . . . . . 3

3 Comparison of skin depths vs. frequency for several materials. . . . . . . . . . . 5

4 Illustration of magnetic field lines crossing austenitic stainless steel and coupling through the martensitic corroded layer. . . . . . . . . . . . . . . . . . 5

5 Linear relationship between magnetizing force and flux in vacuum $\left(\mu_{0}\right) \ldots \ldots \ldots$

6 Flux density versus magnetizing force curve for a typical ferromagnetic alloy showing saturation and permeability. . . . . . . . . . . . . . . . 7

7 Effect of changing effective magnetic area on saturation; Area 1 is the largest area. . . . . . 7

8 Schaeffler Diagram for predicting phase characteristic of stainless steel as a function of nickel and chromium. . . . . . . . . . . . . . . . . . . . . . . . . . . 9

9 Stainless steel ternary phase diagram. . . . . . . . . . . . . . . . . . . 9

10 Low-temperature experimental apparatus with corrosion test sample. . . . . . . . . . 10

11 System diagram of the bench top testing. . . . . . . . . . . . . . . . . 11

12 Measurement results using a $10 \mathrm{~mm}$ core gap between $100 \mathrm{~Hz}$ and $1 \mathrm{kHz}$. . . . . . . . . 11

13 Susceptibility measurement of a sample in its simplest form using a transformer configuration. 12

14 Lossy transformer model of corrosion transducer. . . . . . . . . . . . . . . . 13

15 SPICE model response of coupled lossy transformer compared with data from highly corroded sample in a $17 \mathrm{~mm}$ gap. . . . . . . . . . . . . . . . . . . . . . . . . 14

16 Photo of transducer apparatus used in initial susceptibility measurement experiments. . . . . 14

17 Physical dimensions of magnetic transducer . . . . . . . . . . . . . . . . 15

18 Increased corrosion results in higher susceptibility values as determined by output signal

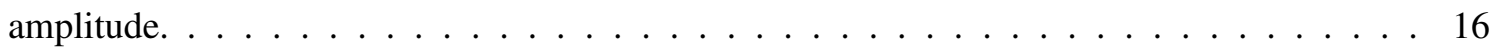

19 Simplified block diagram of an LIA. . . . . . . . . . . . . . . . . . . . . . . 16

20 Example signal-to-noise improvement calculation of LIA based on filter rejection. . . . . . . 17

21 Feedback oscillator using a sensor as a transformer. . . . . . . . . . . . . . . 17

22 A Colpitts oscillator implementation requiring only one port connection (two wires) to the inductive element. . . . . . . . . . . . . . . . . . . . . . . . . 18

23 Configuration for transducer to measure corroded pipe. . . . . . . . . . . . . . . . . . 19

24 Single susceptibility measurement channel using an equation amplifier. . . . . . . . . . . . 20

25 Transducer core lamination configuration and dimensions. . . . . . . . . . . . 20

26 Core loss as a function of induction for $0.006-$ inch $(0.15 \mathrm{~mm})$ sheet. . . . . . . . . . . 21

27 High-temperature corrosion sensor, single lamination. . . . . . . . . . . . . . . . 21

28 Annealed laminations with black oxide bolts prior to the addition of boron nitride layers. . . 22

29 Photos of the stacks of Hiperco ${ }^{\circledR} 50$ sheets before and after annealing. . . . . . . . . . . . 23

30 Fume hood containing boron nitride application to Hiperco ${ }^{\circledR} 50$ process. . . . . . . . . . . 23

31 Hiperco ${ }^{\circledR} 50$ laminations with boron nitride layer applied. . . . . . . . . . . . . . . 24

32 Annealed Hiperco ${ }^{\circledR} 50$ stack with boron nitride insulation. . . . . . . . . . . . . . . . . . . 24

33 Prototype PTFE bobbin drawing. . . . . . . . . . . . . . . . . . . . . 26

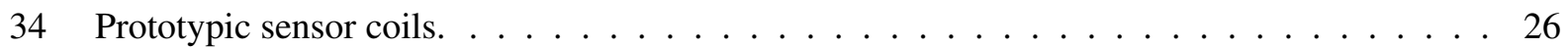

35 High-temperature ceramic bobbin. . . . . . . . . . . . . . . . . . . . 27

36 Hysteresis curves for magnetically soft and hard materials showing hysteresis loss. . . . . . 27

37 Circuit used to measure the relative hysteresis curves of the sensor cores. . . . . . . . . . 28 
38 Relative hysteresis curves of Hiperco ${ }^{\circledR} 50$ for the unannealed segmented core, the unannealed single-cut core, and the annealed single-cut core at $300 \mathrm{~Hz}$ and $1000 \mathrm{~Hz}$. . . . . 29

39 Geometry of the corrosion monitor model. . . . . . . . . . . . . . . . . . . . 30

40 Geometry of a wrapped wire, Where $\mathrm{h}$ is the height of a single packed layer in $\mathrm{mm}$, and $\mathrm{d}$ is the diameter of the wire in $\mathrm{mm} . \ldots \ldots \ldots \ldots \ldots$

41 Comparison of model to theory for the magnetic flux density on the axis of a stranded coil. . 31

42 Magnetic flux density ( $\mathrm{T}$ ) of a $25 \mathrm{~mm}$ diameter coil with $0.5 \mathrm{~A}$ current and 150 turns. . . . . 31

43 Response surface of a stranded coil as a function of coil diameter and offset from the point of measurement. . . . . . . . . . . . . . . . . . . . . . 32

44 Measured and simulated relative hysteresis curves of the core with no tube present. . . . . . 34

45 Flux density (T) within the core with no tube present for a current of 0.5 A. . . . . . . . 34

46 Flux density (T) outside the core with no tube present for a current of 0.5 A. . . . . . . 36

47 Flux density (T) in the corrosion layer for a nominal $28.5 \mathrm{~mm}$ coil with a current of $0.5 \mathrm{~A}$ for a corrosion layer $30 \mu \mathrm{m}$ and $130 \mu \mathrm{m}$ thick. Notice there is little change between the cases. 36

48 Flux density $(\mathrm{T})$ in the corrosion layer for a nominal $28.5 \mathrm{~mm}$ coil with a current of $0.8 \mathrm{~A}$ for a corrosion layer $30 \mu \mathrm{m}$ and $130 \mu \mathrm{m}$ thick. . . . . . . . . . . . . 38

49 Flux density $(\mathrm{T})$ in the corrosion layer for a large $43.6 \mathrm{~m}$ coil with a current of $0.5 \mathrm{~A}$ for a corrosion layer $30 \mu \mathrm{m}$ and $130 \mu \mathrm{m}$ thick. . . . . . . . . . . . . 38

50 Flux density $(\mathrm{T})$ in the corrosion layer for a nominal $28.5 \mathrm{~mm}$ coil with a current of $0.8 \mathrm{~A}$ for a corrosion layer $30 \mu \mathrm{m}$ and (130 $\mu$ m thick. The wires are wrapped with more layers. . . 40

51 Response surface for the receiver flux density as a function of corrosion layer thickness and coil offset. . . . . . . . . . . . . . . . . . . . . . 41

52 Relative sensitivities of output parameters to the input parameters for the case of a nominal sensor with an $80 \mu \mathrm{m}$-corroded pipe. Larger bars indicate more impactful parameters. 41

53 Flux density (T) within the core with a $30 \mu \mathrm{m}$-corroded pipe present, for nominal coil dimensions and a 0.5 A current. . . . . . . . . . . . . . . . . . . . 42

54 Alumina crucible used for initial exposure of stainless steel cubes to molten chloride salt. . . 43

55 Photo showing stainless steel sample in the bottom of the nearly salt-free alumina crucible. . 44

56 Stainless steel pipe capsule providing outer containment of the quartz crucible-which contained the chloride salt and two stainless steel cubes-shown before and after elevated temperature exposure at $750{ }^{\circ} \mathrm{C} \ldots \ldots \ldots \ldots \ldots \ldots$

57 Photo showing quartz crucible containing the salt and stainless cubes after elevated temperature exposure, demonstrating successful containment of the salt in the quartz crucible. 45

58 Micrographs of 304L stainless steel samples exposed to molten salt at $750{ }^{\circ} \mathrm{C}$ for 20 hours, demonstrating a weight loss of $12.0 \mathrm{mg}$ and $23.6 \mathrm{mg}$. . . . . . . . . . . . . 45

59 Example magnetization curve for magnetite showing the effect of decreasing permeability with temperature and Curie point. . . . . . . . . . . . . . 46

60 A dual channel system constructed to permit simultaneous readout of a measurement transducer and a reference transducer. . . . . . . . . . . . . . . 47

61 Complex impedance of the coils. . . . . . . . . . . . . . . . . . . . . 49

62 System block diagrams of the room temperature experiment and the furnace experiment. . . 49

63 Graphical user interface for the LabVIEW data collection program. . . . . . . . . . . . . 50

64 Room temperature testing of pipe using single corrosion sensor topology. . . . . . . . . . 50

65 Room temperature testing of pipe using single sensor with TCR topology. . . . . . . . . . 51

66 Furnace testing $\left(200-300^{\circ} \mathrm{C}\right)$ of pipe using single sensor with TCR topology. . . . . . . . 52 
67 Cartridge heater testing $\left(700-800{ }^{\circ} \mathrm{C}\right)$ of pipe using a single sensor with TCR topology. . . . 53

68 Cartridge heater bench-top evaluation of performance. . . . . . . . . . . . . . . . 54

69 Thermal imaging system used as secondary performance monitoring system. . . . . . . . . . 54

70 C-shaped Hiperco ${ }^{\circledR} 50$ core with transmit and receive coils. . . . . . . . . . . . . . . . 55

71 Magnitude response for cube samples with annealed core (a) and unannealed core (b). . . . 55

72 Magnitude response of the H-FM-10 sample for annealed and unannealed sensors. . . . . . . 56

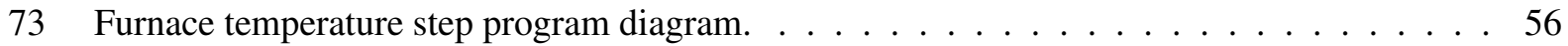

74 System verification placement without pipe and with pipe. $\ldots \ldots \ldots \ldots$

75 Temperature response of the system verification tests. . . . . . . . . . . . 58

76 TCR placement within the furnace. . . . . . . . . . . . . . . . . 58

77 Temperature responses of all sensors in the TCR test and the differences between their trendlines. . . . . . . . . . . . . . . . . . . . . . 59 



\section{LIST OF TABLES}

1 Calculated skin depths for several materials $\ldots \ldots \ldots \ldots \ldots$

2 Example compositions of austenitic Types 304 and 304L and martensitic 420 stainless steel . 8

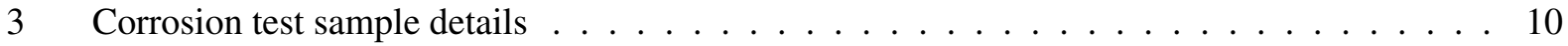

4 Lossy transformer circuit parameters . . . . . . . . . . . . . . . . . . . . 13

5 Elemental composition of Hiperco ${ }^{\circledR} 50 \ldots \ldots \ldots \ldots \ldots \ldots$

6 Annealing conditions used for Hiperco ${ }^{\circledR} 50$ strips $\ldots \ldots \ldots \ldots \ldots$. . . . . . . . . 22

7 Inputs for the illustrative cases and optimization study used in the analysis of the monitor sensitivity, or change in average receiver coil flux density per change in corrosion layer

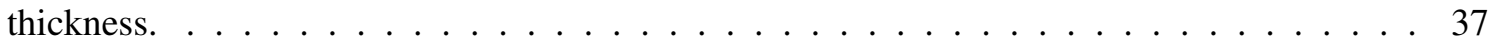

8 Summary of samples exposed in $\mathrm{NaCl}-\mathrm{MgCl} 2$ salt at $750{ }^{\circ} \mathrm{C} \ldots \ldots \ldots$. . . . . . . . . 44

9 Coil characteristics . . . . . . . . . . . . . . . . . . . . . 48

10 Experimental test parameters for system verification $\ldots \ldots \ldots \ldots \ldots$ 

ACRONYMS

$\begin{array}{ll}\text { AC } & \text { alternating current } \\ \text { AWG } & \text { American Wire Gauge } \\ \text { BCC } & \text { body-centered cubic } \\ \text { DC } & \text { direct current } \\ \text { FCC } & \text { face-centered cubic } \\ \text { FY } & \text { fiscal year } \\ \text { GUI } & \text { graphical user interface } \\ \text { HTP } & \text { high-temperature prototype } \\ \text { ID } & \text { inner diameter } \\ \text { LIA } & \text { lock-in amplifier } \\ \text { LTP } & \text { low-temperature prototype } \\ \text { MMF } & \text { magnetomotive force } \\ \text { MSR } & \text { molten salt reactor } \\ \text { OD } & \text { outer diameter } \\ \text { ORNL } & \text { Oak Ridge National Laboratory } \\ \text { PLL } & \text { phase-lock loop } \\ \text { PTFE } & \text { polytetrafluoroethylene } \\ \text { RMS } & \text { root mean square } \\ \text { RSM } & \text { response surface methodology } \\ \text { TCR } & \text { temperature compensation reference }\end{array}$





\section{ACKNOWLEDGMENTS}

This work is funded by the US Department of Energy's office of Nuclear Energy, Molten Salt Reactor (MSR) Campaign under the Advanced Reactor Technology (ART) program. The authors would like to thank Dave Bryant, Shay Chapel, Christi Johnson, Mike Stephens, and Adam Willoughby for their efforts on this project. 



\section{EXECUTIVE SUMMARY}

Molten salt reactors (MSRs) have been identified as one of several possible next-generation advanced reactor designs that could replace the aging fleet. There are many inherent advantages to MSRs, including higher power density, lower pressure, low stored energy, and prompt negative temperature reactivity coefficient Ezell et al. [2018]. However, there are challenges related to the operating temperatures, as well as, the corrosive salts attacking the structural materials. During the Molten Salt Reactor Experiment (MSRE), which was operated at Oak Ridge National Laboratory (ORNL) (Ignatiev et al. [2014], Forsberg et al. [2007], Forsberg et al. [2008], Delpech et al. [2009], Serp et al. [2014], Ignatiev and Surenkov [2017]) corrosion was monitored by sampling the salt for chromium. However, this type of monitoring does not identify the location of corrosion. In FY18, ORNL developed a novel in-situ corrosion sensor that could be placed on the outside of the structure to monitor changes in magnetic susceptibility of salt-wetted alloys as corrosion occurs Holcomb et al. [2019].

Initial testing with this novel sensor demonstrated a correlation between the change in signal output from the sensor to the various levels of pre-corroded test specimens. However, all initial testing was performed at room temperatures, which is not realistic for the harsh MSR environment. Based on this research, FY19 funding allowed for development of a high-temperature version of the sensor to be installed at various locations on the reactor infrastructure. The high-temperature sensor can operate at up to $750{ }^{\circ} \mathrm{C}$ and can monitor development of corrosion inside the pipe. This sensor measures the increase in magnetic susceptibility that occurs as chromium dissolves from the inner surface of the pipe, when paramagnetic structural alloys become ferromagnetic with the loss of chromium.

This report will discuss the development of corrosion monitoring sensor and the testing with results of corroded specimens at increasing temperatures. 



\section{BACKGROUND}

The purpose of the corrosion sensor is to observe the onset and progress of corrosion in molten salt container alloys under molten salt reactor (MSR) operating conditions. Molten halide salts can become highly corrosive if contaminated with oxygen. Consequently, development of a sensor to monitor the onset and progress of corrosion is of high-value and interest to MSR developers. The sensor functions by detecting the change in alloy magnetic properties caused by corrosion, or more specifically, the development of ferromagnetism in the alloy surface upon the selective removal of chromium. Details of the measurement principles progress during the initial phase of the project were reported at the 2019 Nuclear Power Instrumentation, Controls and Human-Machine Interface Technology conference Holcomb et al. [2019].

The project began in mid FY2018. The first phase of the project focused on establishing whether a useful measurement could be made under MSR conditions. The work included multiple subtasks:

1. Materials property assessment - Determine whether ferromagnetism will persist above $700{ }^{\circ} \mathrm{C}$. Determine whether the increase in ferromagnetism can be detected through the pipe wall.

2. Basic sensor design - Use of the corroded material as a leg in a transformer and a phase-lock style signal processing system were selected.

3. Laboratory sensor prototype fabrication - The laboratory prototype is to be designed and built using readily available materials.

4. Corroded sample preparation - Preparation of corroded samples will be accomplished under fixed conditions and metallographic examination.

5. System sensitivity demonstration - Response measurement will be performed using the corroded samples and laboratory prototype.

6. Initiation of high-temperature design - Materials will be selected and a plan developed for Phase 2 . The potential for remotely locating detection electronics and only employing extremely radiation-tolerant materials near an MSR fuel circuit will be assessed.

The first project phase was successful in that the project team did identify and successfully perform measurement of progressively increasing amounts of corrosion on representative material samples at room temperature, and the team also identified a path forward for performing equivalent measurement at high (above $700{ }^{\circ} \mathrm{C}$ ) temperature. 



\section{DESIGN GEOMETRY AND MATERIAL SELECTIONS}

\subsection{MEASUREMENT PHYSICS}

\subsubsection{Eddy Current Loss Discussion}

An alternating current (AC) produces a proportional alternating magnetic flux that in turn induces an eddy current, as shown in Figure 1a. Eddy currents in solid core materials take unimpeded paths with attendant heat loss. Eddy currents flow orthogonal to magnetic flux, so a solid iron core will develop shorted turns along its length. The eddy current circulates in the core and dissipates energy. Constructing the core using ferromagnetic laminations that are electrically insulated individually prevents full circulating eddy current loss, thus reducing the eddy currents to shorter confined paths, as shown in Figure 1b.

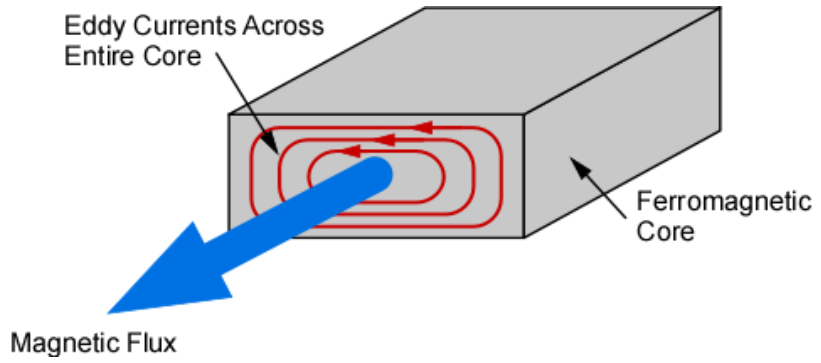

(a) Eddy currents in solid core.

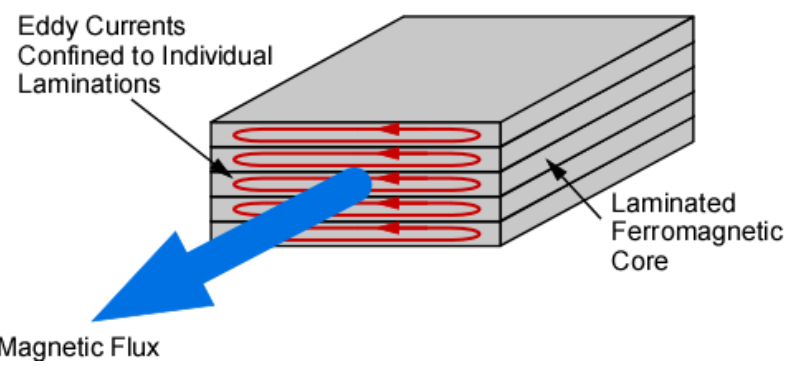

(b) Eddy currents in laminated core.

Figure 1. Eddy current losses.

Eddy currents will develop in the corrosion zone of the pipe wall as magnetic flux passes through. These eddies are illustrated in Figure 2. A skin depth of $1 \mathrm{~mm}$ or greater is expected over the frequency range from $100-1,000 \mathrm{~Hz}$ for the emerging magnetically susceptible region (see Figure 3 ). The actual chromium depleted region will be much thinner, so eddy currents should not introduce a significant detrimental factor. Table 1 provides the skin depth vs. frequency data required to fully understand the eddy current in the corrosion zone of the samples.

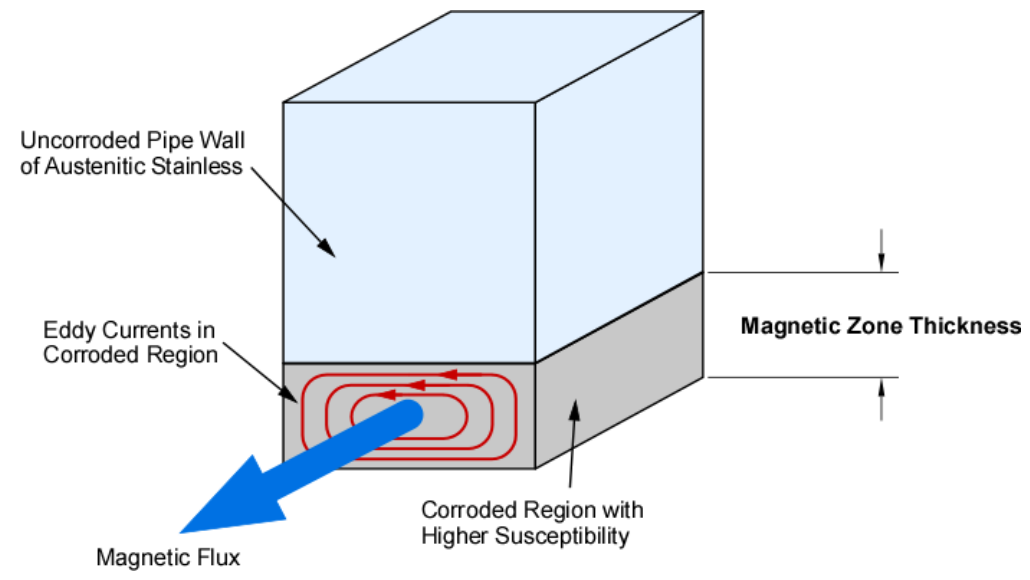

Figure 2. Eddy currents develop in the corrosion zone of the pipe wall. 


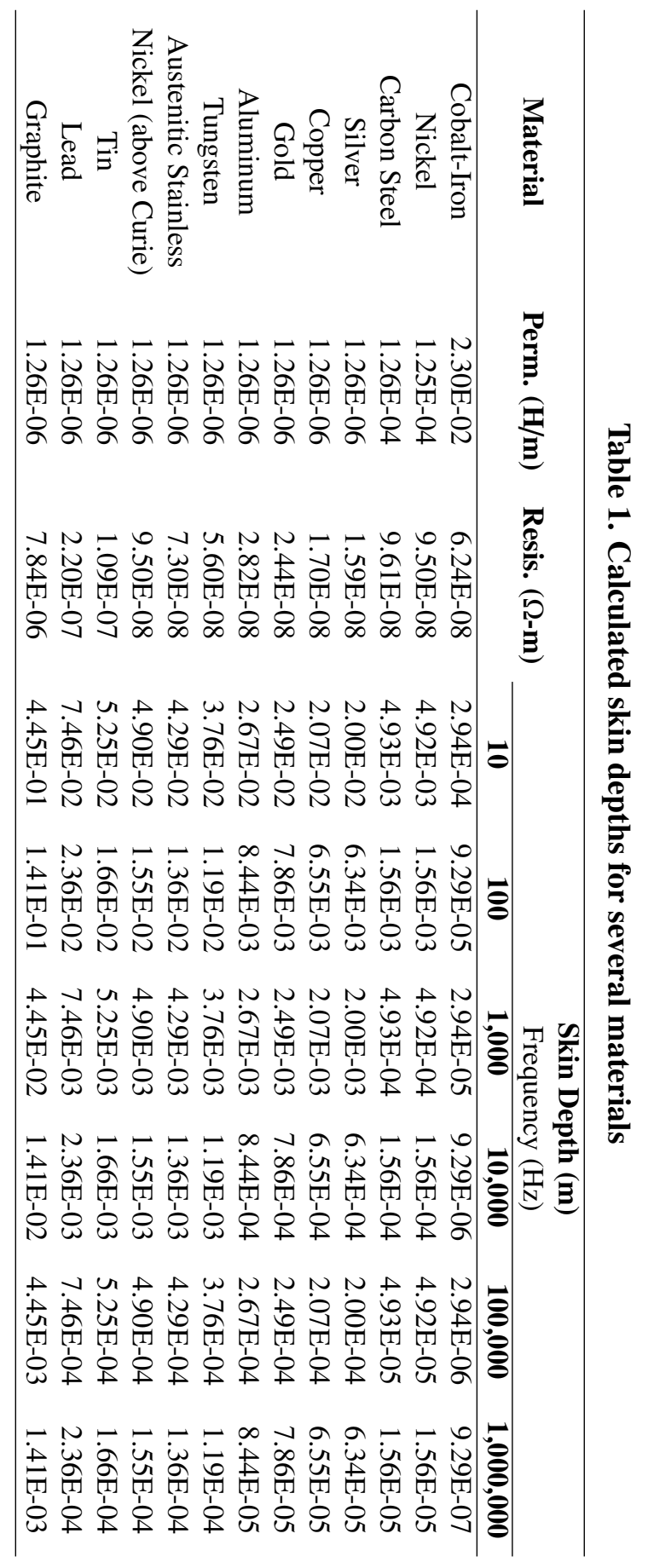




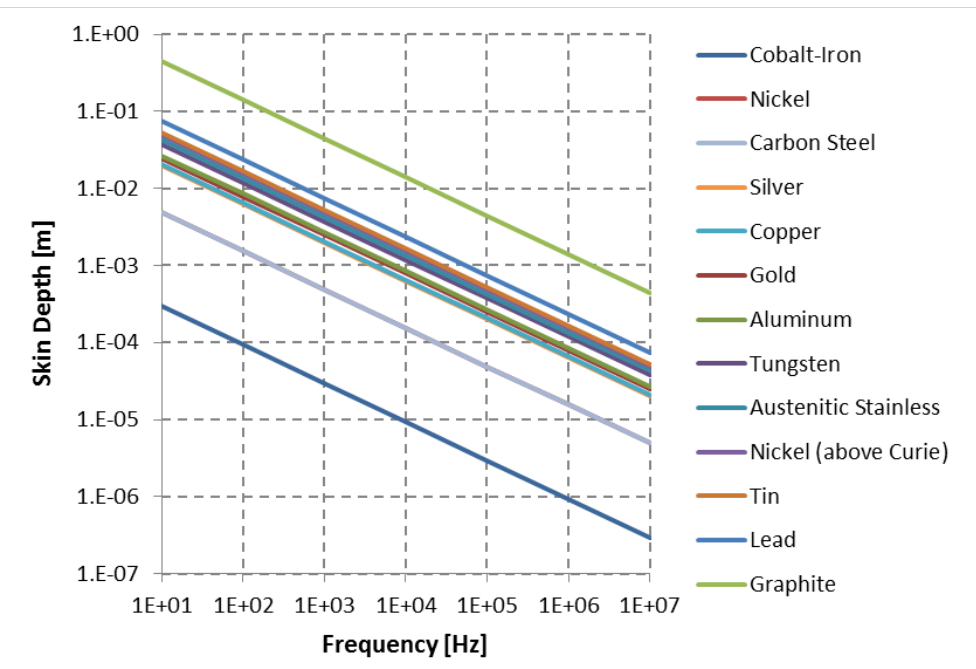

Figure 3. Comparison of skin depths vs. frequency for several materials.

\subsubsection{Field Saturation Concepts}

The objective is to detect corrosion onset by observing small changes in permeability (susceptibility) resulting from removal of chromium, as illustrated in Figure 4 in which the pipe is modeled simply as a plate. The chromium removal process occurs at the interface between the metal and the molten salt. Chromium is removed from progressively deeper levels in the wall thickness. At first, with no corrosion, the austenitic stainless steel behaves as mostly paramagnetic, which results in high magnetic reluctance; the field lines connect between poles as through in a vacuum. The relationship approaches that of free space, which is linear and has no saturation component, as shown in Figure 5.

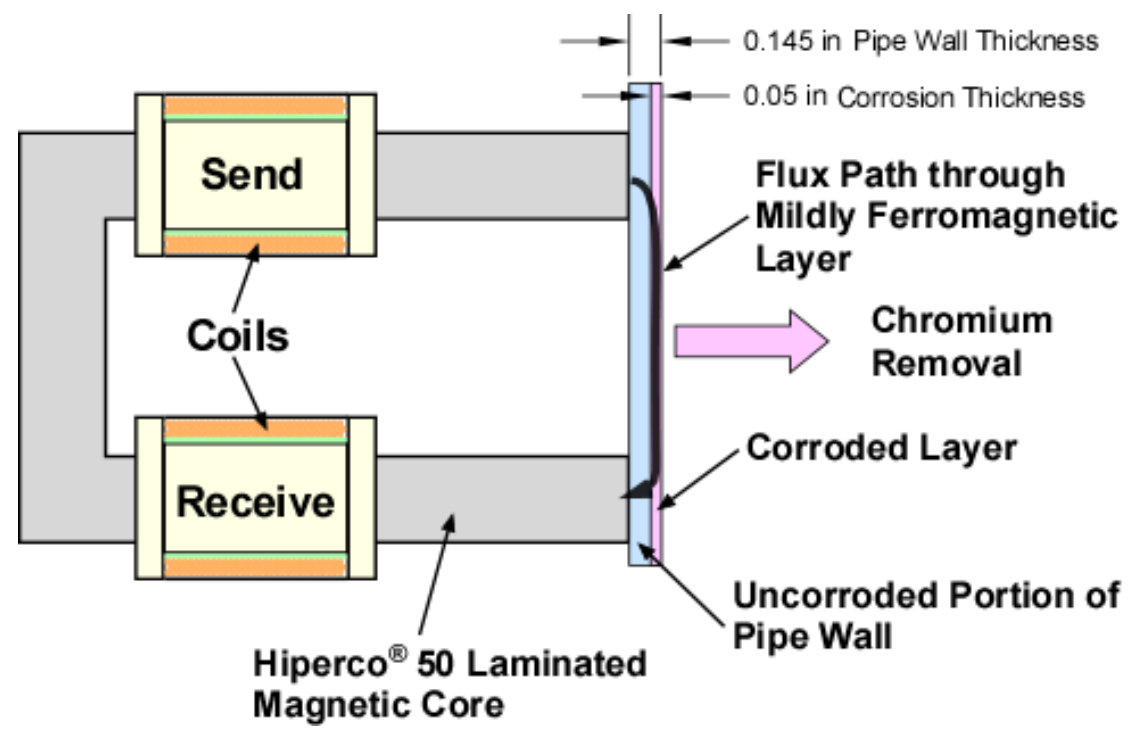

Figure 4. Illustration of magnetic field lines crossing austenitic stainless steel and coupling through the martensitic corroded layer. 


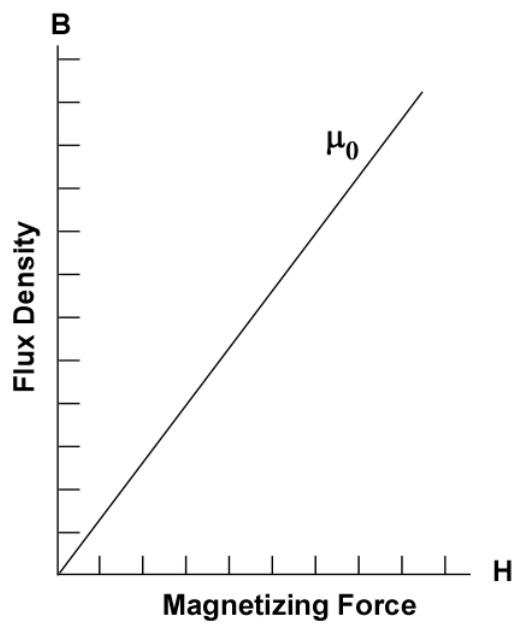

Figure 5. Linear relationship between magnetizing force and flux in vacuum $\left(\mu_{0}\right)$.

However, as a chromium-depleted layer forms and thickens, as shown in Figure 4, magnetic flux enters this lower reluctance region of the plate and is conducted to the opposite pole. The flux $(\phi)$ is inversely proportional to the magnetic reluctance $(\mathscr{R})$, as shown in Equation 1, where $\mathscr{F}$ is the magnetomotive force $(\mathrm{MMF})(N \times I)$. The total reluctance $\left(\mathscr{R}_{T}\right)$ is the summation of all reluctances (Equation 2$)$ around the magnetic loop, including the stainless steel path, in parallel with the air path. The flux density $(B)$ in the (corroded) stainless steel is inversely proportional to the stainless steel path area $\left(A_{c}\right)$, as shown in Equation 3.

$$
\begin{gathered}
\phi=\frac{\mathscr{F}}{\mathscr{R}_{T}}=\frac{\mathscr{F}}{\sum_{i} \mathscr{R}_{i}} \\
\mathscr{R}_{i}=\frac{l_{i}}{\mu_{0} \mu_{r i} A_{i}} \\
B=\frac{\phi}{A_{c}}=\frac{\mathscr{F}}{\sum_{i} \mathscr{R}_{i}}
\end{gathered}
$$

Saturation in a ferromagnetic material follows a general hysteresis curve, as shown in Figure 6. In the figure, flux density, $B$, develops in the material with the applied field, $H$. The gain (slope of the curve) is proportional to the material's permeability until saturation prevents further increase. Once in the saturation region, further increases in flux density become a function of the paramagnetic permeability of the material, which approaches that of free space $\left(\mu_{0}\right)$. Given the magnetic configuration of Figure 4 , as the corroded layer ranges from a small cross sectional area (area 4 in the figure) to a larger area (area 1), the hysteresis curve is expected to behave as shown in Figure 7, where the effective gains are a function of the cross sectional areas at small magnetizing forces. However, at larger magnetization, the pathway becomes saturated, and the effective gain resorts to that of free space. Free space is shown as the linear red curve which follows $B=\mu_{0} H$. The curves actually may be much more compressed than indicated by the illustration. 


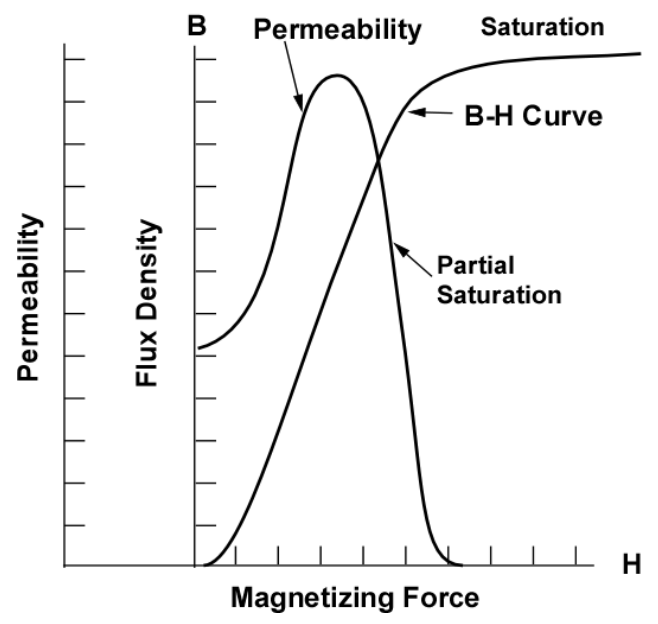

Figure 6. Flux density versus magnetizing force curve for a typical ferromagnetic alloy showing saturation and permeability.

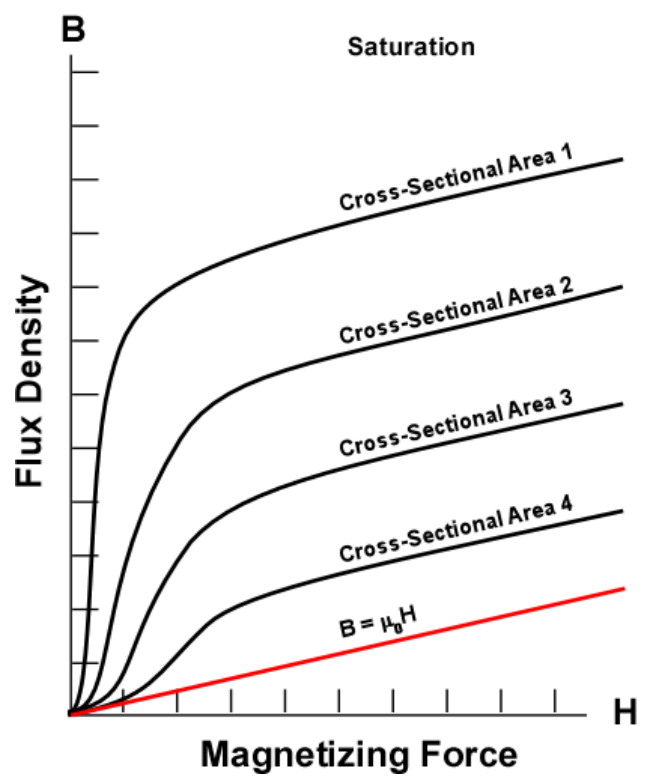

Figure 7. Effect of changing effective magnetic area on saturation; Area 1 is the largest area.

This saturation phenomenon can indicate the need for an additional test to determine whether a zone of higher susceptibility is forming in the target pipe. For the typical measurement, the amplitude of AC magnetization is fixed by driving a constant current at frequency to the sender coil. However, by modulating the amplitude of the magnetizing force (varying the driving current) at a relatively slow frequency compared with the carrier frequency, the resulting flux density as measured by the receiving coil can be used to resolve the curve shape. The curve shape can be back-fitted to identify the emerging ferromagnetic area, as suggested by Figure 7. Experiments using this method have not yet been performed. 


\subsubsection{Permeability of MSR Structural Alloy Changes as Constituent Ratios Change}

The magnetic properties of structural alloys derive from the configuration of their constituent atoms. Nearly all MSR container structural alloys are composed primarily of nickel, iron, and chrome, frequently with a significant amount of molybdenum. Ferromagnetism in solids arises when the orbitals of unpaired outer electrons overlap, causing their electrostatic energy to be lower when the electron spins are aligned in parallel than when they are anti-parallel. The amount of overlap of the orbitals is determined by the configuration of the individual atoms.

Austenitic stainless steels with around 10-12\% nickel (e.g., grades 304, 316, 321 and 347, which are candidate MSR container materials) are predominantly non-magnetic due to the face-centered cubic (fcc) crystal structure of their austenite phase, in which the amount of orbital overlap between unpaired electrons is too small to result in spin alignment. Nevertheless, the 300 series exhibits slight magnetic attraction because (1) samples can contain up to $8 \%$ ferrite formed after solidification or (2) martensitic transformation (a body-centered tetragonal supersaturated with carbon) can result from cold working or machining. Martensite is ferromagnetic. Nearly all structural alloys of interest have an fcc crystal structure due to their higher ductility. Body-centered cubic (bcc) materials tend to be hard/brittle. Pure low-carbon iron is a bcc ferromagnetic material ( $\alpha$-iron), whereas pure nickel is an fcc ferromagnetic material. Iron maintains its ferromagnetic properties up to a higher temperature than nickel due to the comparative stability of the electron orbital overlap provided by its bcc structure. The presence of chromium in an iron-nickel lattice tends to promote formation of an fcc, non-ferromagnetic phase.

Stainless steel types 304, 304L (a lower carbon version of 304 that minimizes detrimental carbide precipitation as a result of welding), and 420 have compositions as shown in Table 2.

\section{Table 2. Example compositions of austenitic Types 304 and 304L and martensitic 420 stainless steel}

\begin{tabular}{cccc}
\hline Element & Type 304 $(\%)$ & Type 304L $(\%)$ & Type 420 $(\%)$ \\
\hline Iron & Balance & Balance & Balance \\
Chromium & $17.5-20$ & $18-20$ & $12-14$ \\
Nickel & $8-11$ & $8-12$ & 0 \\
Manganese & 2 max. & 2 max. & 1 max. \\
Silicon & 1 max. & 0.75 max. & 1 max. \\
Nitrogen & 0.10 max. & 0.10 max. & 0 \\
Carbon & 0.08 max. & 0.03 max. & 0.15 max. \\
Phosphorous & 0.045 max. & 0.045 max. & 0.04 max. \\
Sulfur & 0.03 max. & 0.03 max. & 0.03 max. \\
\hline
\end{tabular}

Note that the 400 series listed in the table has notably lower chromium content and higher carbon than the 304 stainless stell with no nickel. The 400 series stainless steels are martensitic and magnetic.

The magnetic properties of stainless steel alloys are associated with crystalline structure and compositions austenite, martensite, and ferrite. These structures are shown in the Schaeffler diagram in Figure 8. Austenite is paramagnetic, while ferrite is ferromagnetic, and martensite is mildly ferromagnetic. The approximate region for 304 stainless steel in this parameter space is indicated by the dashed line in Figure 8. Type 304 stainless steel lies just at the boundary of being austenite. As chromium is lost, the alloy moves left into the austenite-plus-martensite region, with the martensite being magnetic. Depending on where in the zone (shown in red) the alloy composition starts, there may be a double-valued response. It 


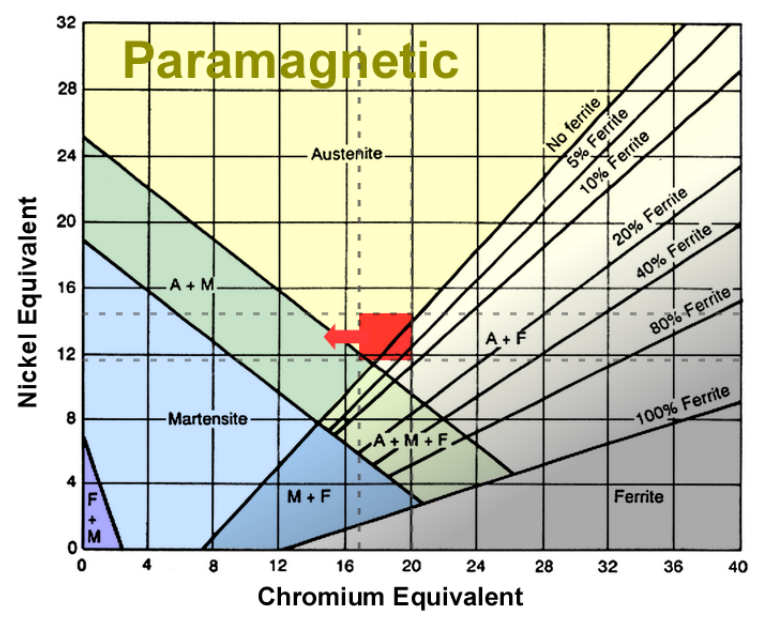

Figure 8. Schaeffler Diagram for predicting phase characteristic of stainless steel as a function of nickel and chromium. Guiraldeng and Duparc [2017]

is possible for an initial loss of chromium at first to lower the apparent susceptibility, although it may have already started quite low. Then, with further chromium loss, the alloy crosses the A+M boundary, where the susceptibility monotonically increases. It is this variation in susceptibility that the corrosion measurement instrument will detect.

Inconel 617 is a nickel-chromium-cobalt-molybdenum alloy that would need to rely on the cobalt magnetism for the high temperature magnetism, as nickel would be above its Curie temperature. Ni-Co would be ferromagnetic. It does not appear that purely nickel-based super alloy will have the same susceptibility changes as 304 stainless steel (Figure 9).

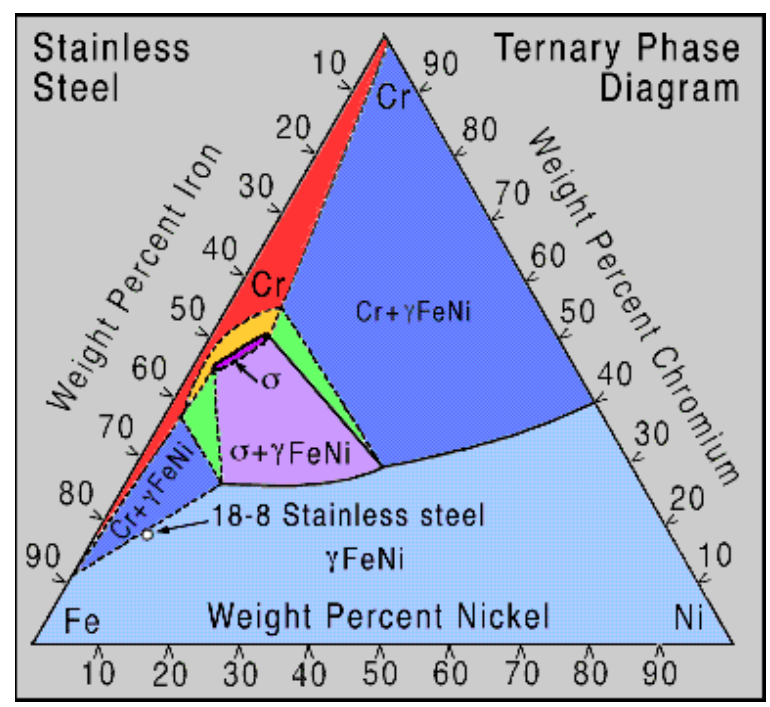

Figure 9. Stainless steel ternary phase diagram. 


\subsection{LOW-TEMPERATURE DESIGN}

A low-temperature prototype (LTP) was built from a modified Hammon Manufacturing 229D40 power transformer. A corrosion test sample was positioned in the gap region, and a printed positioning rail was implemented to ensure repeatability. There is virtually no gap between the poles and the corrosion test sample (see Figure 10).

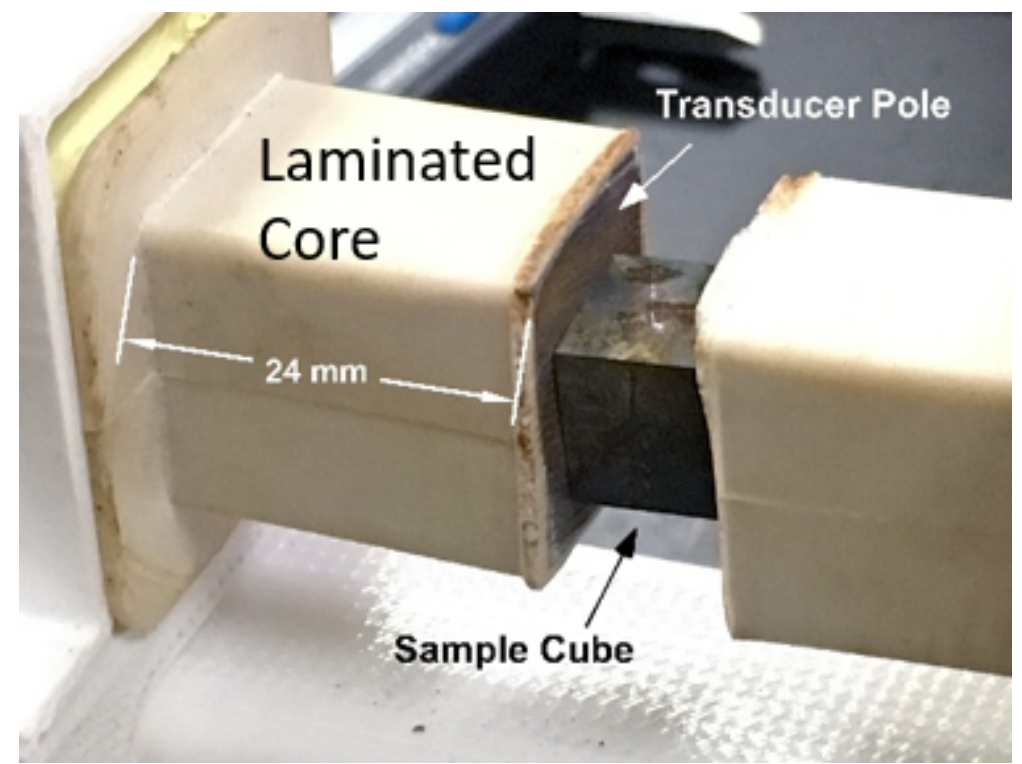

Figure 10. Low-temperature experimental apparatus with corrosion test sample. Holcomb et al. [2019].

Six specimens were fabricated and corroded for testing in the LTP (see Table 3 Holcomb et al. [2019]). The weight changes after corrosion were recorded before testing. After testing, the specimens were examined using a scanning electron microscope to verify the level of corrosion on each sample. Preliminary testing determined that minimizing the gap between the sensor and the test sample ensured the best performance. Also, the effects based on orientation of the test samples were tested, and it was determined that the samples show anisotropic properties.

Table 3. Corrosion test sample details

\begin{tabular}{|c|c|c|c|c|c|c|}
\hline \multirow{2}{*}{ Index } & \multirow{2}{*}{ Sample No. } & \multicolumn{4}{|c|}{ Exposure Conditions } & \multirow{2}{*}{ Weight Change (mg) } \\
\hline & & Time (hr) & Temp $\left({ }^{\circ} \mathrm{C}\right)$ & Salt Mix & Container & \\
\hline 1 & Uncorroded & 0 & $\mathrm{~N} / \mathrm{A}$ & None & Unexposed & 0.00 \\
\hline 2 & 7 & 48 & $\approx 750$ & $\mathrm{NaCl}-\mathrm{MgCl}_{2}$ & Quarts/SS pipe & 14.66 \\
\hline 3 & 6 & 48 & $\approx 750$ & $\mathrm{NaCl}-\mathrm{MgCl}_{2}$ & Quarts/SS pipe & 14.58 \\
\hline 4 & 4 & 20 & $\approx 750$ & $\mathrm{NaCl}-\mathrm{MgCl}_{2}$ & Quarts/SS pipe & 12.00 \\
\hline 5 & 5 & 20 & $\approx 750$ & $\mathrm{NaCl}-\mathrm{MgCl}_{2}$ & Quarts/SS pipe & 23.55 \\
\hline 6 & High Corrosion & $\approx 60$ & $\approx 750$ & $\mathrm{NaCl}-\mathrm{MgCl}_{2}$ & & $\mathrm{~N} / \mathrm{A}$ \\
\hline
\end{tabular}

A class-D switching power amplifier drives one side of the LTP. To ensure a high sensitivity with minimum noise and drift, the output is measured using a lock-in amplifier (LIA) which is swept from $10 \mathrm{~Hz}$ to 100 $\mathrm{kHz}$ (Figure 11). 


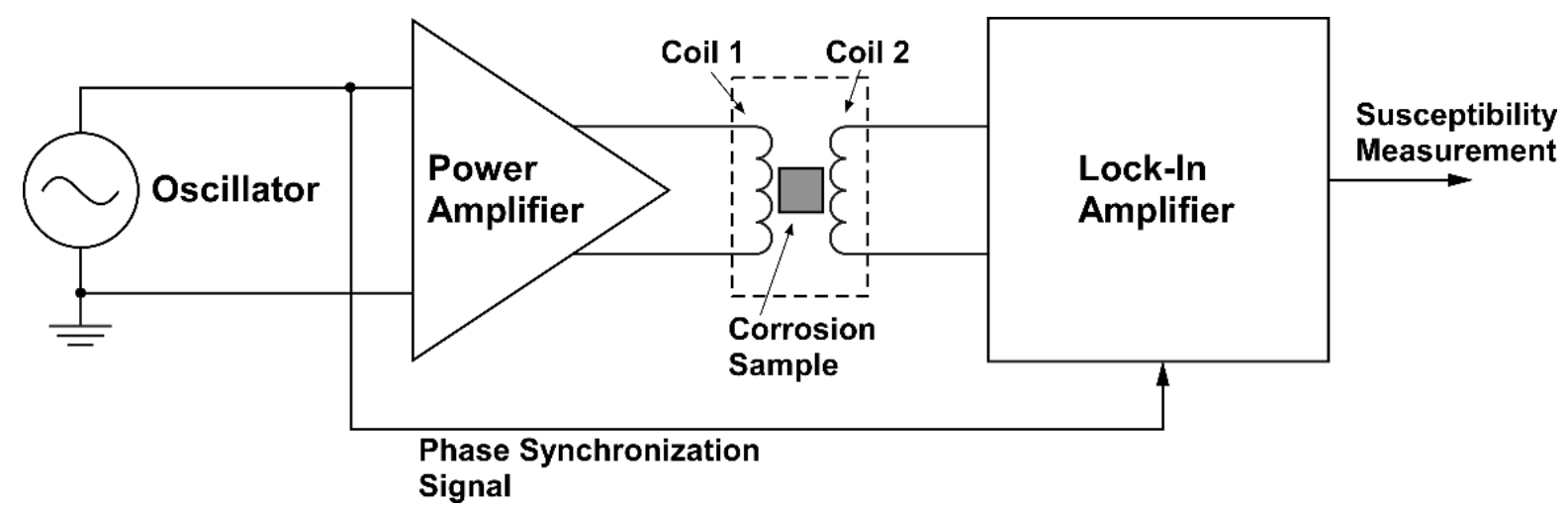

Figure 11. System diagram of the bench top testing. Holcomb et al. [2019].

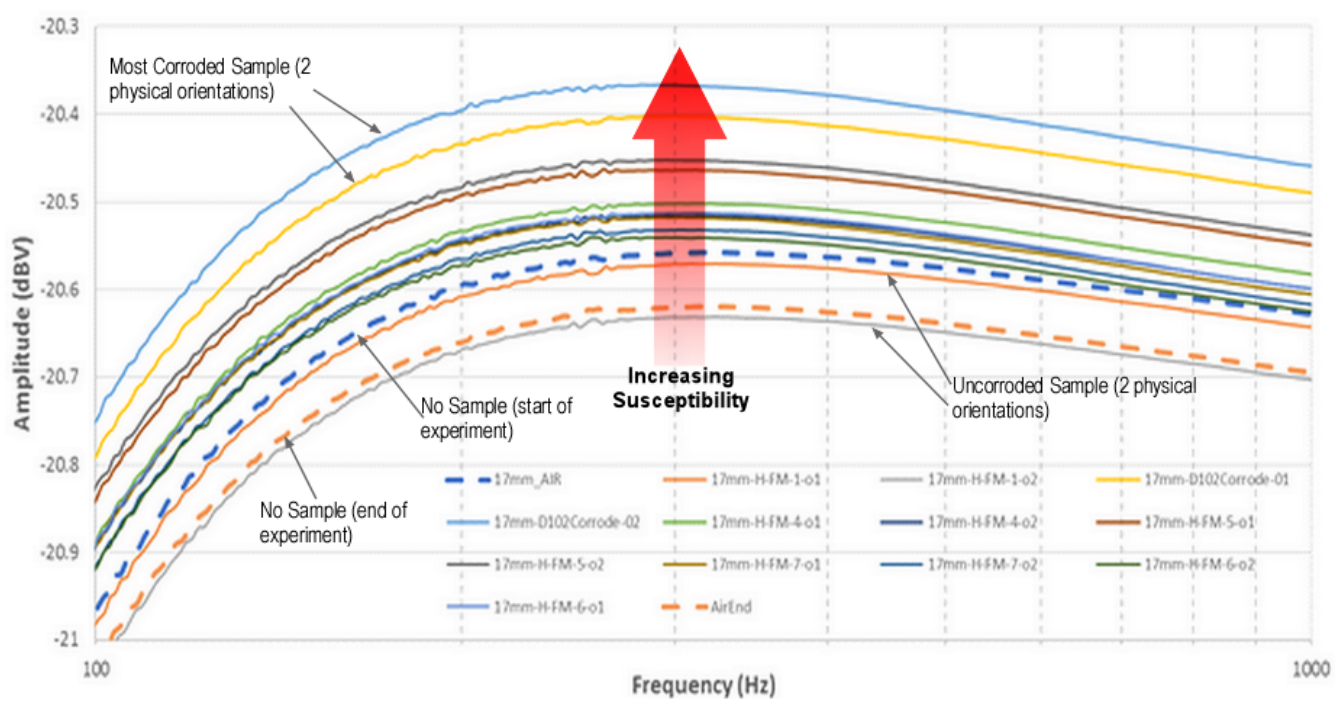

Figure 12. Measurement results using a $10 \mathrm{~mm}$ core gap between $100 \mathrm{~Hz}$ and $1 \mathrm{kHz}$. Holcomb et al. [2019].

The results shown in Figure 12 demonstrate the susceptibility that corresponds to the different levels of corrosion. As the level of corrosion is increased, the measured signal amplitude increases. This prototype demonstrated the ability to measure corrosion, but most of the materials will not survive the harsh environments of an MSR. A high-temperature prototype requires new materials, but it is based on the original low-temperature design.

\subsubsection{Measurement Apparatus to Observe Permeability Changes.}

As described above, a depletion in chromium concentration resulting from corrosion processes also alters permeability. Therefore, monitoring changes in magnetic susceptibility estimates chromium depletion from the lattice structure. A magnetic circuit has been devised that forms a transducer to detect minute changes in the susceptibility of material placed in the gap of a magnetic loop. The strategy is to maximize the instrument's sensitivity by designing a complete magnetic pathway that includes the corrosion sample in the path, as shown in Figure 13. 


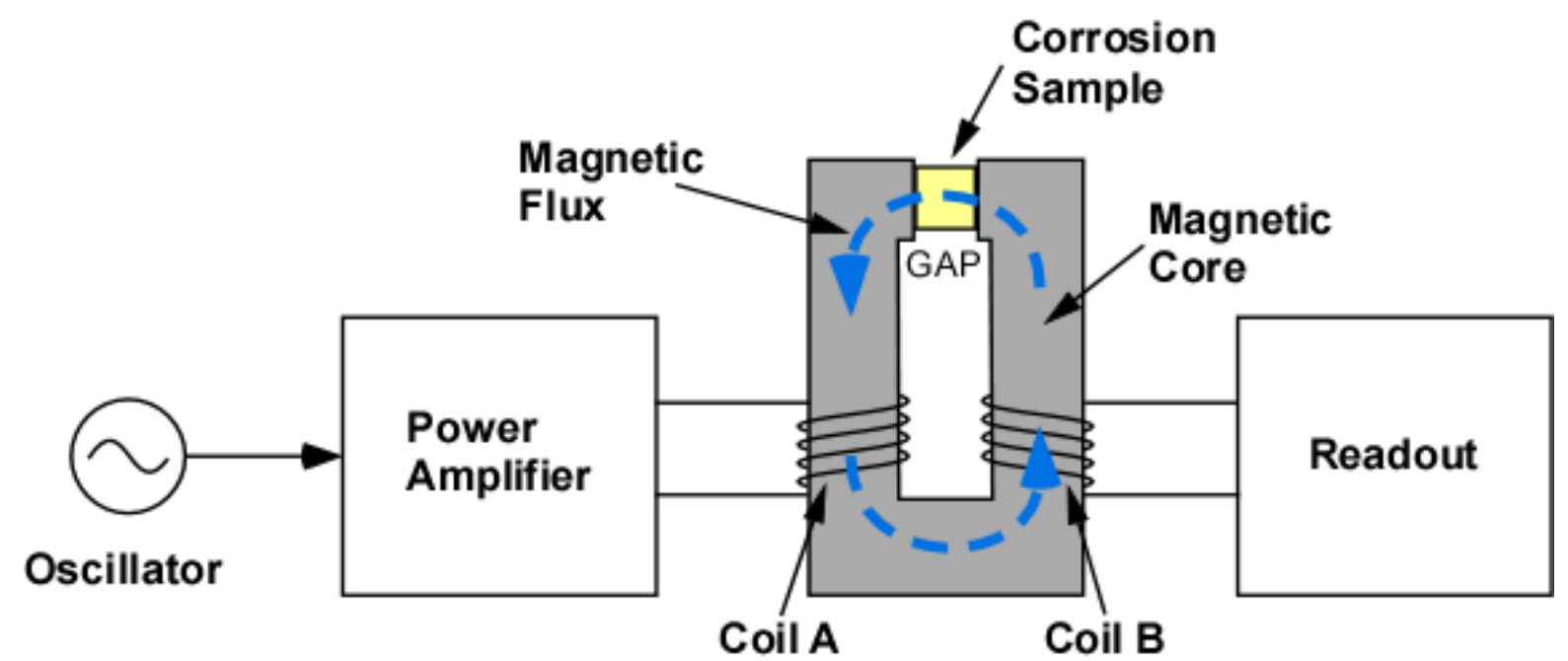

Figure 13. Susceptibility measurement of a sample in its simplest form using a transformer configuration.

The corrosion monitor operates much like a lossy two-coil transformer. Sample material is placed between the primary and secondary winding cores so that flux coupling between them is altered by the sample's susceptibility, which is placed in the air gap of the coupling core. The secondary coil's output voltage becomes a function of susceptibility in the gap.

Susceptibility, $\chi$, is a dimensionless quantity that relates to relative permeability, $\mu_{r}$, as shown in Equation 4. Hence, changes in susceptibility can be calculated by measuring changes in coupled flux.

$$
\mu_{r}=1+\chi_{r}
$$

The corrosion transduction system can be modeled as a lossy transformer. A SPICE model, shown in Figure 14, considers an ideal transformer surrounded by elements that contribute to frequency-dependent loss. The elements can be fine-tuned to conform the model to actual measured results. Approximate component values are listed in Table 4, along with the roles of those components. The driving signal is represented by source V1 placed across coil A. The output voltage of coil B is taken across R1. Changes in the sample's ferromagnetic properties are modeled by the transformer's primary-to-secondary coupling. When using these values, model results compare well with actual measurements as shown in Figure 15. The model accurately represents the frequency response of the experimental setup to within a dB; additionally, fine-tuning could further improve the match. Note that the slight upturn in the actual data is a result of a slight gain variance in the coil-drive amplifier.

\subsubsection{Apparatus Using Independent Primary and Secondary Coils Provided Significant Insight}

An initial series of experiments was conducted using an open return core system as shown in Figure 16; dimensions given in Figure 17. The full description of the apparatus is provided in Holcomb et al. [2019].

Findings from the previous research have led to the design of the current experimental apparatus. Some of the significant findings are described below: 


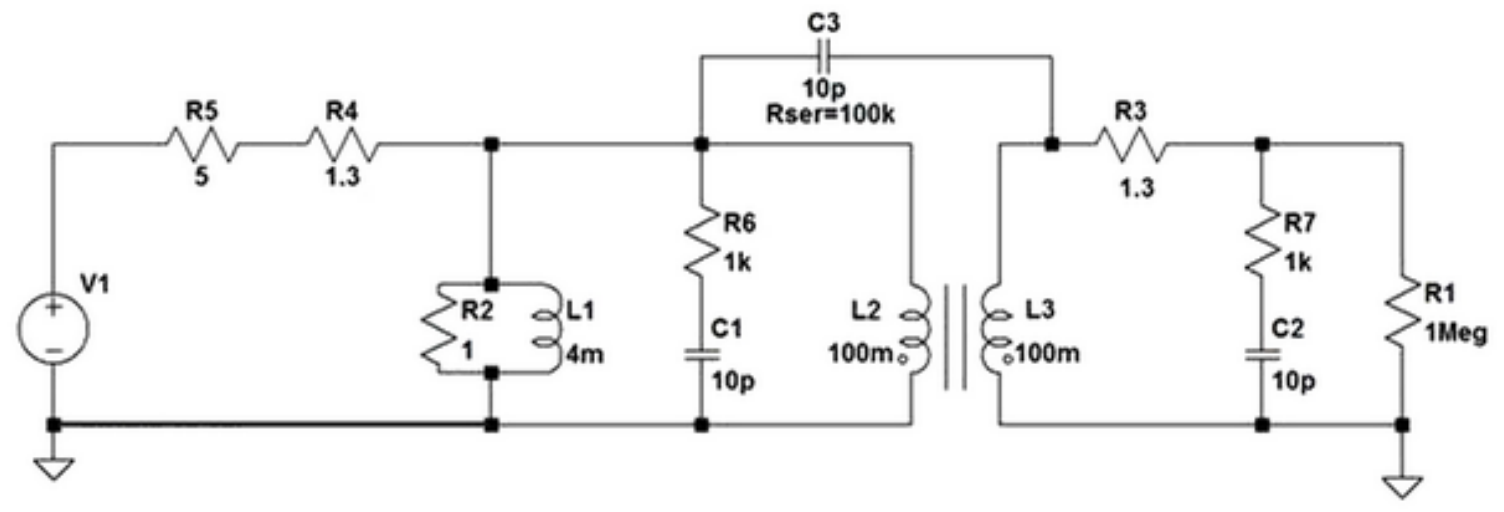

Figure 14. Lossy transformer model of corrosion transducer.

Table 4. Lossy transformer circuit parameters

\begin{tabular}{cccc}
\hline Notation & Component & Value & Purpose \\
\hline$R_{1}$ & Resistance & $1 \mathrm{M} \Omega$ & Load resistance at input to first-stage of LIA \\
$R_{2}$ & Resistance & $1 \Omega$ & Core loss \\
$R_{3}$ & Resistance & $1.3 \Omega$ & Secondary winding effective dc resistance \\
$R_{4}$ & Resistance & $1.3 \Omega$ & Primary winding effective dc resistance \\
$R_{5}$ & Resistance & $5 \Omega$ & Input effect source resistance \\
$R_{6}$ & Resistance & $1000 \Omega$ & Primary winding capacitance equivalent series resistance \\
$R_{7}$ & Resistance & $1000 \Omega$ & Secondary winding capacitance equivalent series resistance \\
$C_{1}$ & Capacitance & $10 \mathrm{pF}$ & Primary winding capacitance \\
$C_{2}$ & Capacitance & $10 \mathrm{pF}$ & Secondary winding capacitance \\
$C_{3}$ & Capacitance & $10 \mathrm{pF}$ & Primary-to-secondary capacitance (ESR=100k $\Omega$ ) \\
$L_{1}$ & Inductance & $4 \mathrm{mH}$ & Magnetizing reactance \\
$L_{2}$ & Inductance & $100 \mathrm{mH}$ & Primary coil inductance \\
$L_{3}$ & Inductance & $100 \mathrm{mH}$ & Secondary coil inductance \\
$V_{1}$ & Voltage source & $10 \mathrm{~V}$ & AC input voltage source \\
$K$ & Pri-Sec Coupling & 0.9 & Ideal is 1.0 \\
\hline
\end{tabular}




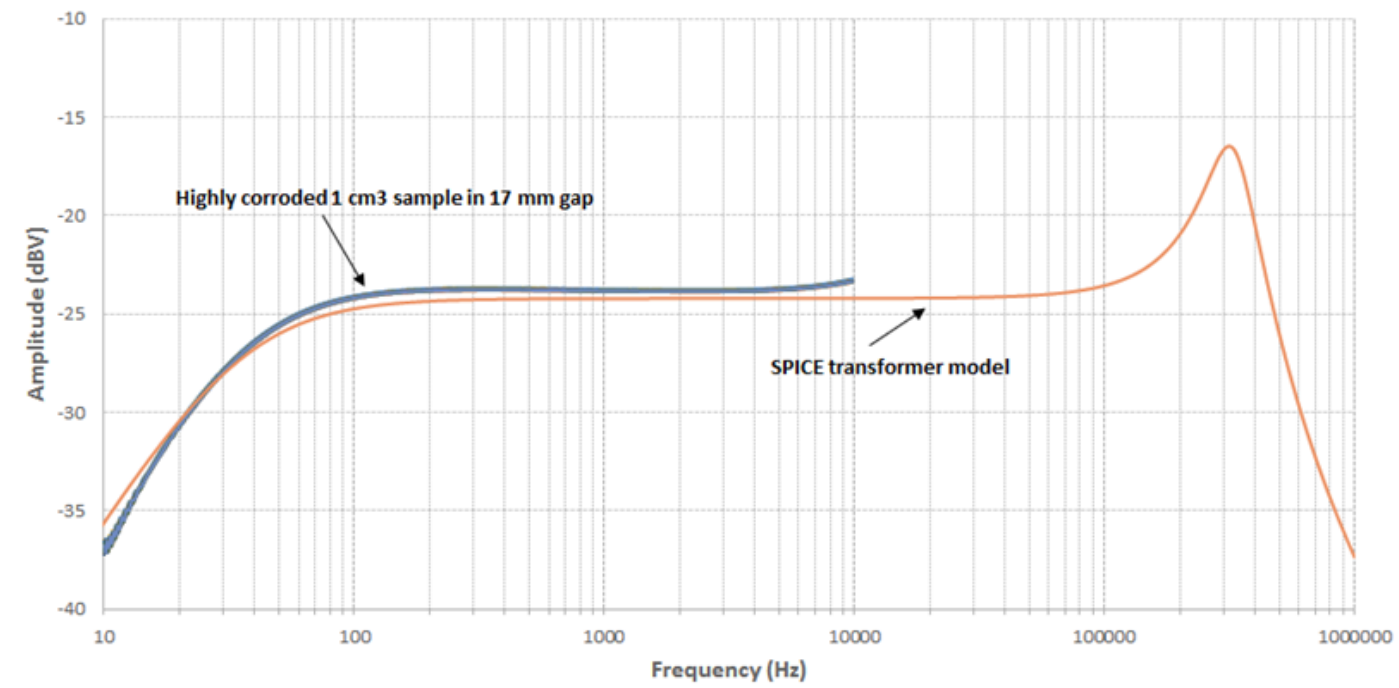

Figure 15. SPICE model response of coupled lossy transformer compared with data from highly corroded sample in a $17 \mathrm{~mm}$ gap (Holcomb et al. [2019]).

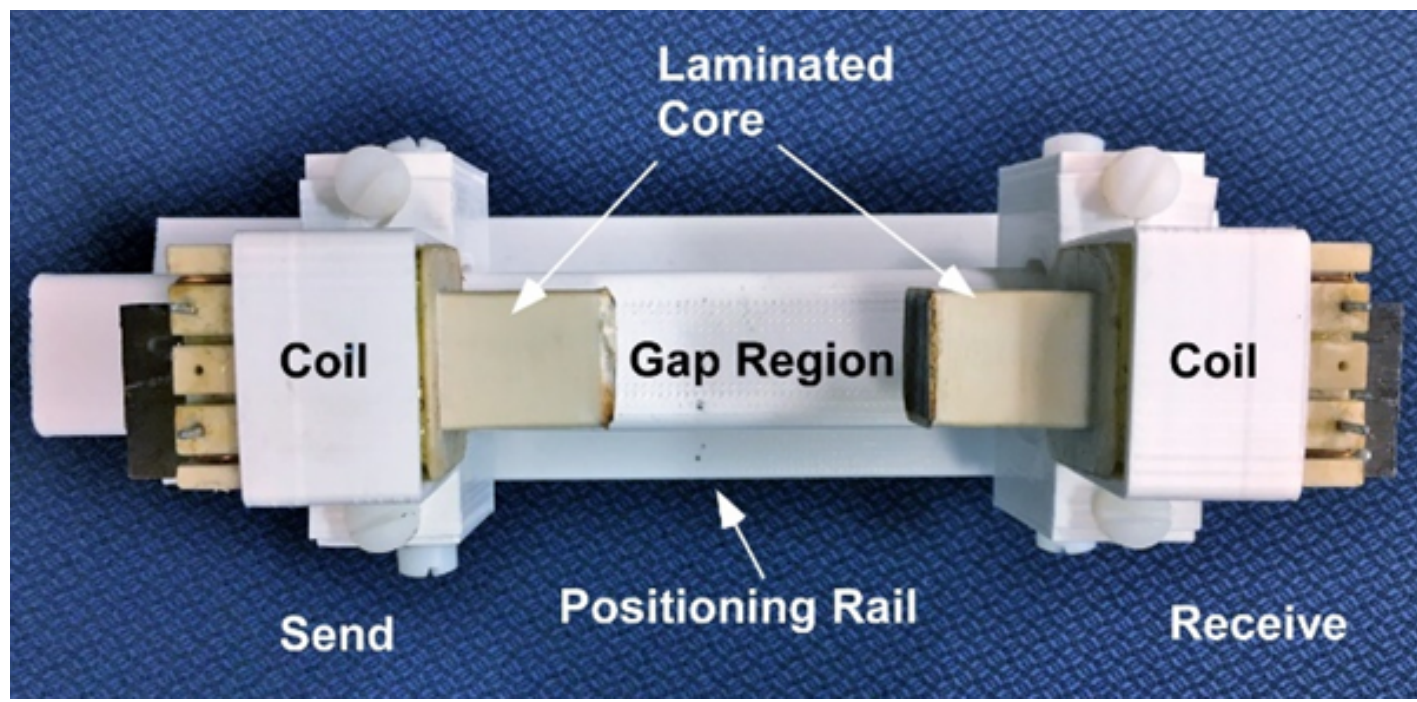

Figure 16. Photo of transducer apparatus used in initial susceptibility measurement experiments (Holcomb et al. [2019]). 


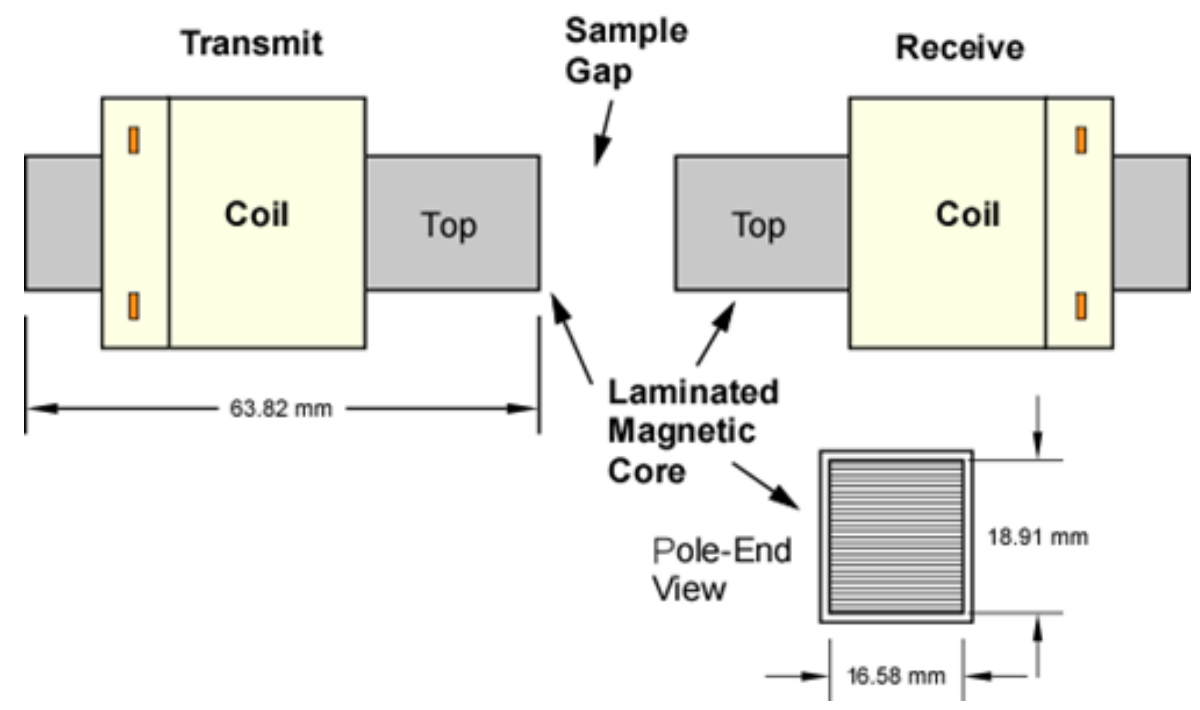

Figure 17. Physical dimensions of magnetic transducer. (Holcomb et al. [2019]).

1. Experiments with the open form transducer confirmed that the more magnetic the field coupled to the receiving coil via the sample, the higher the signal amplitude, and hence, the greater the sample's susceptibility. The samples showed differing susceptibility that roughly corresponded to the degree of corrosion. The apparatus was sensitive to small changes in the susceptibility of a sample placed in the gap. An experimental set of pre-corroded samples with progressively increasing corrosion (as determined by weight change) was correctly sorted by the apparatus.

2. Measurement results were repeatable.

3. Corroded and uncorroded samples showed anisotropy, implying that a crystallographic preference may have been introduced during the rolling or machining steps prior to corrosion. Two measurements were taken for each sample: two orientations each-principal and $90^{\circ}$ rotation. These measurements were taken to determine whether sample crystallography showed a preferred magnetic orientation. In fact, there was a difference for each sample, and it was repeatable.

4. Because of the close proximity to the Austenite-Ferrite boundary shownb in Figure 8, it is possible that for a given sample, the apparent susceptibility will drop slightly as chromium is initially depleted, but with further depletion, the susceptibility will increase. This effect may be seen in the samples of Figure 18, in which samples are progressively more corroded to the right.

5. When gap variation was considered, it was found that a $100 \mu \mathrm{m}$ spacing change at the $10 \mathrm{~mm}$ position roughly corresponds to a $0.055 \mathrm{dBV}$ signal change.

6. The open configuration of the magnetic structure diminished the sensitivity of the measurement, which led to the design of a closed-loop configuration.

7. There was a demonstrated effect of temperature on the measurement value obtained. This effect was anticipated and led to the development of a dual measurement system with one measurement being a reference (no corrosion).

8. The LIA configuration worked well and reduced extraneous noise and drift. 


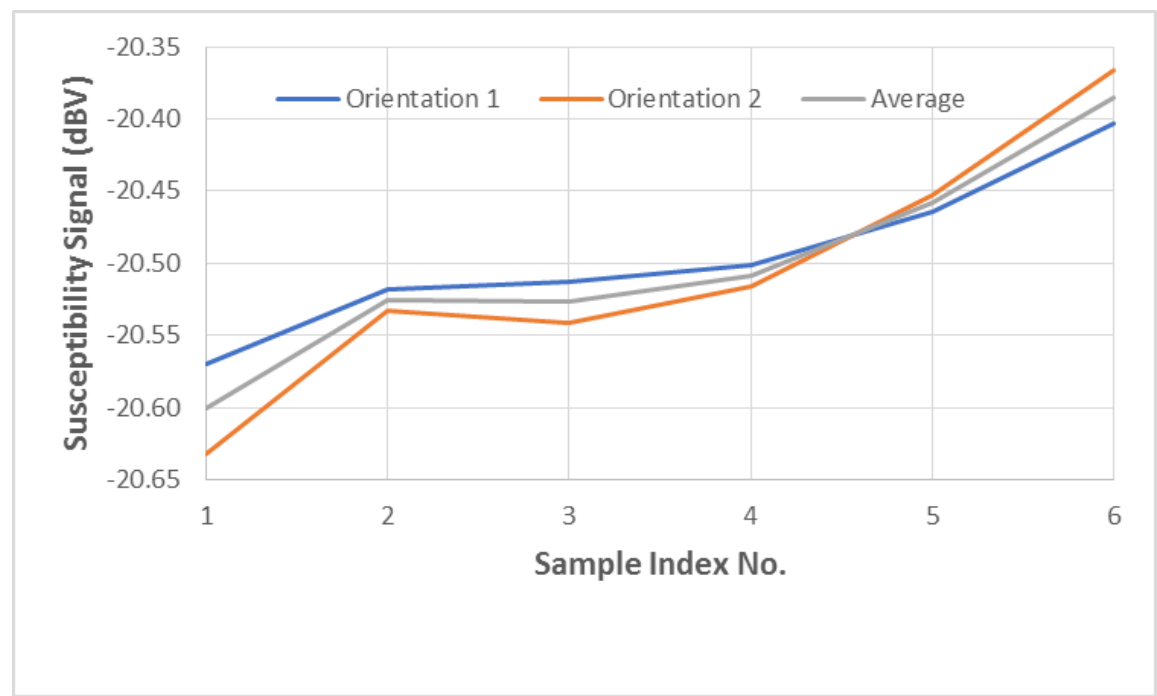

Figure 18. Increased corrosion results in higher susceptibility values as determined by output signal amplitude (Holcomb et al. [2019]).

9. A frequency of $300 \mathrm{~Hz}$ was chosen as the optimum frequency based on the silicon-iron transformer designs used.

\subsubsection{Measurement Sensitivity Improvement Using LIA}

Synchronous detection is widely used to address problems caused by $1 / \mathrm{f}$ noise and unwanted background signals because it can be used to reject signals uncorrelated with an AC carrier to reconstruct a DC or low frequency output. An LIA is an implementation of synchronous detection that can be used with the susceptibility measurement instrument. A simplified block diagram of a single-mixer LIA is shown in Figure 19 for reference. In the figure, a low-frequency or DC signal that has been modulated by a reference

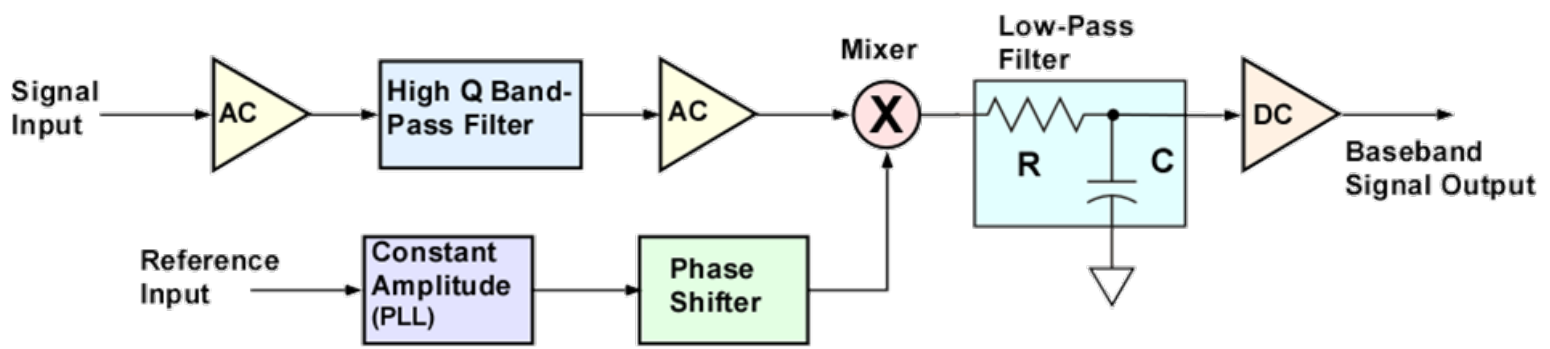

Figure 19. Simplified block diagram of an LIA.

carrier becomes input to the LIA. The signal is amplified and filtered to remove out-of-band noise. The filtered signal is mixed with the reference carrier, which demodulates the input signal. Mixer anomalies are removed by low-pass filtering, leaving the recovered original signal.

An example of signal-to-noise improvement, achievable using an LIA, is shown in Figure 20 . A $10 \mathrm{kHz}$ signal of $10 \mathrm{nV}$ amplitude requires a gain of $1,000 \times$ gain to bring it to $10 \mu \mathrm{V}$. he signal is noise of $5 \mathrm{nV} / \sqrt{\mathrm{Hz}}$ (presumably wideband) is introduced additively. Line A illustrates amplification of signal and 

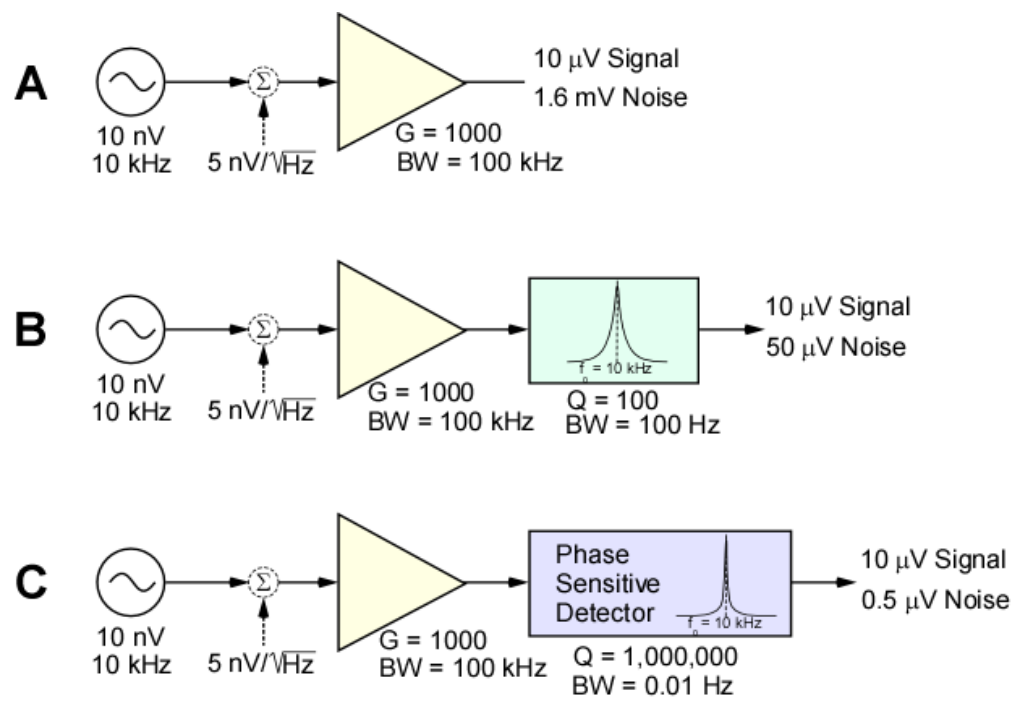

Figure 20. Example signal-to-noise improvement calculation of LIA based on filter rejection.

noise $\left(1.6 m V=\frac{5 n V}{\sqrt{H z}} \times \sqrt{100 \mathrm{kHz}} \times 1,000\right)$ with a $100 \mathrm{kHz}$-bandwidth amplifier. The signal-to-noise ratio is $-44 \mathrm{~dB}$; the signal is lost in the noise. Line B uses the same band-limited amplifier, but it adds a filter of $\mathrm{Q}=100$, having a $100 \mathrm{~Hz}$ bandwidth. The noise is reduced because of the bandwidth's restriction of the filter $\left(50 \mu \mathrm{V}=\frac{5 \mathrm{nV}}{\sqrt{\mathrm{Hz}}} \times \sqrt{100 \mathrm{~Hz}} \times 1,000\right)$. The signal-to-noise ratio is $-14 \mathrm{~dB}$, but the signal is still lost in the noise. Finally, in Line $\mathrm{C}$, with a $\mathrm{Q}=1,000,000$ and a bandwidth of $0.01 \mathrm{~Hz}$, the signal appears out of the noise, having a signal-to-noise ratio of $26 \mathrm{~dB}$, and the noise being reduced to $0.5 \mu V=\frac{5 n V}{\sqrt{H z}} \times \sqrt{100 H z} \times 1,000$. The benefit of the LIA with its phase-sensitive detection is that ultra-high $Q$ values like these are possible, permitting very high signal-to-noise ratios in practical circuits.

It is worth noting that other susceptibility measurement methods are also possible, such as $L C$-based oscillators in which an inductor affected by the sample permeability varies the oscillator frequency. Numerous oscillator varieties are possible, some with single wound inductors, some with center-tapped inductors, and some with inductors arranged in a transformer configuration.

A feedback style oscillator as shown in Figure 21 can be configured to detect a change in permeability through a shift in inductance, $L$. The circuit is a traditional oscillator with center frequency determined by

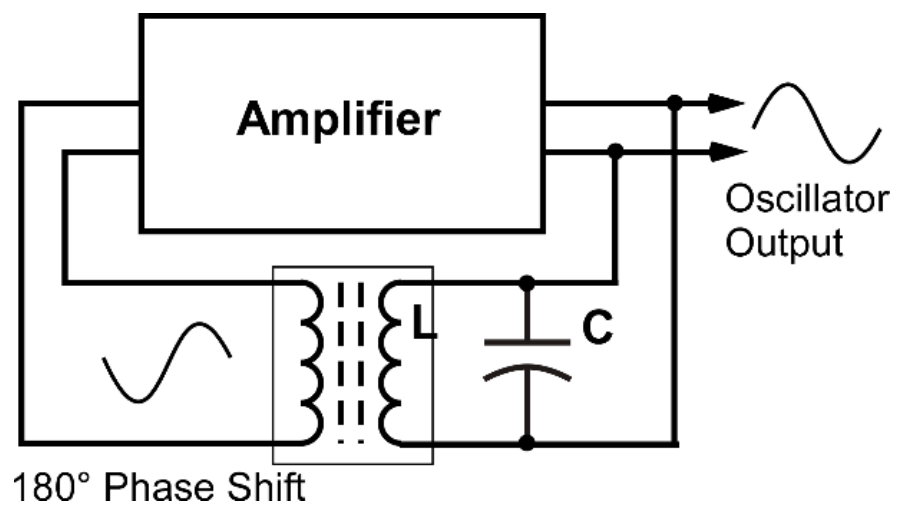

Figure 21. Feedback oscillator using a sensor as a transformer. 
$L$ and $C$, as shown in Equation 5. Because $L$ varies with relative permeability, as shown in Equation 6, the output frequency becomes a measure of permeability.

$$
\begin{aligned}
& f_{0}=\frac{1}{2 \pi \sqrt{L C}} \\
& L=\frac{\mu_{r} \mu_{0} N^{2} A}{l}
\end{aligned}
$$

A two-terminal inductor implementation is shown in Figure 22 using a Colpitts oscillator. Just as in

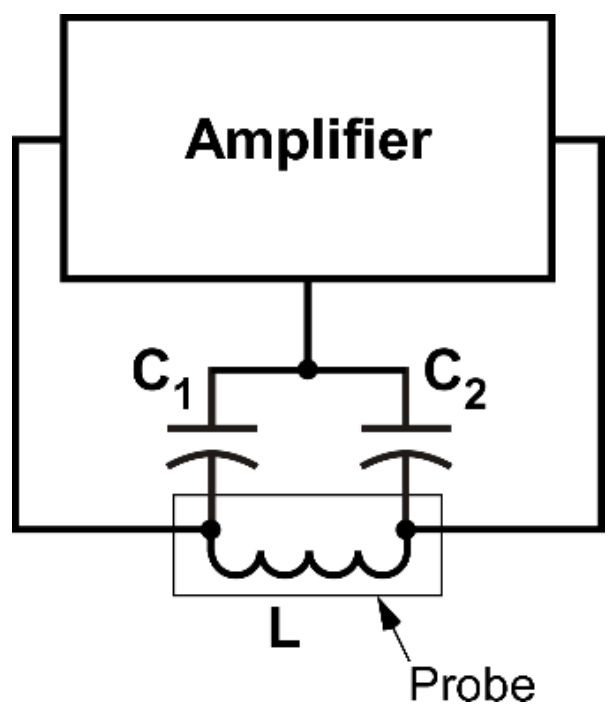

Figure 22. A Colpitts oscillator implementation requiring only one port connection (two wires) to the inductive element.

Figure 21 and Equation 5, amplifier output frequency is a function of the core material's permeability. The possible benefit of this circuit is that only two wires are required to connect to the corrosion probe, which simplifies field installation. Other oscillator styles can be used, as well, including but not limited to Hartley, Clapp, and Armstrong.

\subsection{HIGH-TEMPERATURE DESIGN}

\subsubsection{High Temperature Core Alloy}

Laminated silicon-iron core alloy has been the standard for transformers for a century because of its electrical and magnetic properties. Energy loss in an inductor core is primarily due to (1) $I^{2} R$ losses from induced eddy currents and (2) hysteresis losses in the alloy. Silicon steel is well suited to minimize these losses. However, the Curie temperature of silicon-steel alloy for $3.1 \%$ silicon is $732{ }^{\circ} \mathrm{C}$, which is too low for continuous operation over a $700-750{ }^{\circ} \mathrm{C}$ range. The material of choice for that temperature range is Hiperco ${ }^{\circledR} 50$ (a product of Carpenter Technology Corporation), which has a Curie temperature of $938^{\circ} \mathrm{C}$. Its composition, given in Table 5, is roughly 50/50 iron and cobalt. 
Table 5. Elemental composition of Hiperco ${ }^{\circledR} 50$

\begin{tabular}{cccc}
\hline Element & \% wt. & Element & \% wt. \\
& & & \\
\hline Carbon & 0.01 & Manganese & 0.05 \\
Silicon & 0.05 & Cobalt & 48.75 \\
Niobium & 0.05 & Vanadium & 1.90 \\
Iron & Balance & & \\
\hline
\end{tabular}

The transducer core should be fabricated to minimize the eddy and hysteresis losses because they reduce signal strength and spoil the transducer's signal-to-noise ratio. The transformer should therefore be fabricated using insulated laminations of Hiperco ${ }^{\circledR} 50$. Hiperco ${ }^{\circledR} 50$ Alloy is a soft magnetic alloy that exhibits high magnetic saturation (24 kilogauss), high DC maximum permeability, low DC coercive force, and low AC core loss. Descriptions of eddy current and hysteresis losses are provided in Sections 2.1.1 and 2.3.4, respectively.

\subsubsection{Test Apparatus Using Hiperco ${ }^{\circledR} 50$ Core Material}

A test apparatus was constructed to compare the performance of annealed and unannealed Hiperco ${ }^{\circledR} 50$. The test apparatus consists of the magnetic transducer shown in Figure 23 and the electronic readout system in Figure 24. The transducer forms a closed-loop transformer with the 1-inch 304 stainless steel

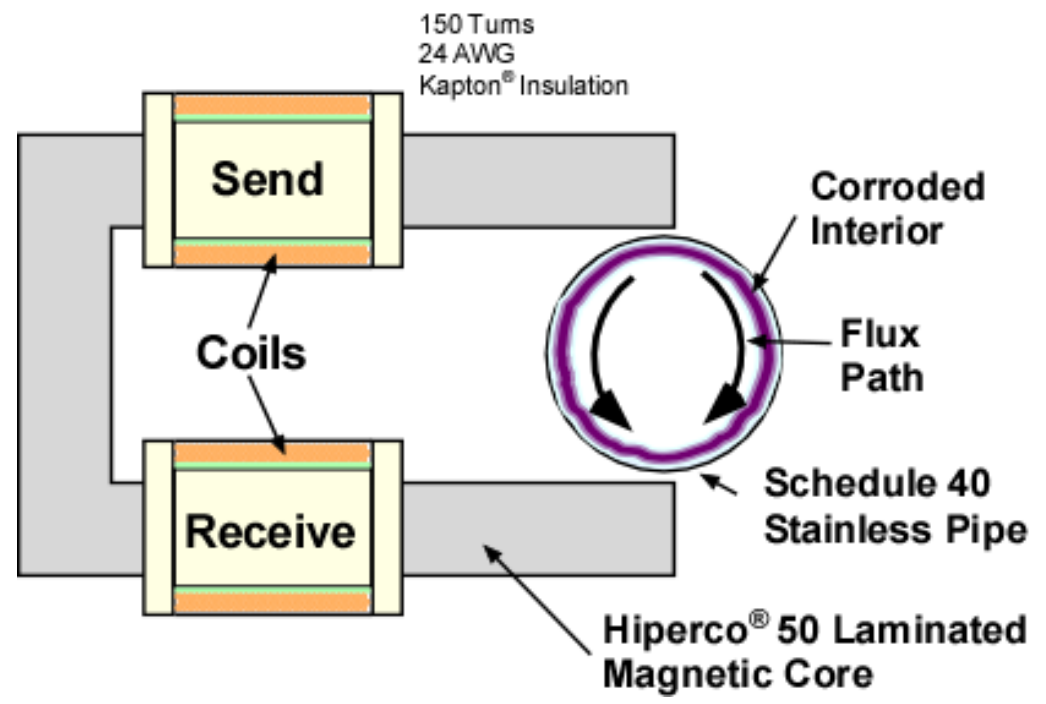

Figure 23. Configuration for transducer to measure corroded pipe.

Schedule 40 pipe, thus completing the loop. The core consists of 70 laminations assembled from individual Hiperco ${ }^{\circledR} 50$ sheets (Figure 25a), cut as one piece to minimize flux path reluctance from the accumulation of small gaps. The lamination dimensions are given in Figure 25b. Each lamination has a width of $19.05 \mathrm{~mm}(0.75 \mathrm{in}$.) around the $\mathrm{C}$-shape. Proper thermomechanical treatment is required to create an optimal alloy microstructure to maximize the magnetic properties of Hiperco ${ }^{\circledR} 50$. The Hiperco ${ }^{\circledR} 50$ sheets were received from the supplier in an as-rolled condition, and then they were subsequently annealed at ORNL after being cut into the transformer C-shape. The annealing schedule was as follows: parts were 


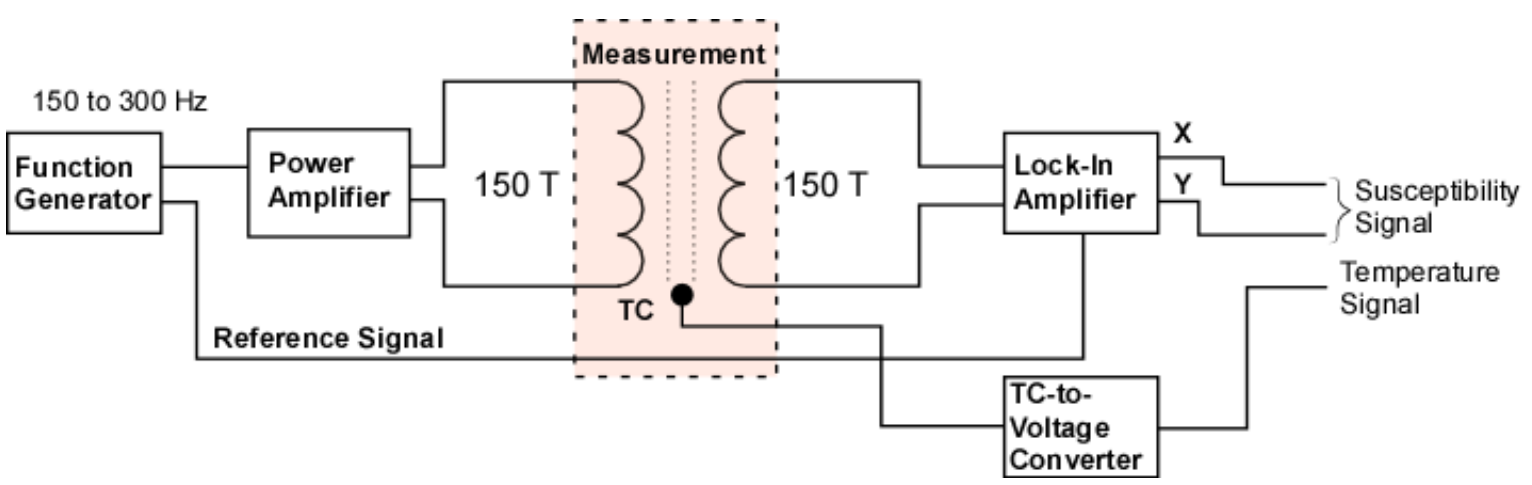

Figure 24. Single susceptibility measurement channel using an equation amplifier.

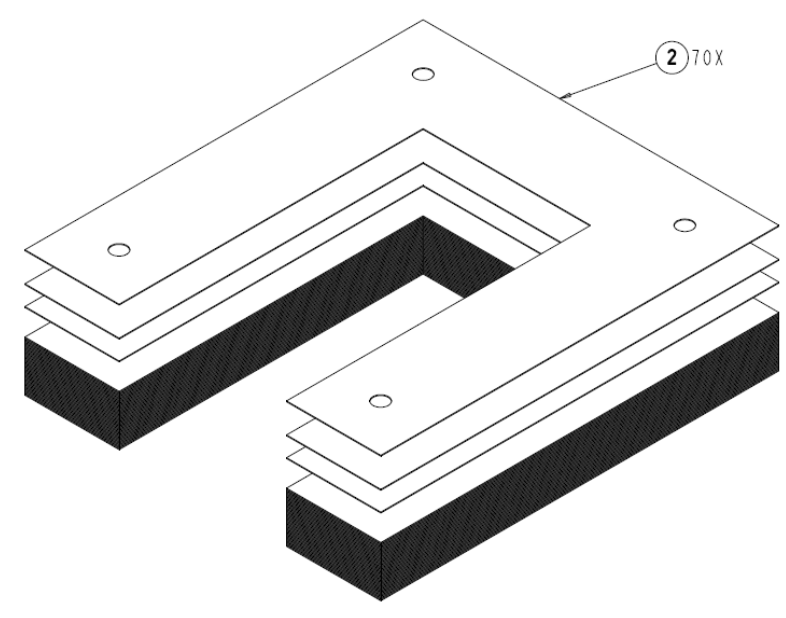

(a) Transducer core lamination configuration.

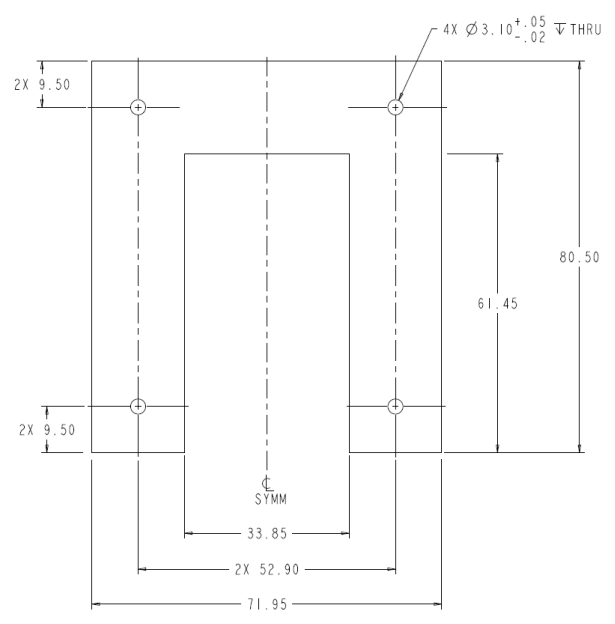

(b) Lamination dimensions.

Figure 25. Transducer core lamination configuration (a) and dimensions (b).

heated to $871{ }^{\circ} \mathrm{C}$ and held for 2 hours in an argon atmosphere (4\% hydrogen) and then were cooled at between 139 and $222{ }^{\circ} \mathrm{C}$ per hour until reaching $316^{\circ} \mathrm{C}$; cooling to room temperature was left uncontrolled. The annealing schedule was selected to maximize magnetic performance over mechanical strength, as the intended use is as transformer sheets (Figure 26). The manufacturer warned that the annealing temperature should not exceed $871{ }^{\circ} \mathrm{C}$ because at that sage, the soft magnetic characteristics start to decline due to formation of an austenitic phase.

\subsubsection{High Temperature Sensor Build}

It was estimated that for the core to have a square cross section, 70 laminations were required. To make two sensors with 70 laminations per sensor, it was determined that a sheet of Hiperco ${ }^{\circledR} 50$ with dimensions of $10 \mathrm{ft} \times 12 \mathrm{ft} \times 0.006 \mathrm{in}$. was needed. The laminations were cut using a laser cutter to keep them as consistent as possible. A single cut lamination can be seen in Figure 27.

During the initial design of this sensor, it was unclear whether to use small bolts or a clamping system to hold the laminations together. The holes in the laminations allow for the option to use bolts to hold the 


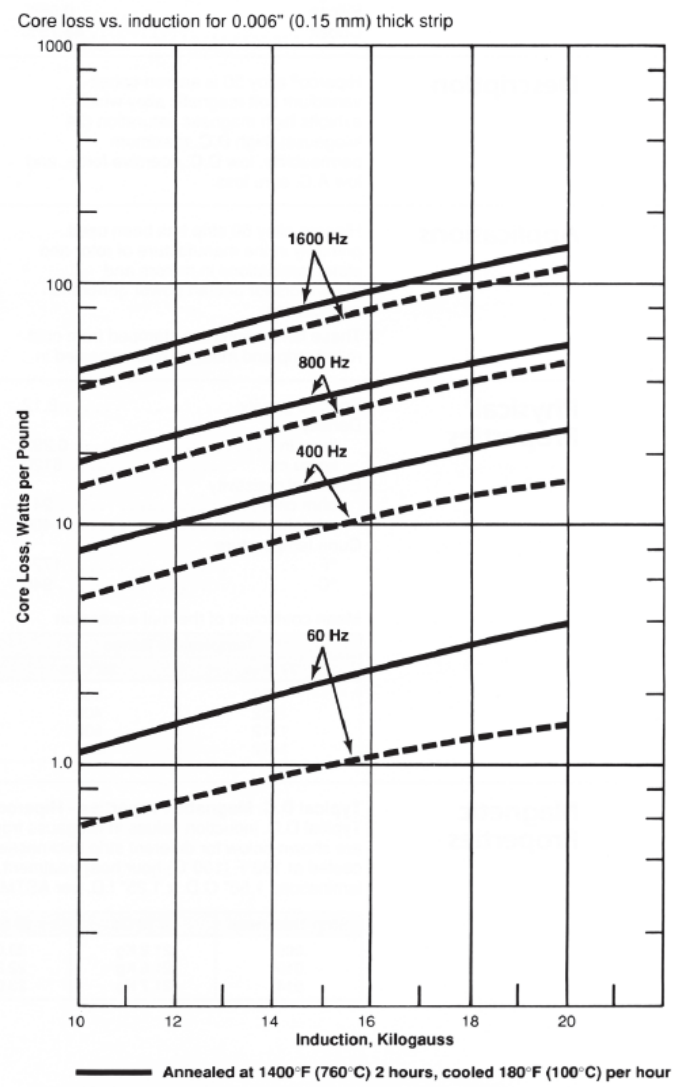

Annealed at $1400^{\circ} \mathrm{F}\left(760^{\circ} \mathrm{C}\right) 2$ hours, cooled $180^{\circ} \mathrm{F}\left(100^{\circ} \mathrm{C}\right)$ per hour

Figure 26. Core loss as a function of induction for 0.006 -inch $(0.15 \mathrm{~mm})$ sheet (Technical Datasheet [2015]).

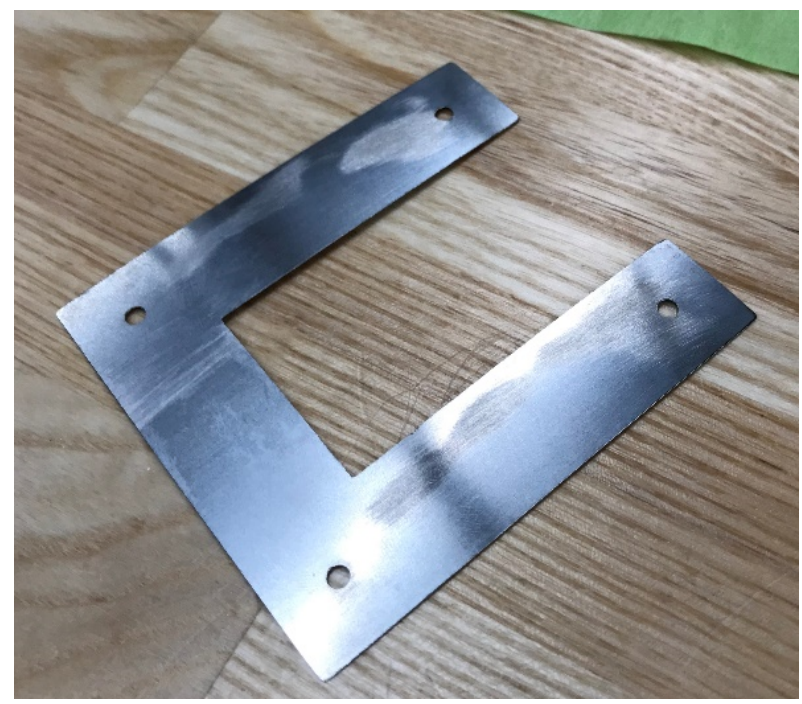

Figure 27. High-temperature corrosion sensor, single lamination. 


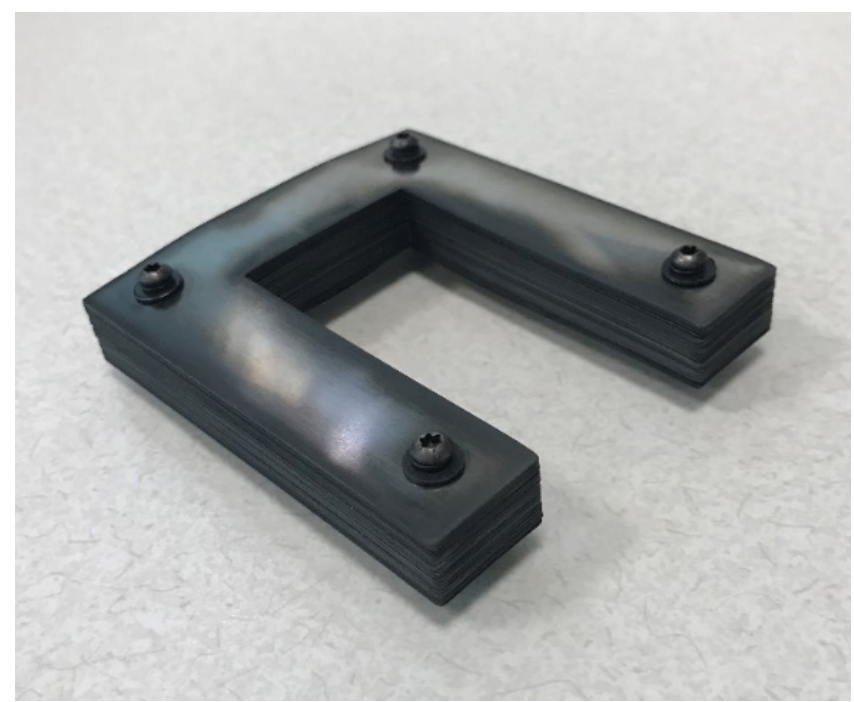

Figure 28. Annealed laminations with black oxide bolts prior to the addition of boron nitride layers.

laminations together. Several bolt material options exist for this sensor, ranging from nylon (low temperature), ceramic (high temperature), and black oxide (high temperature). Nylon bolts can be used for room temperature testing conditions up to $200{ }^{\circ} \mathrm{C}$. Ceramic or black oxide bolts can be used for high-temperature testing up to the maximum temperature for this project, which is $750{ }^{\circ} \mathrm{C}$. Black oxide bolts may be used because they are non-conductive but still have a high maximum operating temperature. The stack up of annealed Hiperco ${ }^{\circledR} 50$ laminations with black oxide bolts can be seen in Figure 28 below. If the bolts are determined to interfere with magnetic fields or with the placement of the coils, then a clamping fixture could be investigated. The clamping fixture would need to be well insulated from the sensor while also being capable of withstanding the testing temperatures.

The annealing treatments were performed on individual strips and, subsequently, stacks of strips of the Hiperco ${ }^{\circledR} 50$ alloy. The two different heat treatments described in Table 6 were used on strips of the alloys. Subsequent testing with the annealed strips showed the higher temperature annealing conditions gave more

Table 6. Annealing conditions used for Hiperco ${ }^{\circledR} 50$ strips

\begin{tabular}{cccc}
\hline Anealing Temperature $\left({ }^{\circ} \mathbf{C}\right)$ & Anealing Time (h) & Cooling Rate $\left({ }^{\circ} \mathbf{C} / \mathbf{h r}\right)$ & Atmosphere \\
\hline 871 & 2 & 100 & $A r-4 \% H_{2}$ \\
760 & 2 & 100 & $A r-4 \% H_{2}$ \\
\hline
\end{tabular}

favorable properties. The higher temperature heat treatment was used to anneal the stacks of strips shown in Figure 29.

One side of each lamination sheet is coated with about $100 \mu \mathrm{m}$ of boron nitride, which acts as an electrical insulator preventing inter-lamination eddy currents. Measurement confirmed that the thin layer performed as an electrical insulator in the ensemble comprising the core. Boron nitride has a maximum operating temperature of $1,000{ }^{\circ} \mathrm{C}$ in air and $1,800{ }^{\circ} \mathrm{C}$ in an inert atmosphere, which is suitable for the salt corrosion monitor. The concern of boron being a strong neutron absorber is not an issue here because this sensor will not be the final product installed on an MSR. For the final sensor, a alumina or zirconia based insulator is a better option. The boron nitride was applied using an aerosol with an ethyl alcohol/acetone carrier (Boron 

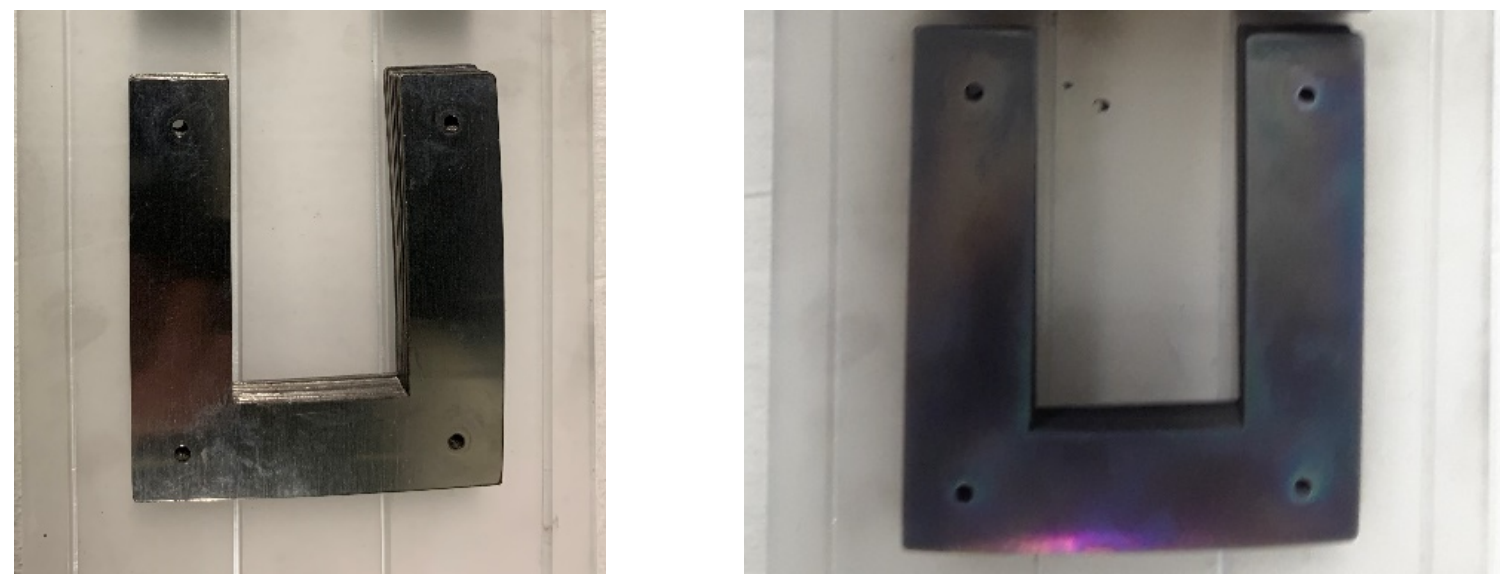

Figure 29. Photos of the stacks of Hiperco ${ }^{\circledR} 50$ sheets before (left) and after (right) annealing.

Nitride Aerosol Lubricoat ${ }^{\circledR}$ available from ZYP Coatings, Oak Ridge, TN). Due to the ethyl alcohol/acetone carrier, application of boron nitride was performed in a fume hood. Figure 30 shows The fume hood with Hiperco ${ }^{\circledR} 50$ laminations during the boron nitride application process. When applying the

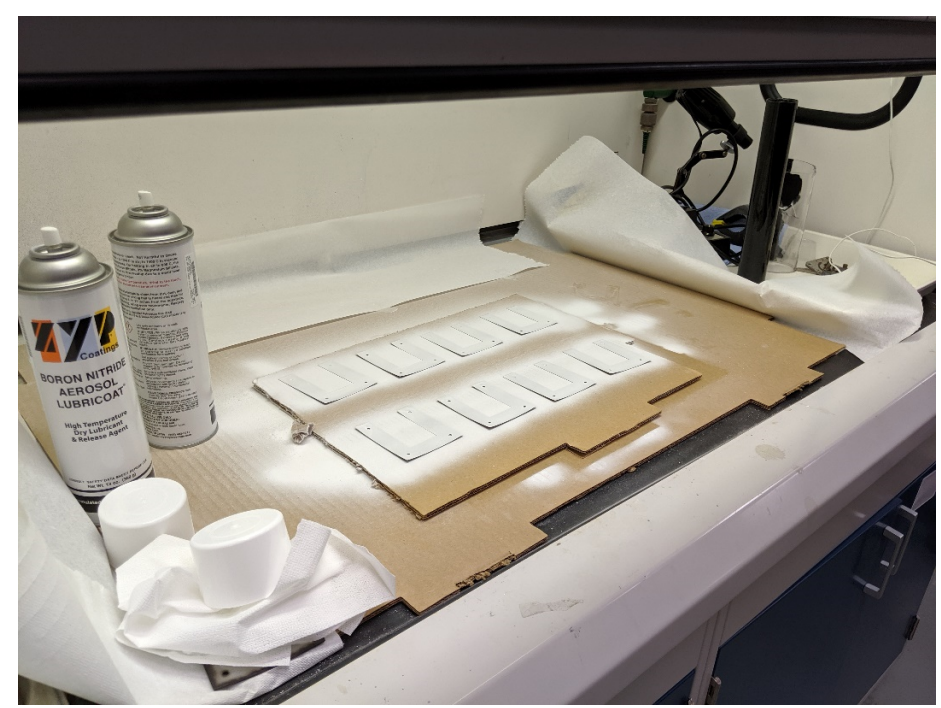

Figure 30. Fume hood containing boron nitride application to Hiperco ${ }^{\circledR} 50$ process.

boron nitride, it is important to keep the aerosol can roughly 12 inches away from the Hiperco ${ }^{\circledR} 50$ and to keep the can moving to ensure an even coating. Some of the Hiperco ${ }^{\circledR} 50$ laminations immediately after the application of the boron nitride can be seen below in Figure 31. The final stack-up after applying boron nitride can be seen in Figure 32.

Prototype coils were developed for initial room temperature and low temperature testing. These coils allowed for determination of critical magnetic properties of Hiperco ${ }^{\circledR} 50$. They are comprised of magnet wire and Polytetrafluoroethylene (PTFE) bobbins. The magnet wire is round, $240{ }^{\circ} \mathrm{C}$ temperature class, 24 AWG copper wire wrapped in a polyimide insulation from MWS Wire Industries. The PTFE bobbins were cut to allow for movement of the coils along the sensor to find the optimum positioning. A drawing of 


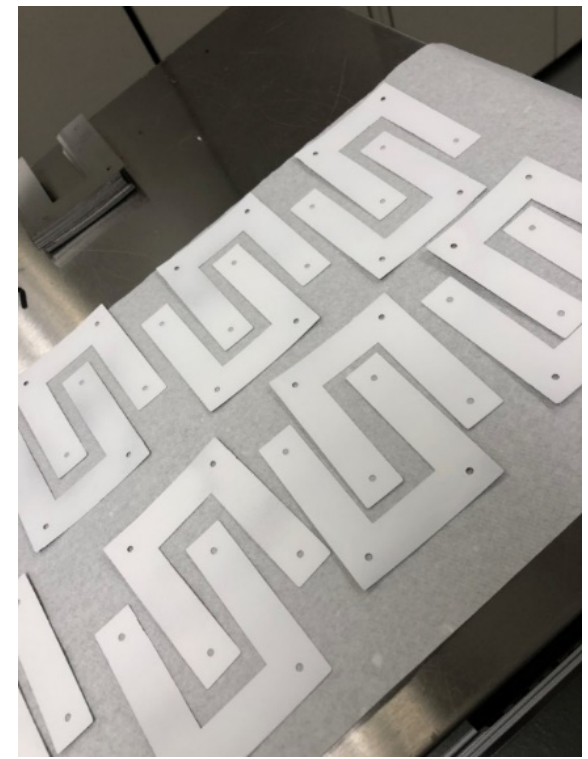

Figure 31. Hiperco ${ }^{\circledR} 50$ laminations with boron nitride layer applied.

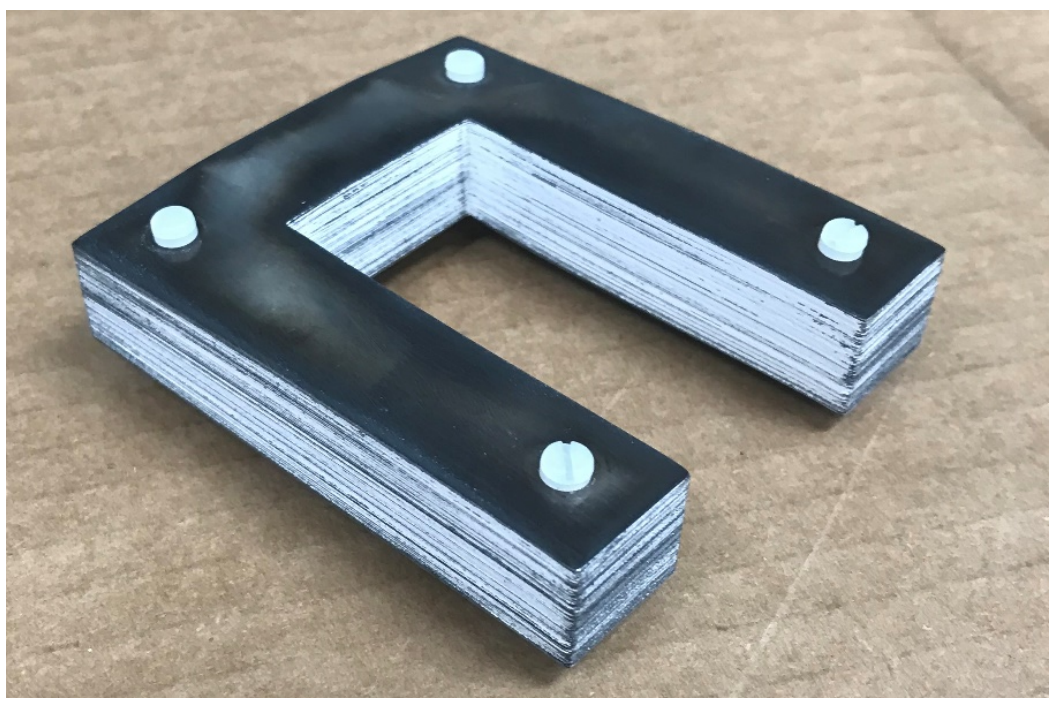

Figure 32. Annealed Hiperco ${ }^{\circledR} 50$ stack with boron nitride insulation. 
the PTFE bobbins can be seen below in Figure 33. These coils were not intended for high-temperature operation. The PTFE has a maximum temperature of $260^{\circ} \mathrm{C}$. The magnet wire was wrapped onto the bobbins at 50 turns per layer for three layers. This brought a total of 150 turns per bobbin. The completed prototype coils can be seen below in Figure 34.

For future efforts, bobbins will be made of alumina or some other high-temperature ceramic $\left(>800{ }^{\circ} \mathrm{C}\right)$. Currently, a design for the high-temperature bobbins is being finalized. A drawing of the high-temperature bobbins can be seen below in Figure 35. The rectangular inner diameter (ID) of the bobbins keeps the laminations compressed without the need for bolts. For the high-temperature coils, ceramic-insulated magnet wire must to replace the polyimide wrapped wire. Ceramawire makes a nickel 205 magnet wire insulated by their proprietary coating. This wire has a maximum operating temperature of $1,090{ }^{\circ} \mathrm{C}$. The Ceramawire nickel 205 magnet wire would work for the high temperatures needed in this testing.

\subsubsection{Hysteresis Loss Discussion}

A typical magnetic transformer core is made of cold-rolled, grain-oriented silicon steel, which is a very good ferromagnetic material; it behaves like magnet when magnetic flux passes through. Ferromagnetic substances have many domains or small regions in the structure in which all dipoles are parallel; that is, the domains are like small permanent magnets situated randomly in the structure, resulting in magnetic field cancellation. When an external magnetic field is applied, these randomly directed domains become arranged parallel to the applied MMF axis. After the external MMF is removed, large numbers of domains return to random positions, although a few remain in their aligned position. The material becomes slightly and permanently magnetized because of the domains that remain aligned. Some opposite MMF must be applied to neutralize this remaining magnetism. The MMF applied in a transformer core is alternating (i.e., $\mathrm{AC})$, so for every cycle, there is a corresponding domain reversal. This represents the extra work done that leads to hysteresis loss. Hysteresis losses increase with frequency.

Hysteresis loss can also be illustrated graphically. Figure 36a shows the hysteresis curve for a magnetically soft material, where $B_{r}$ is the remanence flux density, $B_{s}$ is the saturation flux density, $H_{s}$ is the required magnetizing force to saturate the core, and $-H_{c}$ is the coercivity, which is the required magnetizing force to bring the remanence flux back to zero. Similarly, Figure 36b shows a hard magnetic material in which, for this example, the area enclosed by the hysteresis loop is twice that of the soft magnetic material. The energy consumed per cycle is the product of the core volume and hysteresis loop area, which is 7 , where $A$ is the cross sectional area and $L$ is the core length. Equation 8 represents the total power, which is the per-cycle energy times the frequency (cycles per second).

$$
\begin{aligned}
& W_{\text {cycle }}=A L \int_{0}^{B_{\max }} H d B \\
& W=f(A L) \int_{0}^{B_{\max }} H d B
\end{aligned}
$$

Relative hysteresis curves were measured comparing annealed and unannealed Hiperco ${ }^{\circledR} 50$ sheets and an unannealed segmented laminated core, an unannealed single-cut laminated core, and an annealed single-cut laminated core. The measurement circuit can be seen in Figure 37, where $V_{1}$ and $V_{2}$ are inputs into an oscilloscope. The current through the driving coil is found as $V_{1} / R$. The division operation took place in 


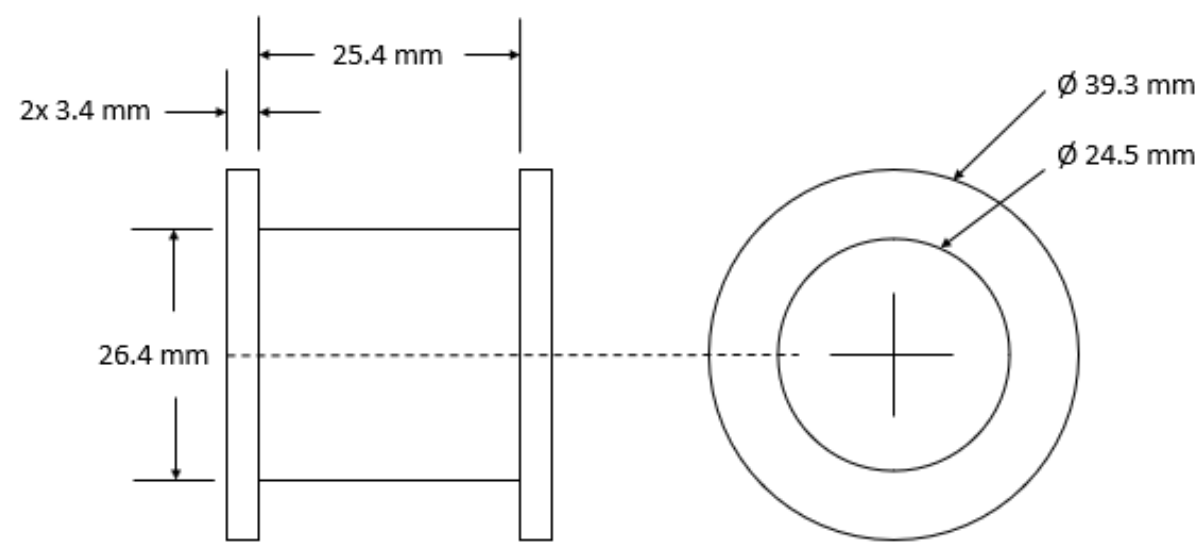

Figure 33. Prototype PTFE bobbin drawing.

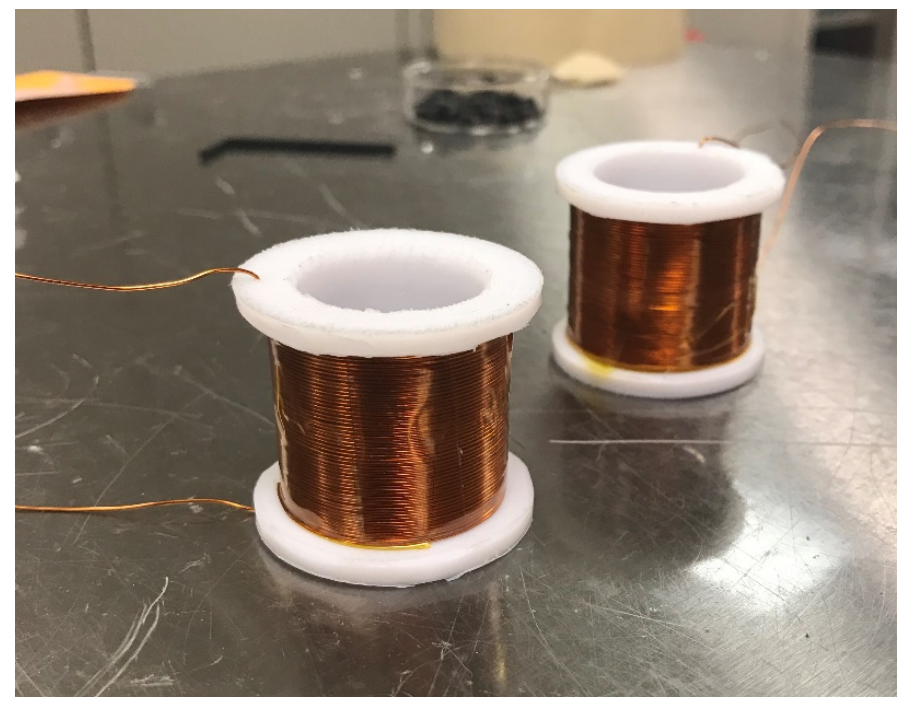

Figure 34. Prototypic sensor coils. 

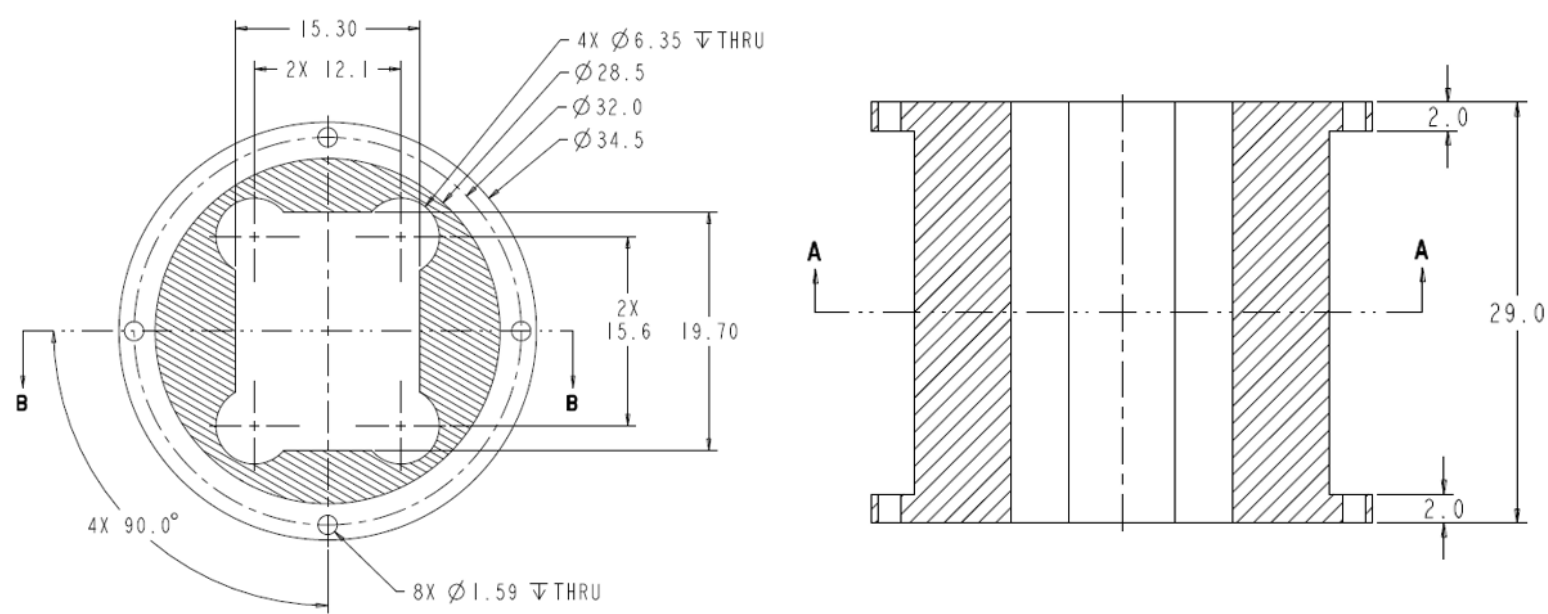

Figure 35. High-temperature ceramic bobbin.

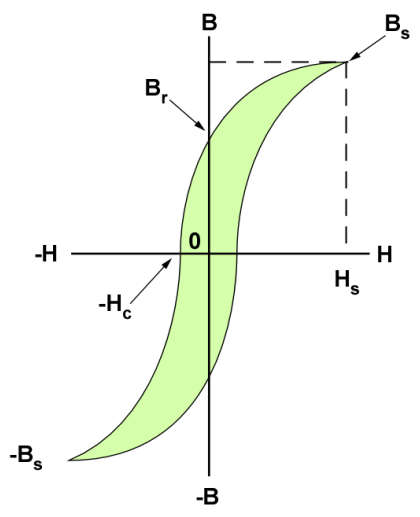

(a) Hysteresis curve for soft magnetic material having small hysteresis loss.

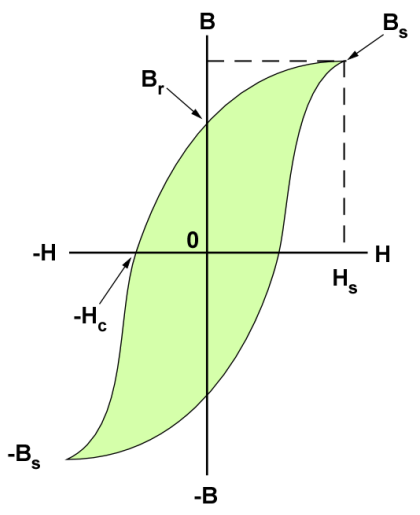

(b) Hysteresis curve for hard magnetic material having high hysteresis loss.

Figure 36. Hysteresis curves for magnetically soft (a) and hard (b) materials showing hysteresis loss.

post-processing. The flux in webers is found by integrating the voltage $V_{2}$ with respect to time $\left(\int V_{2} d t\right)$. The integration was performed digitally within the Lecroy scope. The data were taken from the scope and entered into a Python algorithm in which they were post-processed and plotted as flux vs. driving current. When measuring hysteresis curves in this fashion, the core should make a complete magnetic circuit with minimal or no air gap. Because of the large air gap in these cores, they are referred to as relative hysteresis curves."

Results of the measured relative hysteresis curves for Hiperco ${ }^{\circledR} 50$ are shown for assembled cores at $300 \mathrm{~Hz}$ and $1 \mathrm{kHz}$ (see Figure 38a and Figure 38b respectively). The relative hysteresis curves show that the magnetic performance of the annealed Hiperco ${ }^{\circledR} 50$ is superior to the unannealed alloy by a factor of about 3.5. The annealed cores will be used in the salt corrosion monitor. 


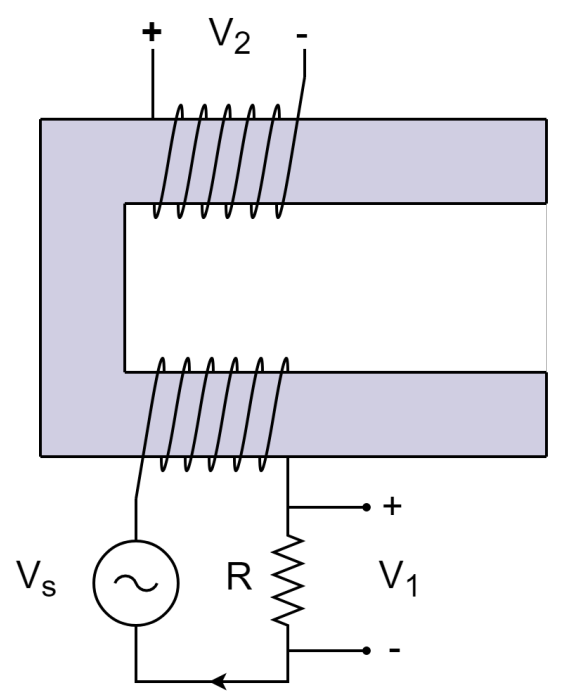

Figure 37. Circuit used to measure the relative hysteresis curves of the sensor cores.

\subsection{MODELING AND SIMULATION OF HIGH-TEMPERATURE DESIGN/ELECTROMAGNETIC PERFORMANCE}

To validate the results of this experiment and obtain an optimized design, a magnetostatic model of the corrosion sensor experiment has been developed using the ANSYS v19.2 software package. First, the geometry of the sensor was constructed using the built-in DesignModeler program as seen in Figure 39. To represent the corroded layer, a thin section was cut out of the inside of the pipe. The area around the experiment was filled with air using the enclosure tool in order to calculate the field around the sensor. Relevant dimensions such as the axial position and diameter of the coil were parameterized. The core of the sensor was divided into multiple sections so that the flux density in each region could be varied during analysis.

This model was then imported into the mechanical application, where material properties, coordinate systems, and boundary conditions were implemented. The current density in the coil was modeled by creating a cylindrical coordinate system at the centroid of the loop and providing the current, number of turns, and cross sectional area of the coil. Note that the thickness of the coil can be estimated by calculating the packing of the wires, as shown in Figure 40.

Parallel magnetic flux conditions were imposed at the boundaries of the air enclosure to approximate the field strength dropping as it goes to infinity. After parameterizing additional values of interest—such as the wire diameter and the number of wire layers-and relating these to dependent values such as the cross sectional area of the coil, the complete model was finally imported into the DesignXplorer application. This software uses smart sampling of the various input parameters to characterize the system's response, allowing many different cases to be run. This is also known as response surface methodology (RSM). To do so, first, the user selects a set of input parameters using a particular DOE method. Then, approximate the relations between inputs and outputs with a metamode. Then finally, use the trained model to characterize the system response. 


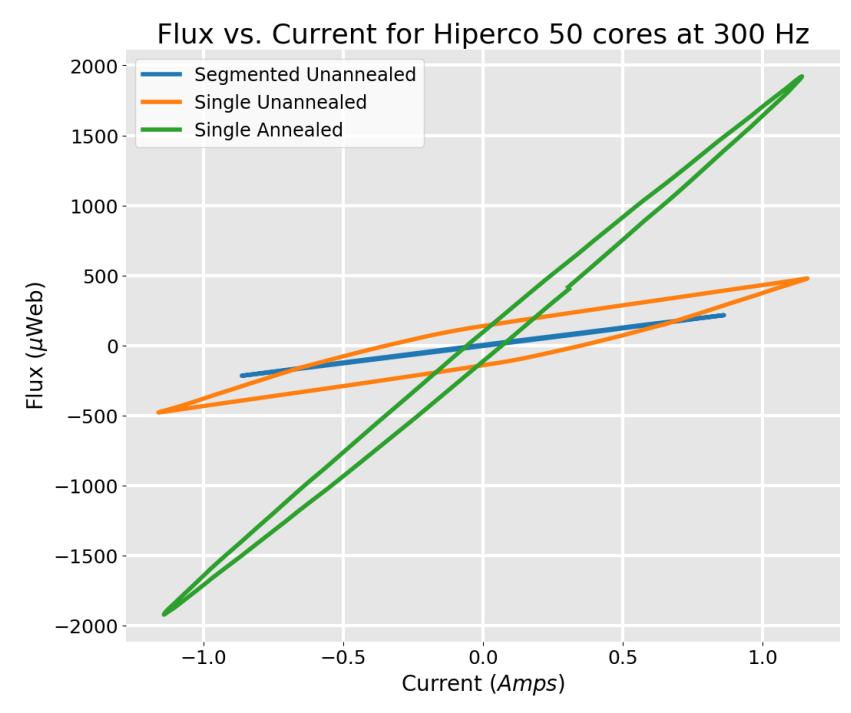

(a)

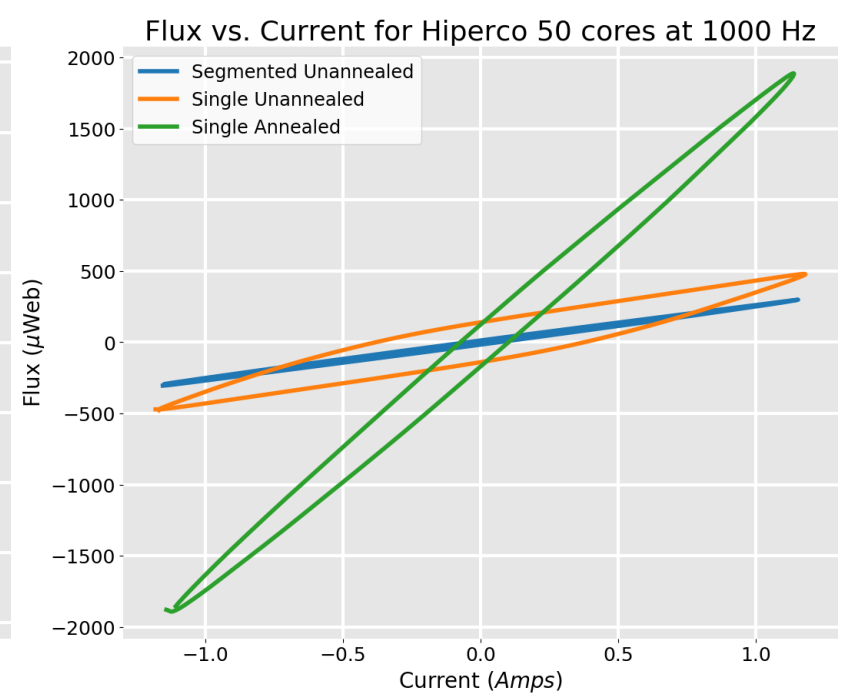

(b)

Figure 38. Relative hysteresis curves of Hiperco ${ }^{\circledR} 50$ for the unannealed segmented core (blue), unannealed single-cut core (orange), and annealed single-cut core (green) at $300 \mathrm{~Hz}$ (a) and 1,000 $\mathrm{Hz}$ (b).

\subsubsection{Verification of Model Theory}

The established model was then used to analyze different scenarios by altering the material properties of the constituent parts. First, to compare the results of the model to theory, the case of an isolated coil in air was analyzed. Starting with the equation for the magnetic flux density along the axis of a single loop, Equations 9-11 derive the field along the axis of a coil by integrating the fields from a number of infinitesimal loops:

$$
\begin{gathered}
B_{x, \text { center }}=B_{x}=\frac{\mu_{0}}{4 \pi} \frac{2 \pi R^{2} I}{\left(x^{2}+R^{2}\right)^{\frac{3}{2}}} \rightarrow d B_{x}=\frac{N}{L} \frac{\mu_{0}}{4 \pi} \frac{2 \pi R^{2} I}{\left[(x+\Delta)^{2}+R^{2}\right]^{\frac{3}{2}}}, \\
\int \frac{A}{\left[(x+z)^{2}+C^{2}\right]^{\frac{3}{2}}} d z=\frac{A(x+z)}{C^{2} \sqrt{(x+z)^{2}+C^{2}}+c} \\
\int_{0}^{L} d B_{x} \rightarrow B_{x}=\frac{\mu_{0} N I}{2 L}\left[\frac{x+L}{\sqrt{(x+L)^{2}+\boldsymbol{R}}}-\frac{\boldsymbol{x}}{\sqrt{\boldsymbol{x}^{2}+\boldsymbol{R}^{2}}}\right]
\end{gathered}
$$

where $B_{x}$ is the field along the axis of the loop/coil $(T), x$ is the axial distance from the face of the coil in millimeters, $R$ is the radius of the coil in millimeters, $\mu_{0}$ is the vacuum permeability $\left(N / A^{2}\right), I$ is the current (A), $N$ is the number of turns, and $L$ is the length of the coil in meters. In ANSYS, all parts except for the coil were set to air, and the maximum flux density at the entry face of the now absent core was measured to approximate $B_{x}$ from Equation 11. The results of this can be found in Figures 41-43, where Figure 41 shows a $2 \mathrm{D}$ plot of the theoretical and model values as a function of axial position and diameter, Figure 42 shows the field in the coil, and Figure 43 is the 3D response surface equivalent of Figure 41 generated by the model. These results match theory very well, with $R^{2}=99.95 \%$ for the data in Figure 41 . 


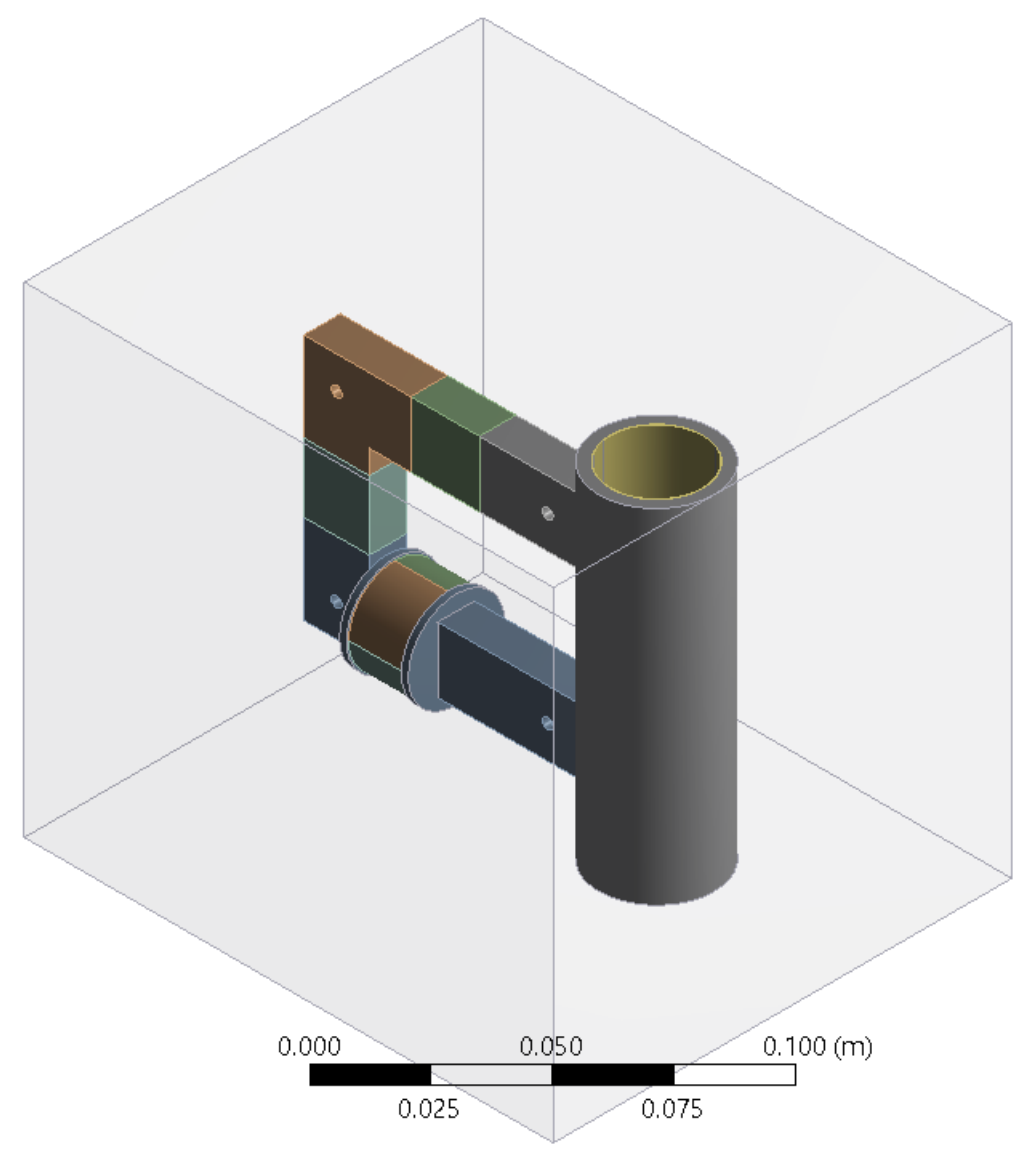

Figure 39. Geometry of the corrosion monitor model.

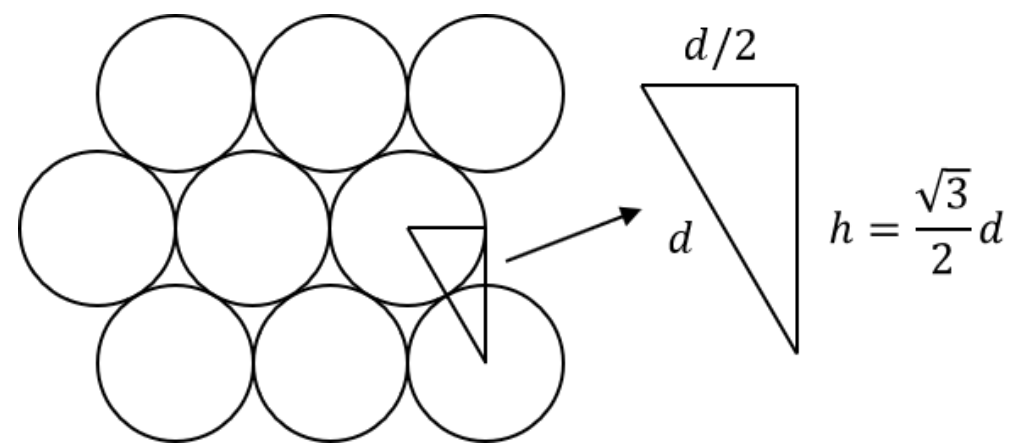

Figure 40. Geometry of a wrapped wire, Where $h$ is the height of a single packed layer in $\mathrm{mm}$, and d is the diameter of the wire in $\mathbf{m m}$.

\subsubsection{Verification of Model to Experiment}

With the case of an isolated coil verified by theory, the core of the sensor was reinstated into the model for comparison to experiments involving the core without a tube. Specifically, current in the source coil was ramped from -1.25 A to 1.25 A while the flux through the receiver coil on the other end of the sensor was measured, giving a relative hysteresis curve of flux vs. current. Properties for the Hiperco ${ }^{\circledR} 50$ core were 


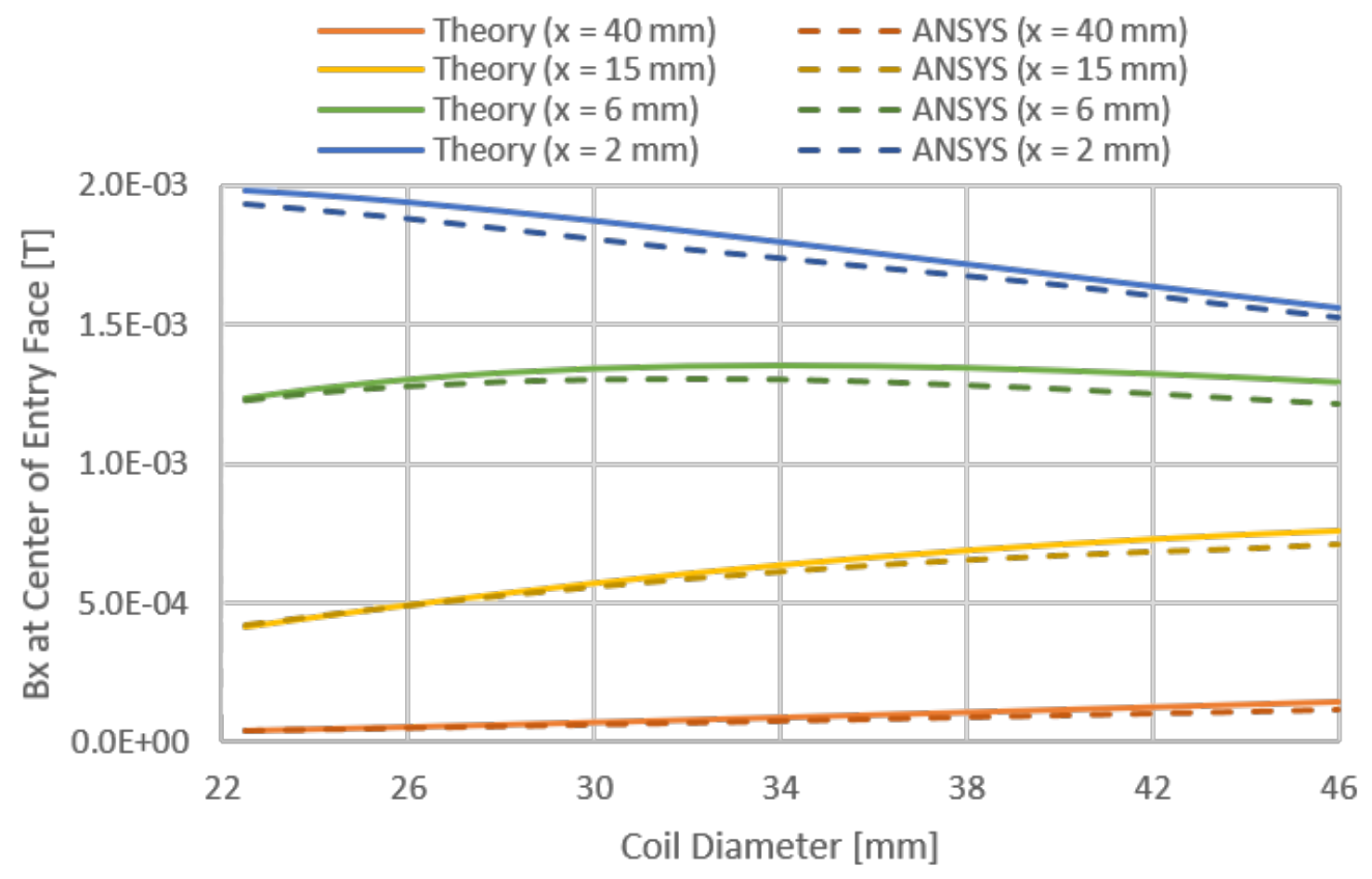

Figure 41. Comparison of model to theory for the magnetic flux density on the axis of a stranded coil.

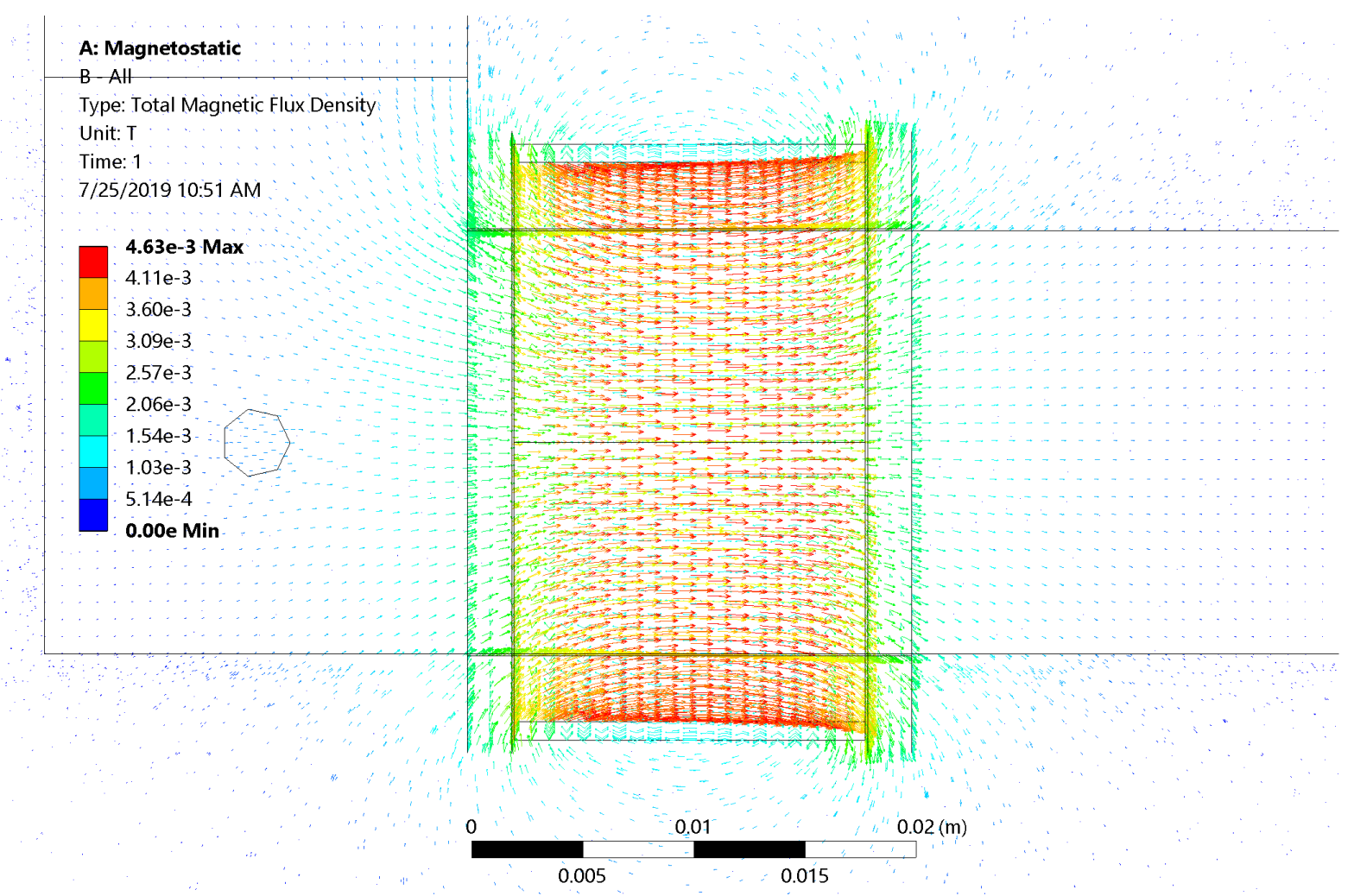

Figure 42. Magnetic flux density (T) of a $25 \mathrm{~mm}$ diameter coil with 0.5 A current and 150 turns. 


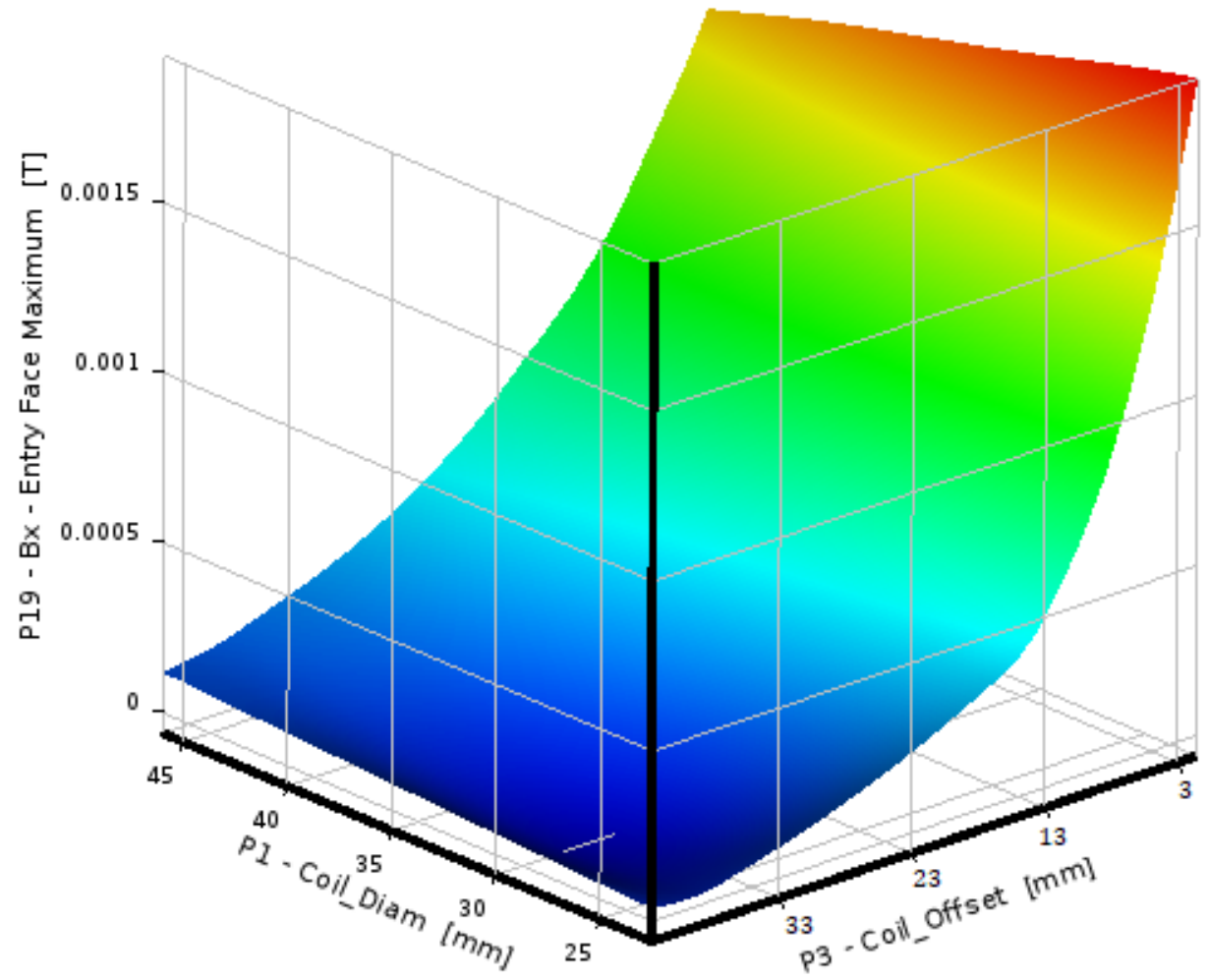

Figure 43. Response surface of a stranded coil as a function of coil diameter and offset from the point of measurement. 
taken from temperature-dependent data measured by de Groh et al. [2018], where the "Return to $21{ }^{\circ} \mathrm{C}$ " curve was selected to represent an annealed core at room temperature. In the model, the flux through the receiver coil was calculated by simulating the flux density in that region and multiplying it by the area and number of turns of the coil. Figure 44 displays the result of this comparison, while Figures 45 and 46 show the flux density in and around the sensor, respectively. The simulated data match that of the annealed core well, although, because it is a static model, it does not account for time-dependent losses such as those from hysteresis and eddy currents. Additionally, the core in the model is assumed to be pure Hiperco ${ }^{\circledR} 50$ as opposed to layered stacks of Hiperco ${ }^{\circledR} 50$ and boron nitride as in reality. 


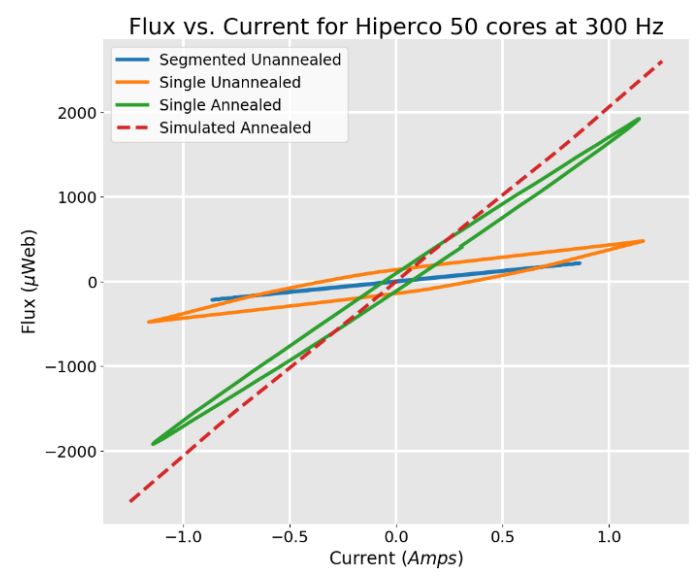

(a)

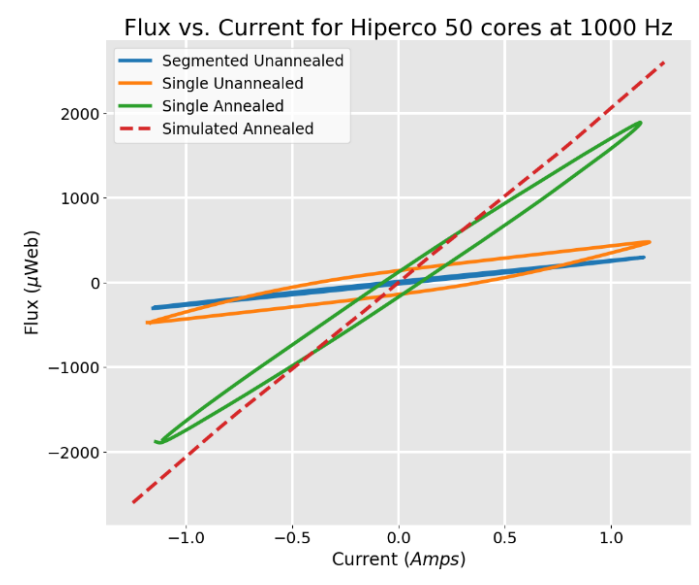

(b)

Figure 44. Measured and simulated relative hysteresis curves of the core with no tube present for (a) $300 \mathrm{~Hz}$ and (b) $1000 \mathrm{~Hz}$. Note that in both cases, the simulated values have no time dependency.

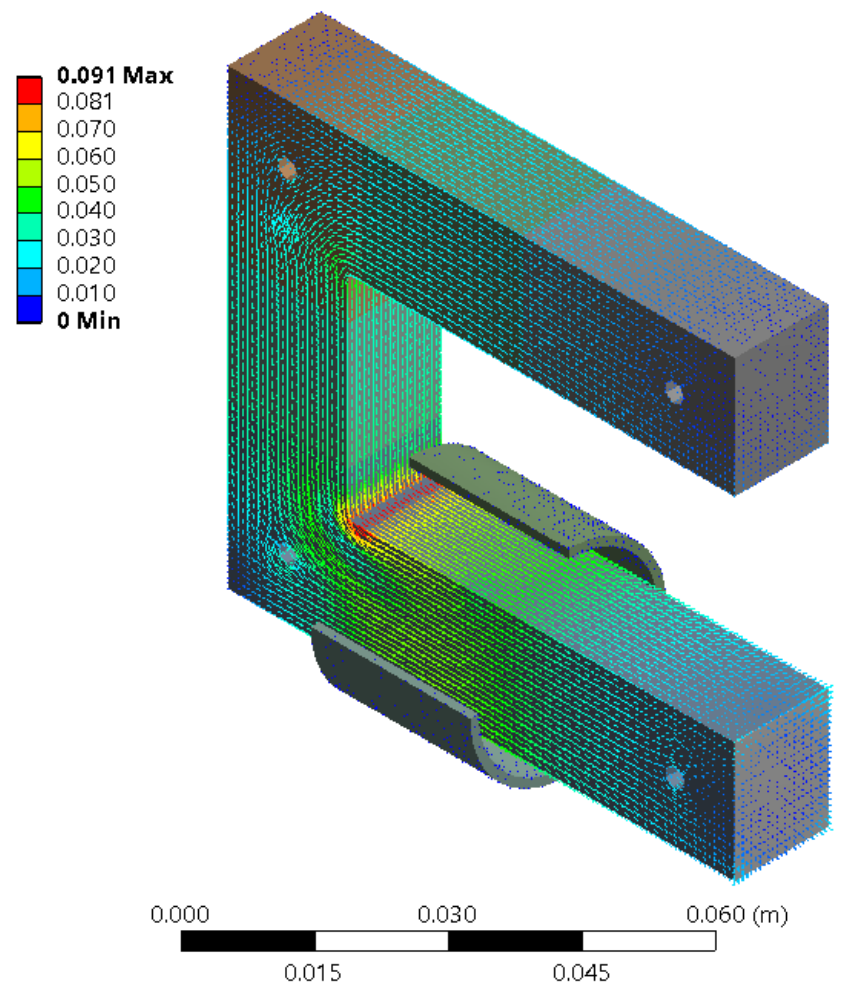

Figure 45. Flux density (T) within the core with no tube present for a current of $0.5 \mathrm{~A}$. 


\subsubsection{Optimization of the Core with a Corroded Tube}

As verified by theory and experiment, the model was used to help optimize the design of the sensor. To accomplish this, the corroded tube was reinstated into the model, and key inputs were parameterized to characterize the response. Specifically, the coil diameter, the coil offset from the C-shaped wall, the number of wire layers in the coil (proportional to the length of the coil), and the thickness of the corrosion layer were varied as described in Table 7. From this response, the approximate maximum sensitivity - given by the change in the average flux density in the receiver coil divided by the change in corrosion layer thickness - was determined. In addition to the analysis inputs, Table 7 summarizes the results for various cases of interest, while Figures 47-50 show the flux density in the corrosion layer for each of these cases. Figure 51 shows the response surface of the receiver's flux density vs. its two most impactful parameters,coil offset and corrosion layer thickness. Figure 52 shows the relative sensitivities of each output parameter to the various inputs, and Figure 53 shows the flux density in the sensor core with a nominal coil and a slightly corroded pipe.

This analysis led to two major observations. The first observation is that beyond a certain threshold of energy being put into the system, the monitor becomes increasingly sensitive to changes in the thickness of the corrosion layer. For example, the nominal case (Figure 47) would be considered "below threshold" in that it showed relatively little change in flux density for a large increase in the layer thickness. Therefore, although the monitor could detect a corrosion layer at this power level (compare Figure 45 to Figure 53), it would have difficulty measuring it. Conversely, the remaining three cases presented in Table 7 are all "above threshold," but they achieve this in different ways. The most effective method for improving the sensitivity was to simply increase the current (Figure 49). This is not surprising given the square dependence of energy stored in a coil on current, as shown in Equation 12,

$$
E=\frac{1}{2} L I^{2}=\frac{\mu N^{2} I^{2} A}{2 l}
$$

where $\mathrm{E}$ is the stored energy $(\mathrm{J}), \mathrm{L}$ is the inductance $(\mathrm{H}), \mathrm{I}$ is the current $(\mathrm{A}), \mu$ is the magnetic permeability $\left(\mathrm{N} / \mathrm{A}^{2}\right), \mathrm{N}$ is the number of turns, $\mathrm{A}$ is the area $\left(\mathrm{m}^{2}\right)$, and $\mathrm{l}$ is the length of the coil $(\mathrm{m})$. However, holding the current constant at $0.5 \mathrm{~A}$ results in the optimization algorithm selecting coils with large diameters (Figure 49) or a tightly wrapped wire (Figure 50) as alternative ways of increasing the magnetic energy. Notably, for the same percent increase in stored energy, increasing the area of the coil was found to be more effective in improving the sensitivity than reducing the length of the coil. While Figures 49 and 50 show similar results, Figure 49 represents a $130 \%$ increase in energy compared to a $270 \%$ increase in Figure 50.) This implies that, at least for the orientation of sensor and pipe shown, the core needs to be larger to make better use of the corrosion layer pathway. This is in addition to the inefficiency associated with having air between the core and the coil.

The second observation is that the thin corrosion layer was approaching saturation for a relatively low current in the input coil. Therefore, while the sensitivity is proportional to energy in the system past a specific threshold, it also has a ceiling. Because of this, the most successful cases in the optimization analysis were those that maximized the field while hovering right below the threshold limit. Furthermore, the flux density in the corrosion layer was found to be inversely proportional to the cross sectional area of the layer. This implies that, in order to measure very thin layers using the initially envisioned approach, the sensor must operate at a lower power and thus lower sensitivity and signal-to-noise ratio to avoid saturation. 


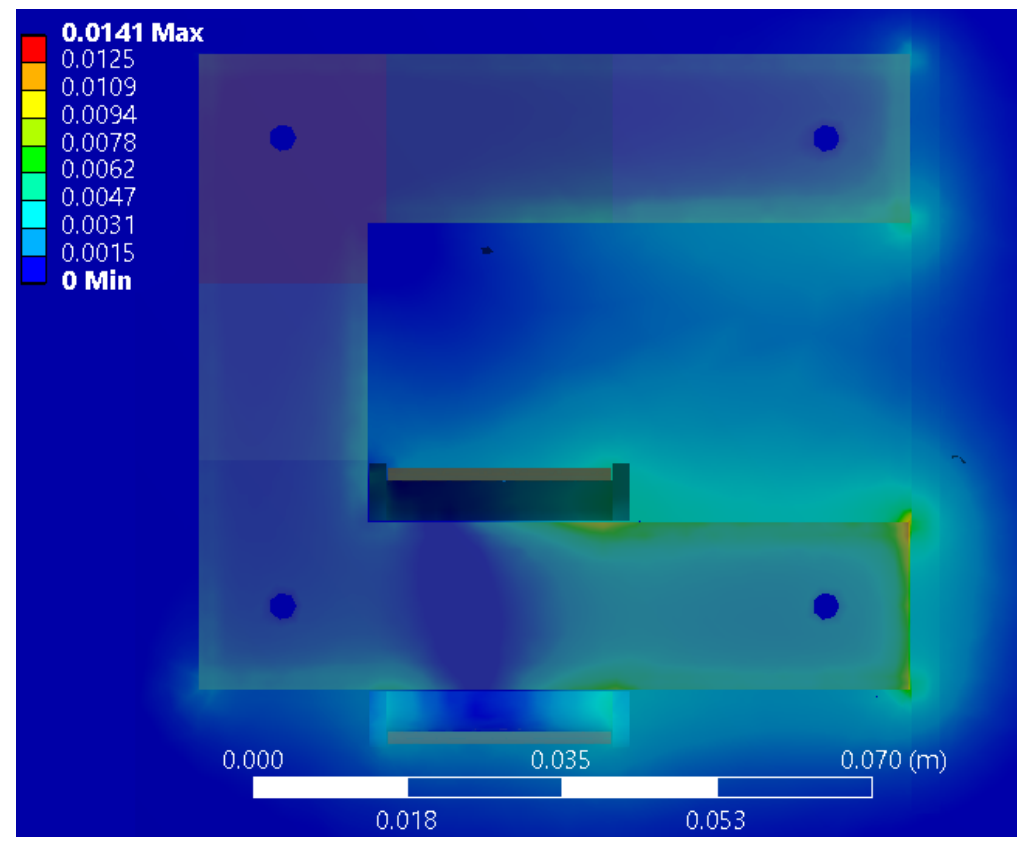

Figure 46. Flux density (T) outside the core with no tube present for a current of $0.5 \mathrm{~A}$.

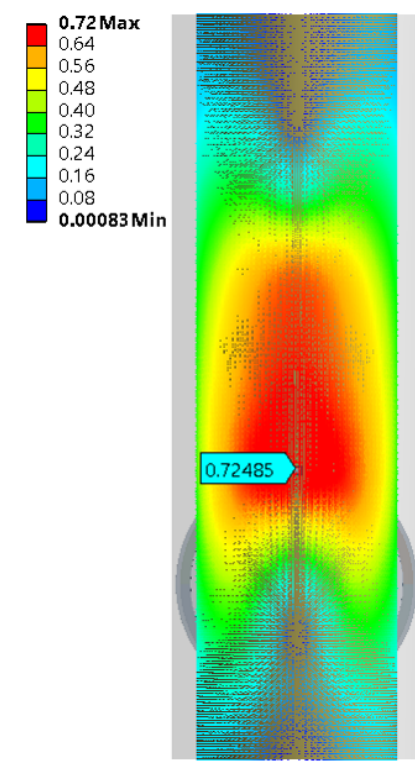

(a)

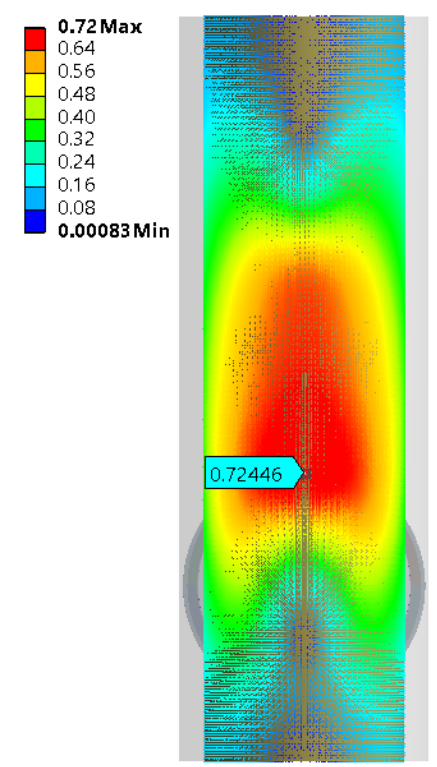

(b)

Figure 47. Flux density (T) in the corrosion layer for a nominal $28.5 \mathrm{~mm}$ coil with a current of $0.5 \mathrm{~A}$ for a corrosion layer (a) $\mathbf{3 0} \mu \mathrm{m}$ and (b) $130 \mu \mathrm{m}$ thick. Notice there is little change between the cases. 


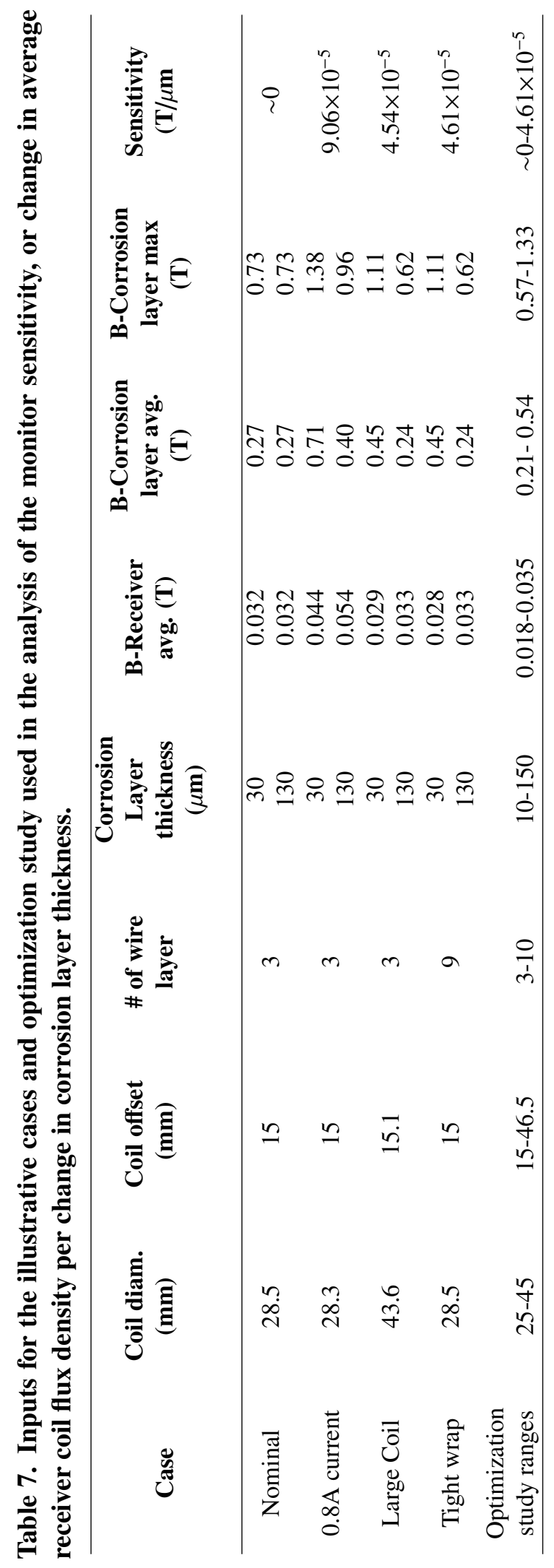




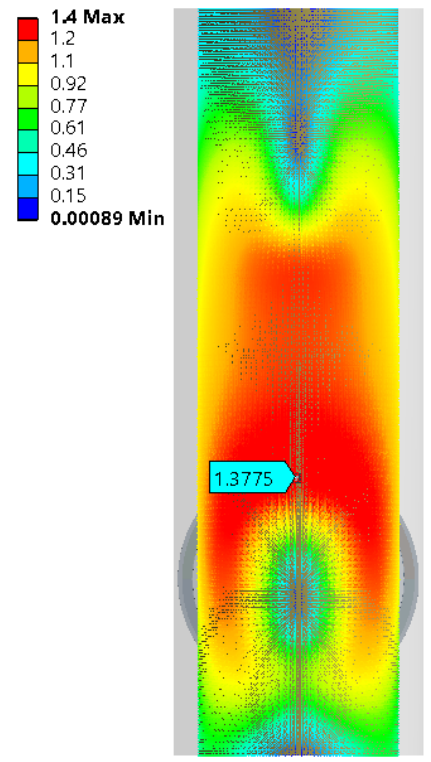

(a)

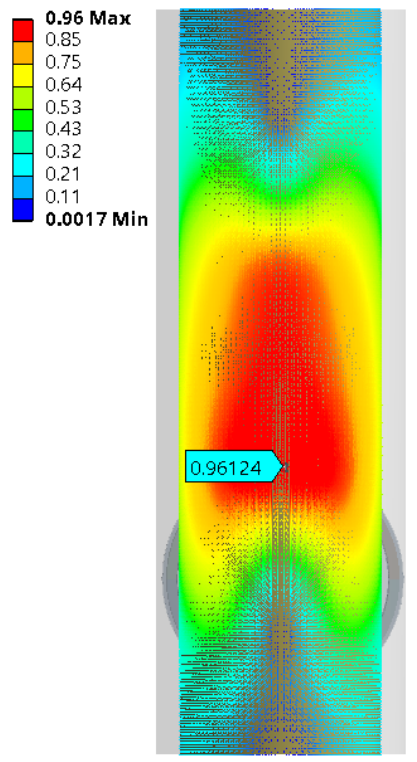

(b)

Figure 48. Flux density ( $T$ ) in the corrosion layer for a nominal $28.5 \mathrm{~mm}$ coil with a current of $0.8 \mathrm{~A}$ for a corrosion layer (a) $30 \mu \mathrm{m}$ and (b) $130 \mu \mathrm{m}$ thick.

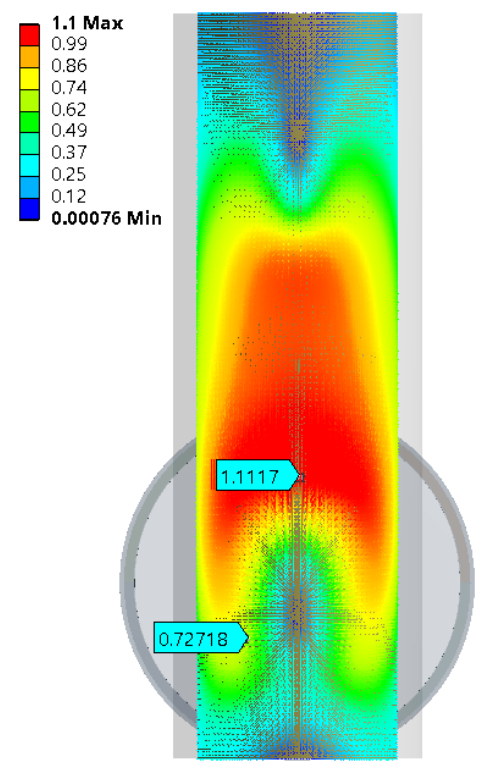

(a)

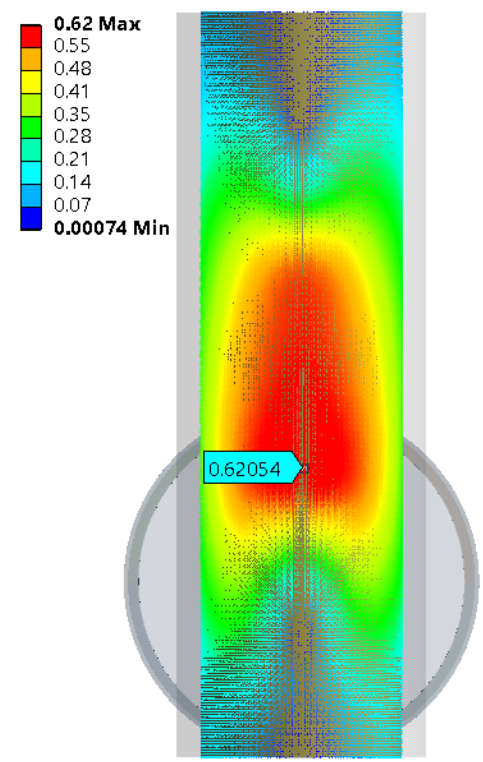

(b)

Figure 49. Flux density (T) in the corrosion layer for a large $43.6 \mathrm{~m}$ coil with a current of $0.5 \mathrm{~A}$ for a corrosion layer (a) $30 \mu \mathrm{m}$ and (b) $130 \mu \mathrm{m}$ thick. 
Alternatively, this rapid saturation of the corrosion layer also opens the door to a second type of measurement. Rather than detect a relatively small change in an unsaturated field as described above, it is theoretically possible to sweep the amplitude of the input current to purposefully saturate the layer and thus measure a relatively large change in how the system responds. Future work looks to experimentally validate this effect, while more information on the topic can be found in Section 2.1.2. When considering these results and the geometry of the sensor, the nominal coil presented in Table 7 was determined to be sufficiently robust for the final design. 


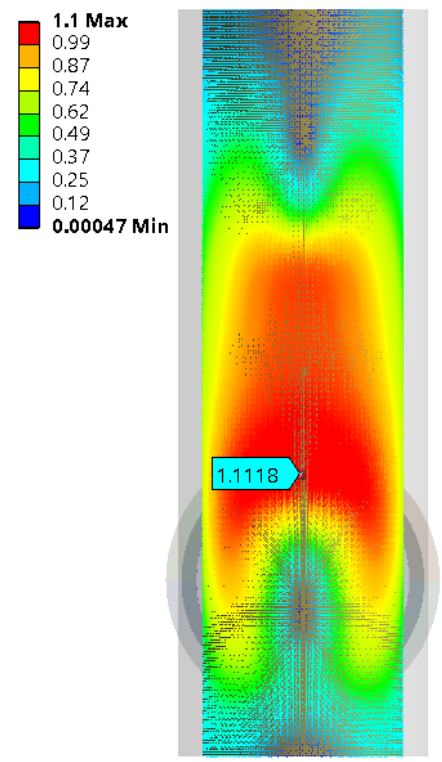

(a)

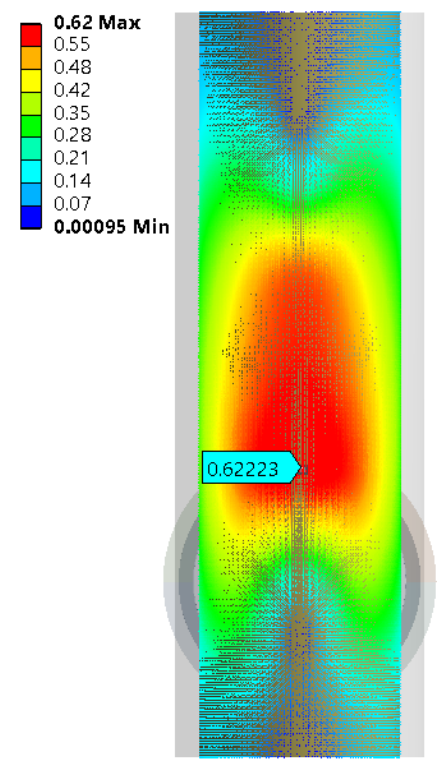

(b)

Figure 50. Flux density ( $\mathrm{T}$ ) in the corrosion layer for a nominal $28.5 \mathrm{~mm}$ coil with a current of $0.8 \mathrm{~A}$ for a corrosion layer (a) $\mathbf{3 0} \mu \mathrm{m}$ and (b) $130 \mu \mathrm{m}$ thick. The wires are wrapped with more layers. 


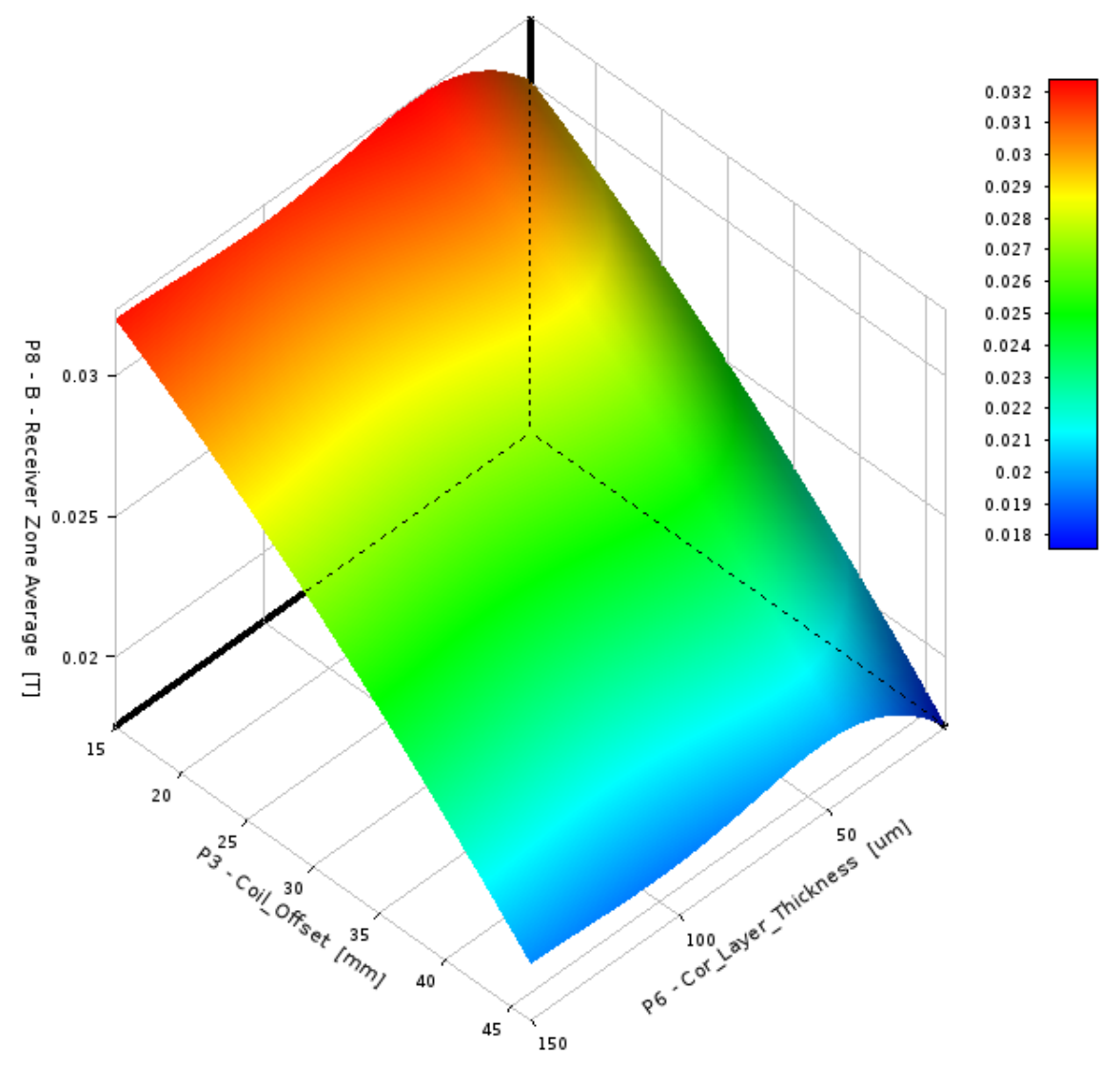

Figure 51. Response surface for the receiver flux density as a function of corrosion layer thickness and coil offset.

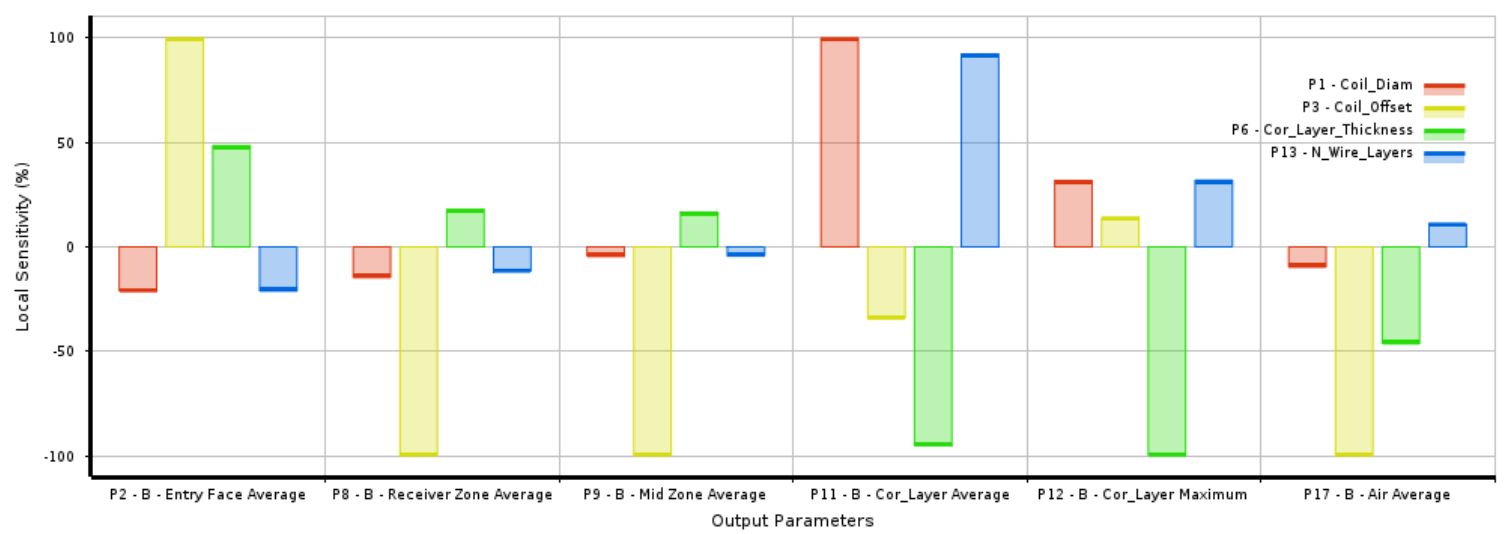

Figure 52. Relative sensitivities of output parameters to the input parameters for the case of a nominal sensor with an $80 \mu$ m-corroded pipe. Larger bars indicate more impactful parameters. 


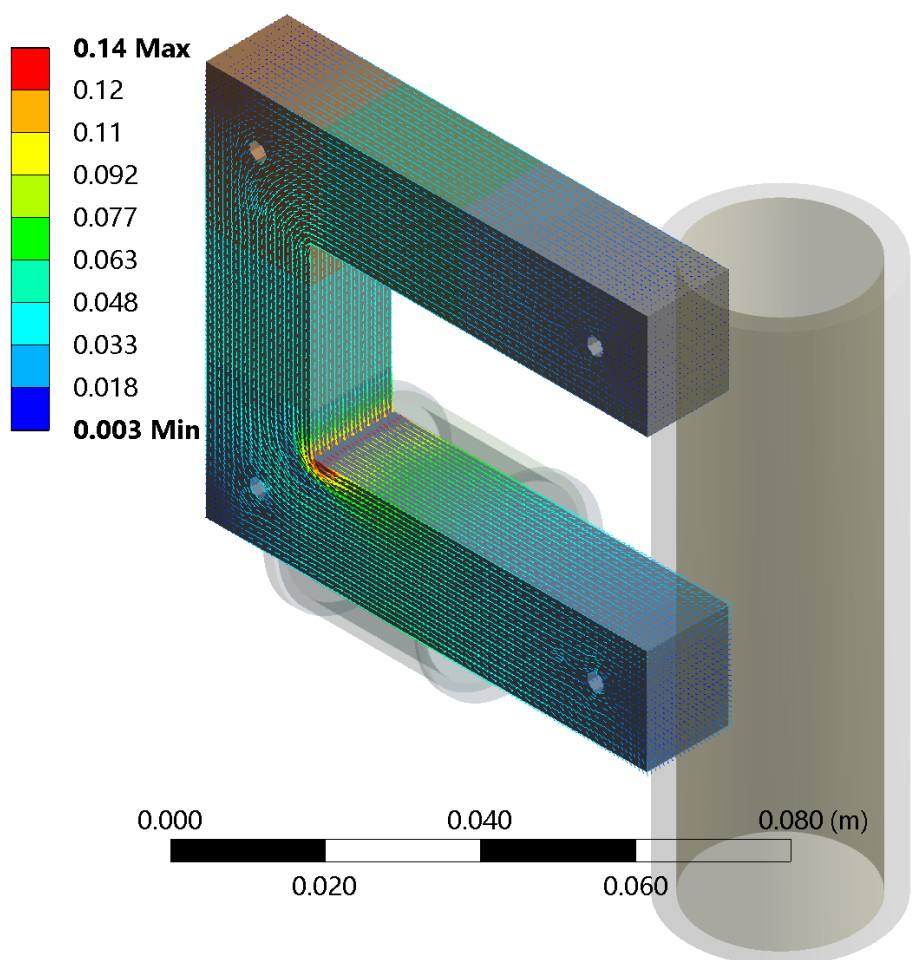

Figure 53. Flux density ( $T$ ) within the core with a $30 \mu \mathrm{m}$-corroded pipe present, for nominal coil dimensions and a 0.5 A current. 


\section{EXPERIMENT TESTBED DESIGN AND IMPLEMENTATION}

\subsection{CORROSION SPECIMENS}

The first corrosion specimens provided for testing were cubes of $304 \mathrm{~L}$ stainless steel that had been corroded to varying degrees. The first effort at exposing 304L stainless steel cubes to molten chloride salt involved two $9.5 \mathrm{~cm}$ tall covered alumina crucibles. A stainless cube was placed in the bottom of each crucible, and then the crucibles were filled with large chunks of solidified salt. Since no identification markings could be made on the stainless steel cubes, a platinum wire was wrapped around one of them. The crucibles were placed in a metal pan in a furnace, and the furnace was heated to $750{ }^{\circ} \mathrm{C}$ for about 40 hours. On the second day of testing, word was received that instruments and tools in the laboratory were being corroded by material escaping from the furnace. The furnace was turned off and allowed to cool. When the furnace could be opened, it was apparent that the salt had not remained in the alumina crucibles. Figure 54 shows one of the crucibles before it was removed from the furnace.

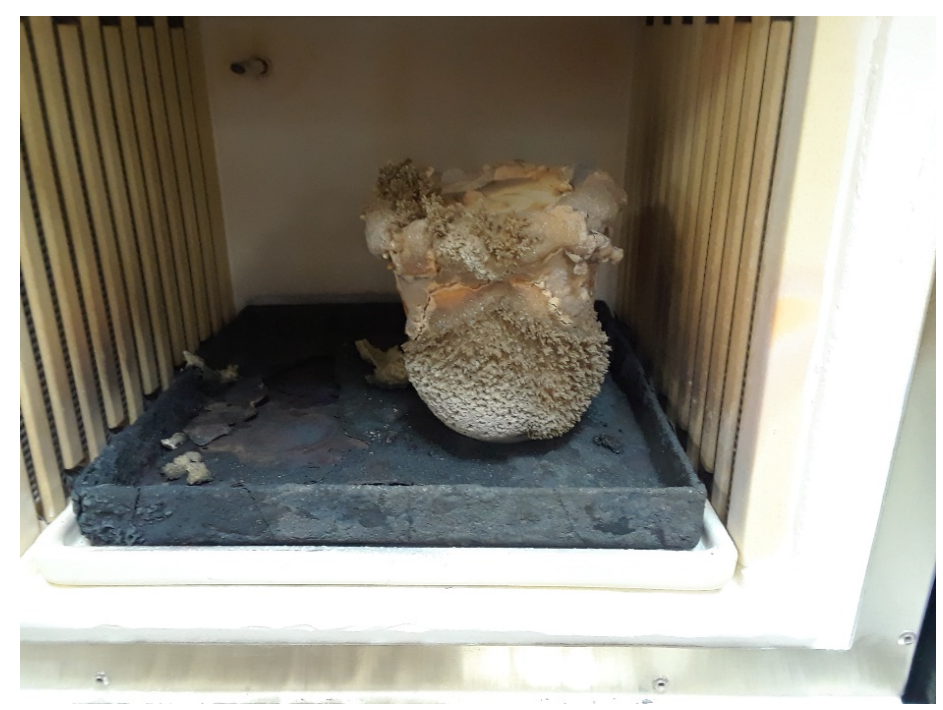

Figure 54. Alumina crucible used for initial exposure of stainless steel cubes to molten chloride salt.

After the crucibles were removed from the furnace, the salt deposits on the outside of the crucible were removed, and the crucibles were opened. The interiors of the crucibles were essentially free of salt; the bottom of one crucible is shown in Figure 55, in which one stainless cube with the attached platinum wire is sitting in the bottom of the nearly empty crucible.

Both samples were recovered, and they showed significant weight loss as indicated in the sample summary shown in Table 8.

For subsequent exposure of stainless steel cubes to molten salt, a quartz crucible was used in an effort to better contain the salt. This quartz crucible, which was loaded with salt in an argon atmosphere glovebox, was contained in a stainless steel pipe nipple with endcaps that were tightly screwed in place. One of these capsules is shown before and after exposure in Figure 56.

This design successfully contained the salt within the crucible; an opened capsule and crucible are shown in Figure 57. 


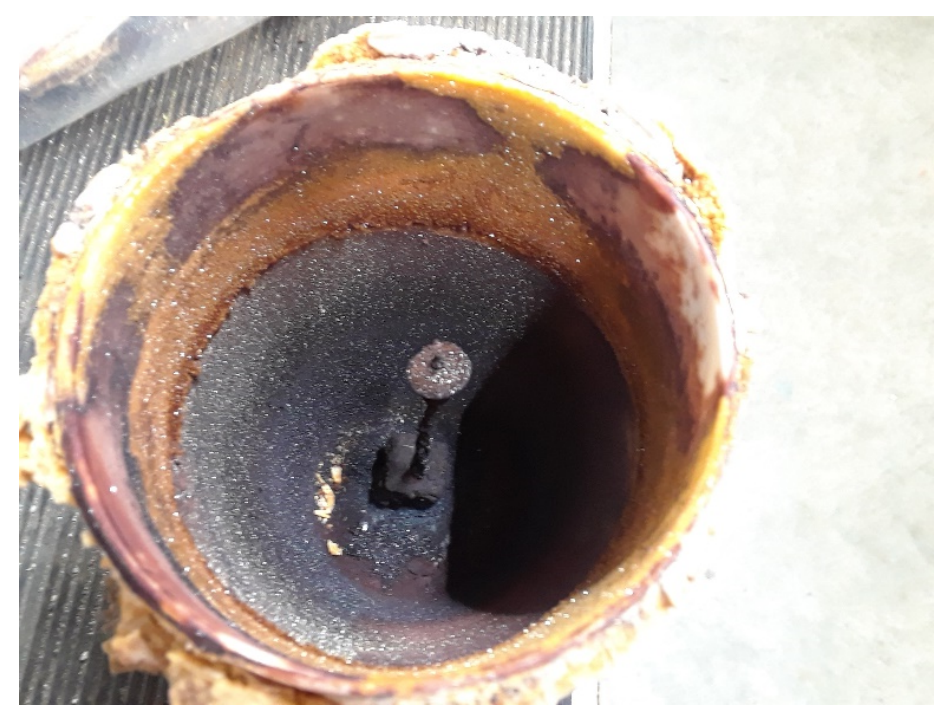

Figure 55. Photo showing stainless steel sample in the bottom of the nearly salt-free alumina crucible.

Table 8. Summary of samples exposed in NaCl-MgCl2 salt at $750{ }^{\circ} \mathrm{C}$

\begin{tabular}{ccccc}
\hline Sample \# & Exposure time (h) & Container & Weight loss (mg) & Metallography \\
\hline 1 & 0 & Unexposed & 0 & \\
2 & $<40$ & Alumina & & Not done \\
3 & $<40$ & Alumina & & Completed \\
4 & 20 & Quartz & 12.00 & Completed \\
5 & 20 & Quartz & 23.55 & Completed \\
6 & 48 & Quartz & 14.58 & Completed \\
7 & 48 & Quartz & 14.66 & Completed \\
8 & 6 & Quartz & 9.66 & Not done \\
9 & 6 & Quartz & 10.87 & Not done \\
\hline
\end{tabular}
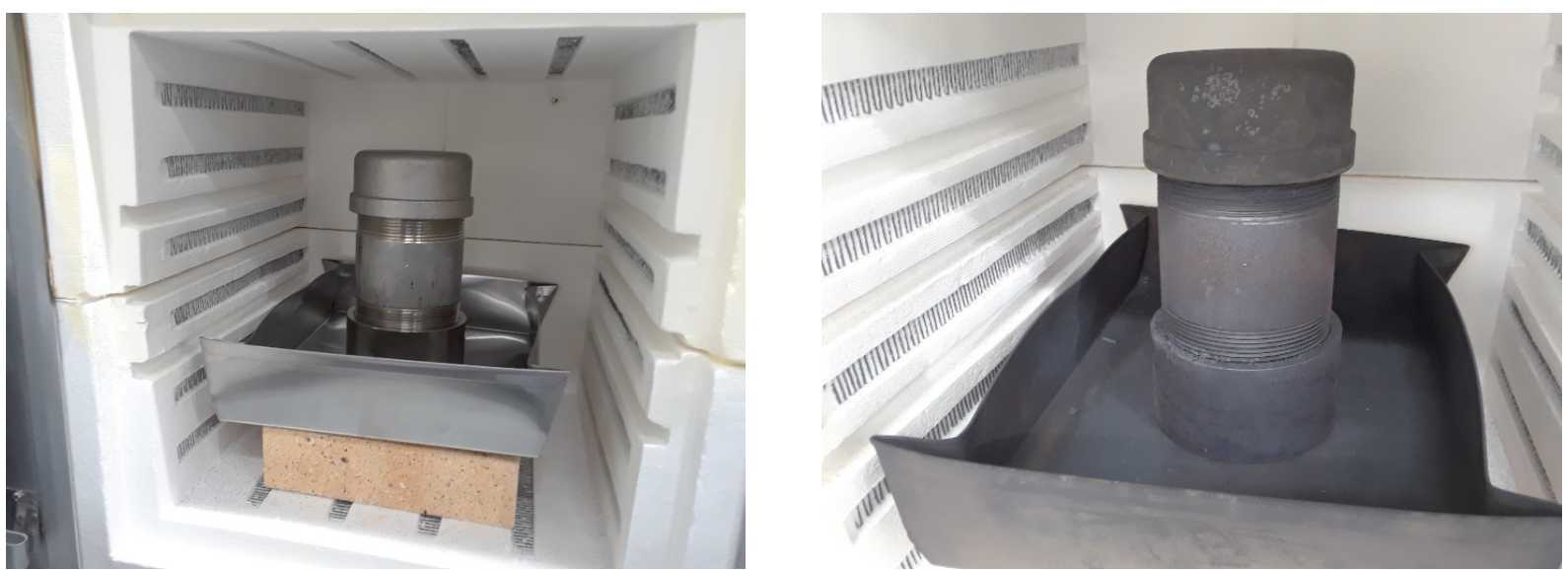

Figure 56. Stainless steel pipe capsule providing outer containment of the quartz crucible-which contained the chloride salt and two stainless steel cubes-shown before and after elevated temperature exposure at $750{ }^{\circ} \mathrm{C}$. 


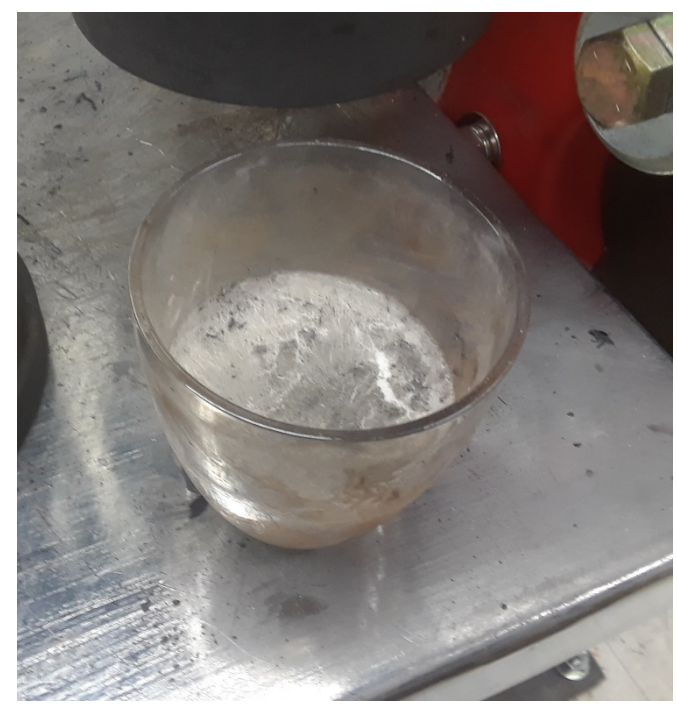

Figure 57. Photo showing quartz crucible containing the salt and stainless cubes after elevated temperature exposure, demonstrating successful containment of the salt in the quartz crucible.

In total, 8 cubes were exposed to molten salt, with two cubes being exposed to each condition. A summary of all the cube exposures is given in Table 8. The chromium depletion associated with the weight loss resulted in transformation of some of the austenite phase to ferrite, with an associated change in magnetic properties. Micrographs taken of cross sections of the exposed cubes are shown in Figure 58. Based on
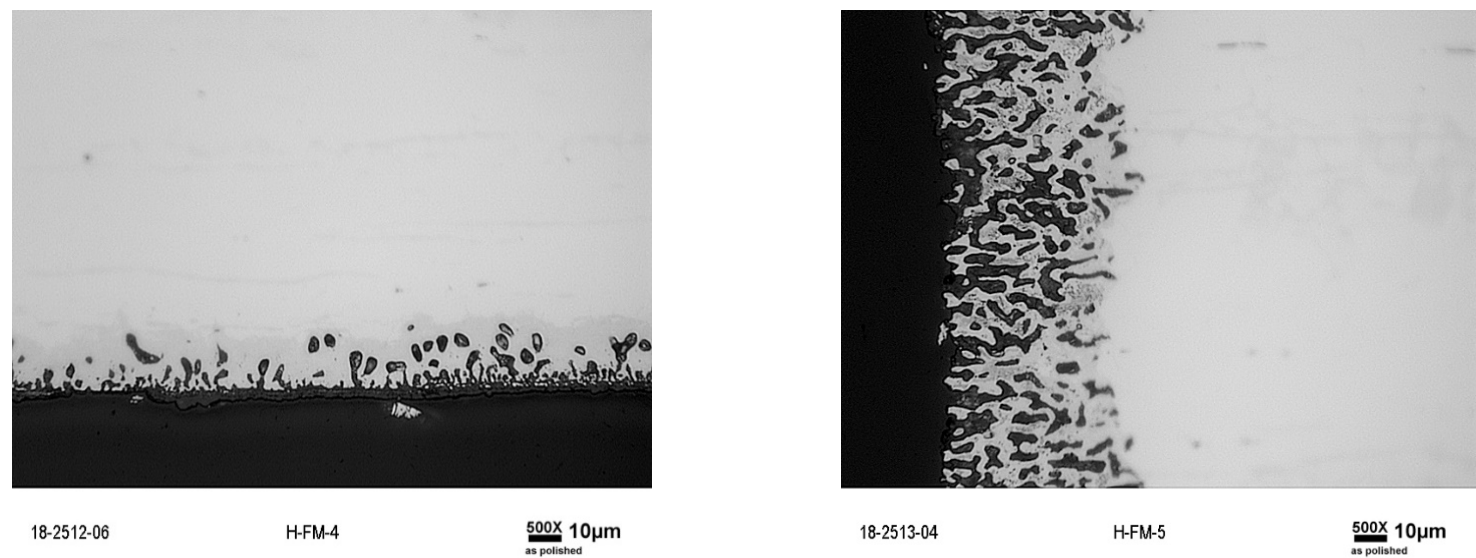

Figure 58. Micrographs of 304L samples exposed in molten salt at $750{ }^{\circ} \mathrm{C}$ for 20 hours and demonstrating a weight loss of (left) $12.0 \mathrm{mg}$ and (right) $23.6 \mathrm{mg}$.

successful demonstration of the test method, more tests were planned in which a portion of the interior surface of stainless steel pipe sections would be exposed to molten salt.

Multiple stainless steel pipes are corroded to different corrosion levels for testing. A tube "capsule" is fabricated from 7-inch long pieces of the 1-inch sch 40 (1.315-inch OD) pipe. The bottom is welded shut to allow for salt loading. Half of the capsule's surface is exposed to molten salt, and the other half relatively free of molten salt exposure. Because of the capability of this salt to "climb" vertical surfaces, it is 
important to clean and polish the ID surface of the pipe to minimize the capability of the salt to climb onto the upper half of the capsule, which is intended to be free of molten salt exposure. The weight change in these pipes will be minimal compared to the cube specimens. However, this information will be documented if accountable. A section of the pipe will be cut off for destructive testing to characterize the amount of corrosion on each pipe. Since the corrosion is controlled through exposure time, this is a critical step to ensure that the corrosion sensor is operating as designed.

\subsection{REFERENCE USED TO COMPENSATE FOR TEMPERATURE EFFECTS}

Temperature affects inductance through several mechanisms:

1. Material expansion with temperature changes the coil and material geometry, to include diameters and spacing, at the macro level, changing the volume (length and area) of the magnetic flux. The thermal expansion of Hiperco ${ }^{\circledR} 50$ is $9.50 \mu \mathrm{m} / \mathrm{m}^{\circ} \mathrm{C}$.

2. At the atomic level, lattice spacing is directly influenced by temperature, which affects permeability. Some powdered ferrite cores exhibit increasing permeability with temperature — up to the Curie temperature. For most metal alloys, the higher the temperature the greater the lattice spacing, which changes the overlap of electron orbitals. An example of temperature effect on magnetite is shown in Figure 59; at $575{ }^{\circ} \mathrm{C}$ (the Curie temperature), the material becomes paramagnetic.

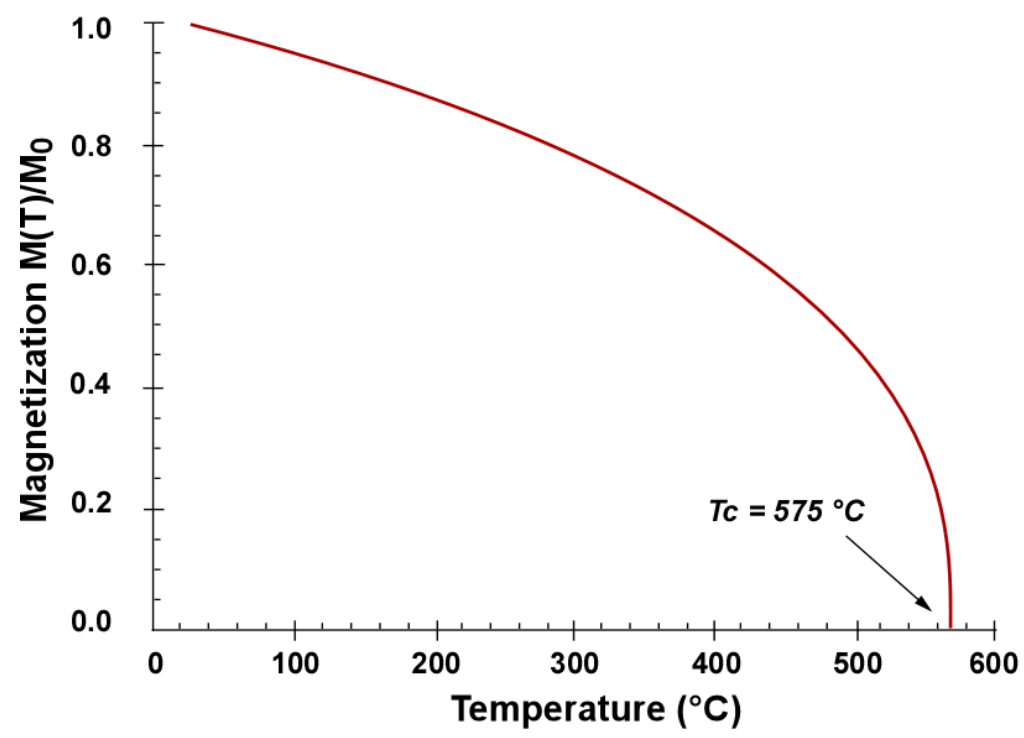

Figure 59. Example magnetization curve for magnetite showing the effect of decreasing permeability with temperature and Curie point.

Because of the variability of inductance with temperature, a means of compensation is required; otherwise, it is impossible to distinguish between temperature variation and permeability variation. A reference channel is provided in Figure 60 that parallels the measurement channel in every way, except it measures an alloy sample of constant permeability for which no corrosion takes place over time.

This reference channel value is compared with the measurement channel value, and a ratio is calculated. Changes in inductance resulting from temperature effects are therefore cancelled, leaving only the small 


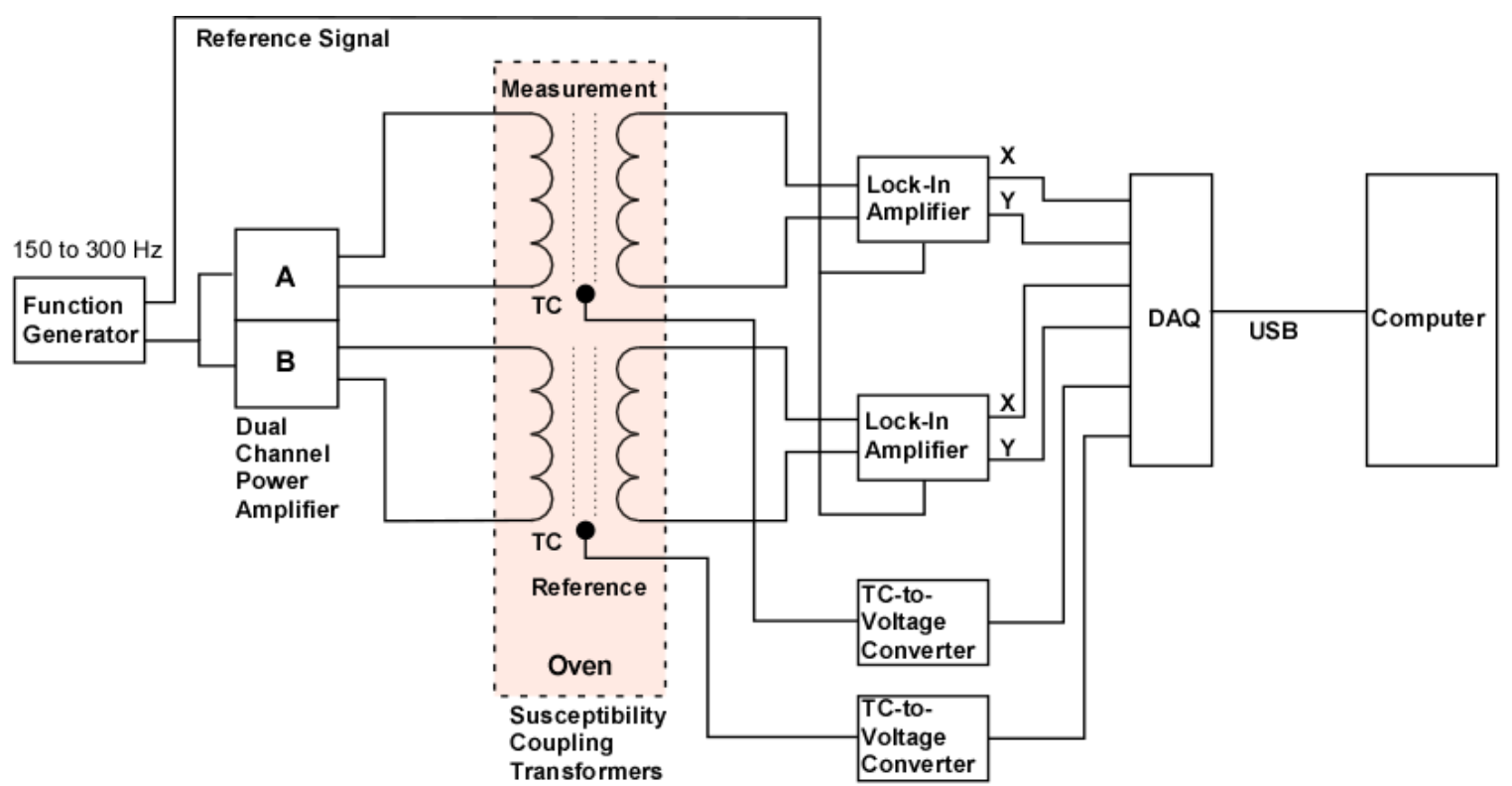

Figure 60. A dual channel system constructed to permit simultaneous readout of a measurement transducer and a reference transducer.

changes resulting from corrosion effects on permeability. In the circuit depicted in Figure 60, temperature is also measured. Both channel signals and temperatures are collected by the data acquisition system.

The LIA's input gain must have sufficient margin to handle the full range of input amplitudes. The input gain is set to handle the largest expected signal plus 25\% without overload (Technical Datasheet [2015]).

The magnetomotive force with an RMS current of $0.5 \mathrm{~A}$ is $75 \mathrm{~A}-\mathrm{T}$, which is far from saturating the core material. The coils are made with an equal number of turns (150) because, after some experimentation, there was no signal-to-noise ratio benefit to having unequal primary-to-secondary turns ratios. The impedance $(\mathrm{Z}=\mathrm{R}+\mathrm{j} \omega \mathrm{L})$ of the coils is shown for air core, unannealed, and annealed Hiperco ${ }^{\circledR} 50$. Over the frequency range of $10-1,000 \mathrm{~Hz}$, the impedance of the coil on the annealed core ranges from about $2 \Omega$ to $30 \Omega$ as shown in Figure 61 and Table 9. The resistance and inductance were measured, and the impedance was calculated based on the measured values. Because the coil impedance lies between $2 \Omega$ to $30 \Omega$ at the frequencies of interest, a class-D audio amplifier of 20-60 watts should have sufficient drive for the transmitting coil.

\subsection{ELECTRONIC PACKAGE SELECTION}

The measurement system used for all test cases consisted of two SRS865 LIAs, two Pyle PFA200 class T audio amplifiers, two Hiperco ${ }^{\circledR} 50$ sensors, an MCCDAQ USB-2408 data acquisition (DAQ) module, and a laptop (see Figure 62a). One LIA generated the oscillating signal, which was referenced by the other LIA and is the input signal to the two power amplifiers. Originally, a dual channel audio amplifier was selected for the experiment, but the gain between channels was approximately $10 \%$ different. Each power amplifier drove a sensor. One sensor was used as a TCR. The other was used to sense the onset of corrosion. Each sensing coil was input to a LIA. The temperature of each sensor was measured with a type-k thermocouple which was read by the MCCDAQ USB-2408 module. The laptop recorded the data from the LIAs and the 
Table 9. Coil characteristics

\begin{tabular}{|c|c|c|c|c|c|c|c|c|c|}
\hline \multirow{2}{*}{ Frequency $(\mathrm{Hz})$} & \multicolumn{3}{|c|}{ Air core } & \multicolumn{3}{|c|}{ Unannealed Hiperco $^{\circledR} \mathbf{5 0}$} & \multicolumn{3}{|c|}{ Annealed Hiperco ${ }^{\circledR} \mathbf{5 0}$} \\
\hline & $\mathbf{R} \Omega$ & L H & $\mathbf{Z} \Omega$ & $\mathbf{R} \Omega$ & L H & $\mathbf{Z} \Omega$ & $\mathbf{R} \Omega$ & L H & $\mathbf{Z} \Omega$ \\
\hline 10 & 1.34 & 0.000498 & 1.37129 & 1.96 & 0.00196 & 2.08315 & 1.715 & 0.004045 & 1.969155 \\
\hline 20 & 1.34 & 0.000498 & 1.402581 & 1.96 & 0.00196 & 2.206301 & 1.715 & 0.004045 & 2.22331 \\
\hline 40 & 1.34 & 0.000498 & 1.465161 & 1.96 & 0.00196 & 2.452602 & 1.715 & 0.004045 & 2.731619 \\
\hline 60 & 1.34 & 0.000498 & 1.527742 & 1.96 & 0.00196 & 2.698903 & 1.715 & 0.004045 & 3.239929 \\
\hline 80 & 1.34 & 0.000498 & 1.590322 & 1.96 & 0.00196 & 2.945203 & 1.715 & 0.004045 & 3.748239 \\
\hline 100 & 1.34 & 0.000498 & 1.652903 & 1.96 & 0.00196 & 3.191504 & 1.715 & 0.004045 & 4.256548 \\
\hline 120 & 1.34 & 0.000498 & 1.715483 & 1.96 & 0.00196 & 3.437805 & 1.715 & 0.004045 & 4.764858 \\
\hline 140 & 1.34 & 0.000498 & 1.778064 & 1.96 & 0.00196 & 3.684106 & 1.715 & 0.004045 & 5.273168 \\
\hline 160 & 1.34 & 0.000498 & 1.840644 & 1.96 & 0.00196 & 3.930407 & 1.715 & 0.004045 & 5.781478 \\
\hline 180 & 1.34 & 0.000498 & 1.903225 & 1.96 & 0.00196 & 4.176708 & 1.715 & 0.004045 & 6.289787 \\
\hline 200 & 1.34 & 0.000498 & 1.965805 & 1.96 & 0.00196 & 4.423009 & 1.715 & 0.004045 & 6.798097 \\
\hline 220 & 1.34 & 0.000498 & 2.028386 & 1.96 & 0.00196 & 4.66931 & 1.715 & 0.004045 & 7.306407 \\
\hline 240 & 1.34 & 0.000498 & 2.090966 & 1.96 & 0.00196 & 4.91561 & 1.715 & 0.004045 & 7.814716 \\
\hline 260 & 1.34 & 0.000498 & 2.153547 & 1.96 & 0.00196 & 5.161911 & 1.715 & 0.004045 & 8.323026 \\
\hline 280 & 1.34 & 0.000498 & 2.216127 & 1.96 & 0.00196 & 5.408212 & 1.715 & 0.004045 & 8.831336 \\
\hline 300 & 1.34 & 0.000498 & 2.278708 & 1.96 & 0.00196 & 5.654513 & 1.715 & 0.004045 & 9.339645 \\
\hline 350 & 1.34 & 0.000498 & 2.435159 & 1.96 & 0.00196 & 6.270265 & 1.715 & 0.004045 & 10.61042 \\
\hline 400 & 1.34 & 0.000498 & 2.591611 & 1.96 & 0.00196 & 6.886017 & 1.715 & 0.004045 & 11.88119 \\
\hline 450 & 1.34 & 0.000498 & 2.748062 & 1.96 & 0.00196 & 7.501769 & 1.715 & 0.004045 & 13.15197 \\
\hline 500 & 1.34 & 0.000498 & 2.904513 & 1.96 & 0.00196 & 8.117522 & 1.715 & 0.004045 & 14.42274 \\
\hline 550 & 1.34 & 0.000498 & 3.060964 & 1.96 & 0.00196 & 8.733274 & 1.715 & 0.004045 & 15.69352 \\
\hline 600 & 1.34 & 0.000498 & 3.217416 & 1.96 & 0.00196 & 9.349026 & 1.715 & 0.004045 & 16.96429 \\
\hline 650 & 1.34 & 0.000498 & 3.373867 & 1.96 & 0.00196 & 9.964778 & 1.715 & 0.004045 & 18.23506 \\
\hline 700 & 1.34 & 0.000498 & 3.530318 & 1.96 & 0.00196 & 10.58053 & 1.715 & 0.004045 & 19.50584 \\
\hline 750 & 1.34 & 0.000498 & 3.68677 & 1.96 & 0.00196 & 11.19628 & 1.715 & 0.004045 & 20.77661 \\
\hline 800 & 1.34 & 0.000498 & 3.843221 & 1.96 & 0.00196 & 11.81203 & 1.715 & 0.004045 & 22.04739 \\
\hline 850 & 1.34 & 0.000498 & 3.999672 & 1.96 & 0.00196 & 12.42779 & 1.715 & 0.004045 & 23.31816 \\
\hline 900 & 1.34 & 0.000498 & 4.156124 & 1.96 & 0.00196 & 13.04354 & 1.715 & 0.004045 & 24.58894 \\
\hline 950 & 1.34 & 0.000498 & 4.312575 & 1.96 & 0.00196 & 13.65929 & 1.715 & 0.004045 & 25.85971 \\
\hline 1000 & 1.34 & 0.000498 & 4.469026 & 1.96 & 0.00196 & 14.27504 & 1.715 & 0.004045 & 27.13048 \\
\hline
\end{tabular}




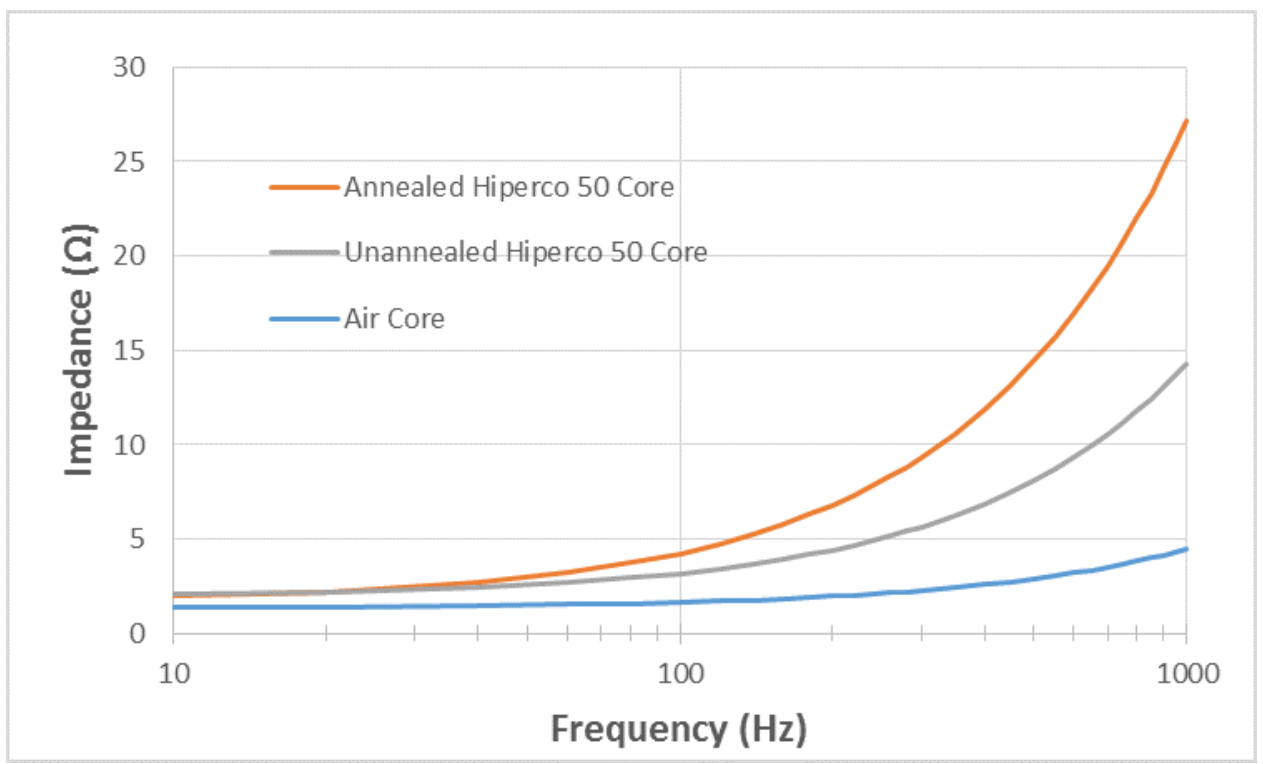

Figure 61. Complex impedance of the coils.

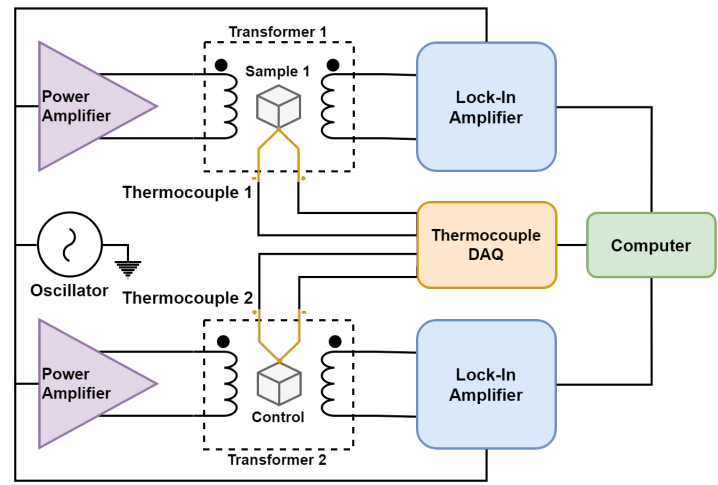

(a)

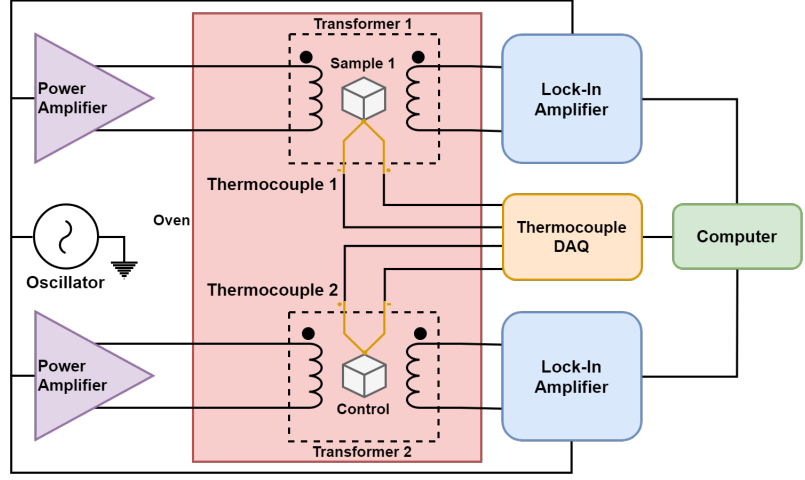

(b)

Figure 62. System block diagrams of the room temperature experiment (a) and the furnace experiment (b).

USB-2408 module. Additionally, a Vulcan 3-550 furnace was used for the $200{ }^{\circ} \mathrm{C}$ test (see Figure $62 \mathrm{~b}$ ). For the high-temperature $\left(750^{\circ} \mathrm{C}\right)$ experiments, a Chromalox 640144026 cartridge header was used. Previously, these tests were performed using sample cubes with $10 \mathrm{~mm}$ edges to verify the temperature compensation before using pipes heated with the cartridge heater.

A program was developed to interface with the LIAs and the USB-2408 in LabVIEW 18. The LabVIEW graphical user interface (GUI) is shown in Figure 63. This program established the measurement parameters of the LIAs, and it also established the LIAs so that one provided the signal source, and the other was referenced to that signal source. The data (X, Y, R, and $\theta$ ) were recorded from each LIA at a capture rate of $1 \mathrm{~Hz}$. Each capture was timestamped, and all data and timestamps were saved into a file for post-processing. The post-processing script was developed in Python to plot the saved data for analysis. 


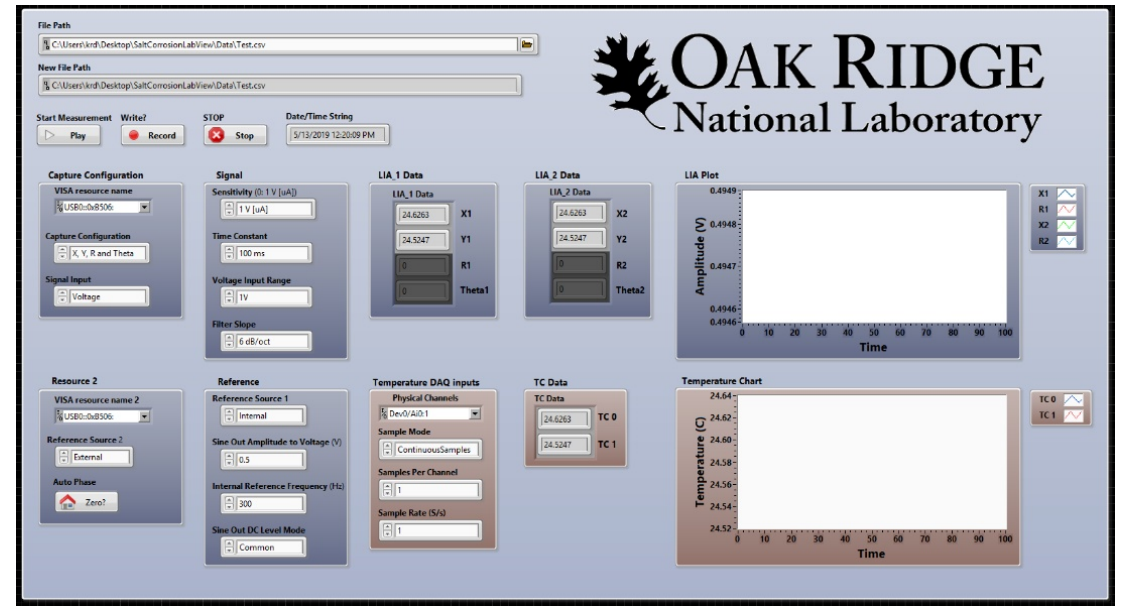

Figure 63. Graphical user interface for the LabVIEW data collection program.

\subsection{TESTBED DESIGN FOR HIGH-TEMPERATURE CORROSION SENSOR}

\subsubsection{ROOM TEMPERATURE TESTING}

The corroded blocks were tested at room temperature using the electronic package described in Section 3.3. A similar testbed was used for room temperature testing of the corroded pipes (Figures 64 and 65). Testing with a single sensor first ensures that the testbed is performing the same for the cubes and the pipes. This also allows for testing of the sensor orientation. As shown in Figure 64, the sensor is parallel to the length of the pipe, whereas in Figure 23, the sensor is "around" the pipe. As mentioned previously, a power amplifier drives the input of the corrosion sensor, and a single LIA receives the signal from the corrosion sensor.

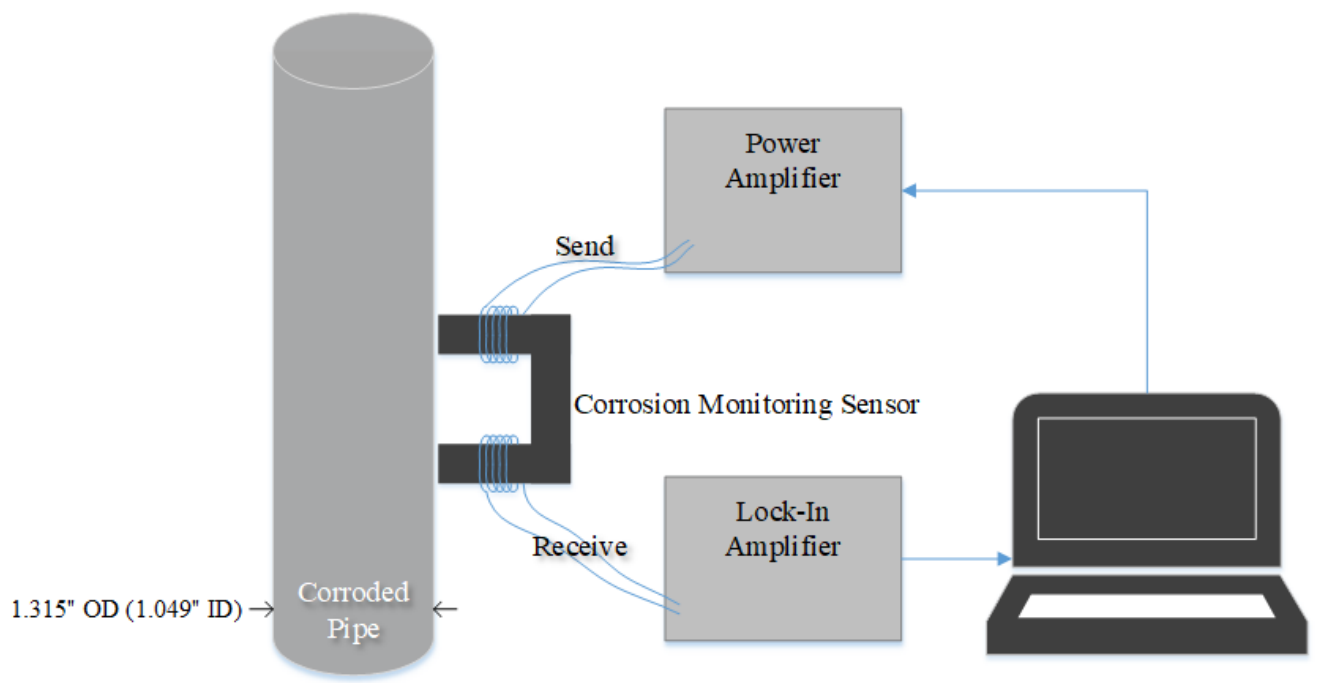

Figure 64. Room temperature testing of pipe using single corrosion sensor topology.

The single corrosion sensor with temperature compensation reference (TCR) topology is displayed in 
Figure 65. The set-up is very similar to that of the single sensor topology, except two LIAs are used. In this report, they are referred to as LIA(1) and LIA(2), as they are identical and can be used interchangeably. The top section of the pipe is polished to prevent the salt from creeping up during corrosion (see Section 3.1). This allows for a second temperature compensation reference measurement to be performed on the same pipe test specimen. This is discussed in detail in Section 3.2. A simple test procedure is used for single sensor with TCR testing:

1. Connect the "SIN+" output of LIA(1) to the reference input of LIA(2) and the input "L"

2. Hard wire the power amplifiers to a bench-top power supply (12V/5.5A current limit)

3. Connect the output channels (channel L+ and L-) of the power amplifiers to the "send" coil on the corrosion sensor

4. Connect the input channel of LIA(1) (channel A) to the "receive" coil on the corrosion sensor, and repeat for the TCR with LIA(2)

5. Ensure that USB communication between the computer and hardware is connected

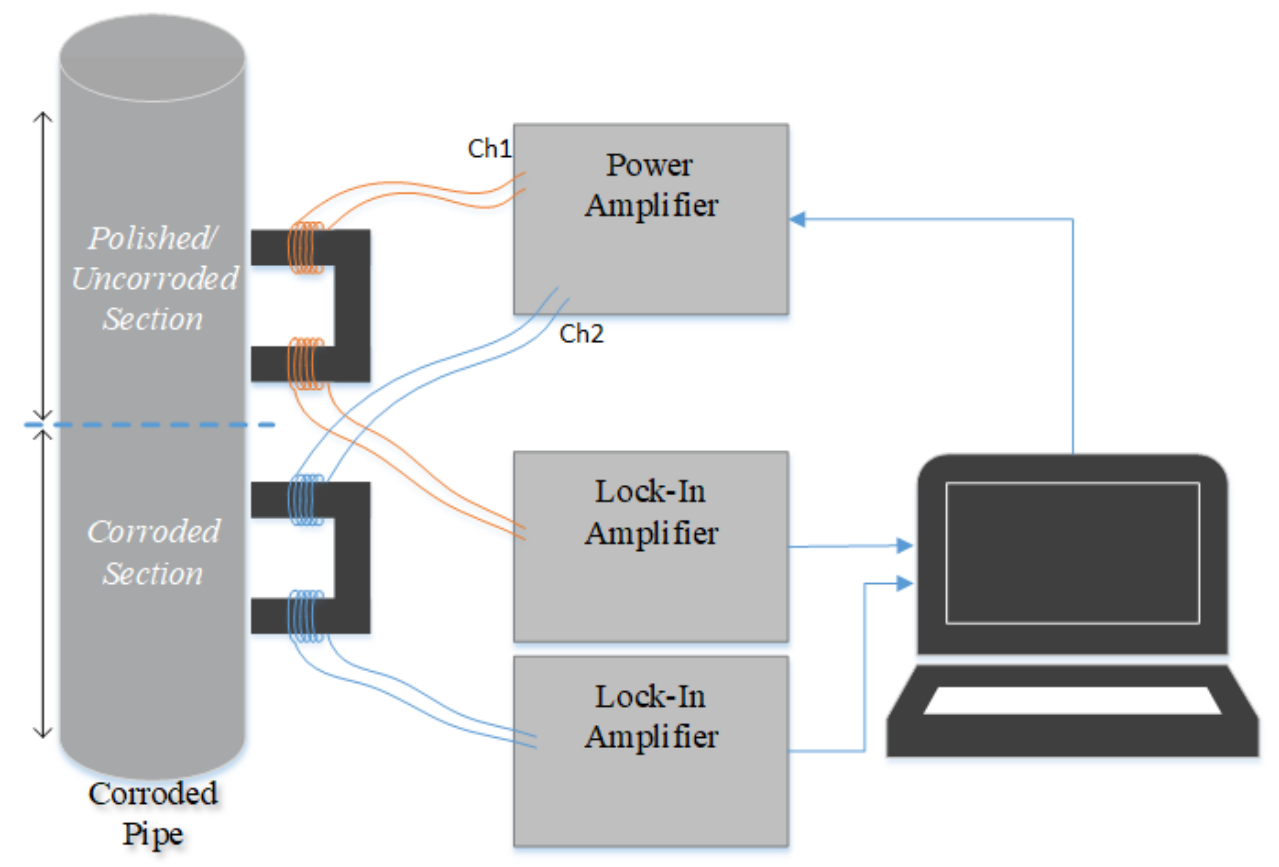

Figure 65. Room temperature testing of pipe using single sensor with TCR topology.

Preliminary results from room temperature testing are discussed in Section 4.1.

\subsubsection{FURNACE TESTING}

The furnace testing is almost identical to bench-top (room temperature) testing (Figure 65 and Figure 66). A Vulcan 3-550 furnace, placed inside a hood was used to test moderately elevated temperatures (see Section 3.3). This intermediate test allowed for step-science demonstrations. The desired temperature range for this testing is $200-300^{\circ} \mathrm{C}$. A simple test procedure was used to set-up the furnace: 
1. Wrap any exposed wire with Kapton tape to prevent electrical shorts

2. Color code all sensor wires for simple identification during set-up, ensuring "send" and "receive" are correctly connected to the experiment equipment

3. Feed the sensor wires through the electrical pass-through at the top of the furnace

4. Connect the sensors following the instruction procedure given in Section 3.4.1

5. Program the furnace ramp rates, temperature set-points, and hold times to meet test requirements

6. Calibrate thermocouples using InstaCal software

7. Acquire data using the custom data acquisition software

8. Save the data, turn off the furnace, and allow for an extended cooling period before handling the sensors inside the furnace

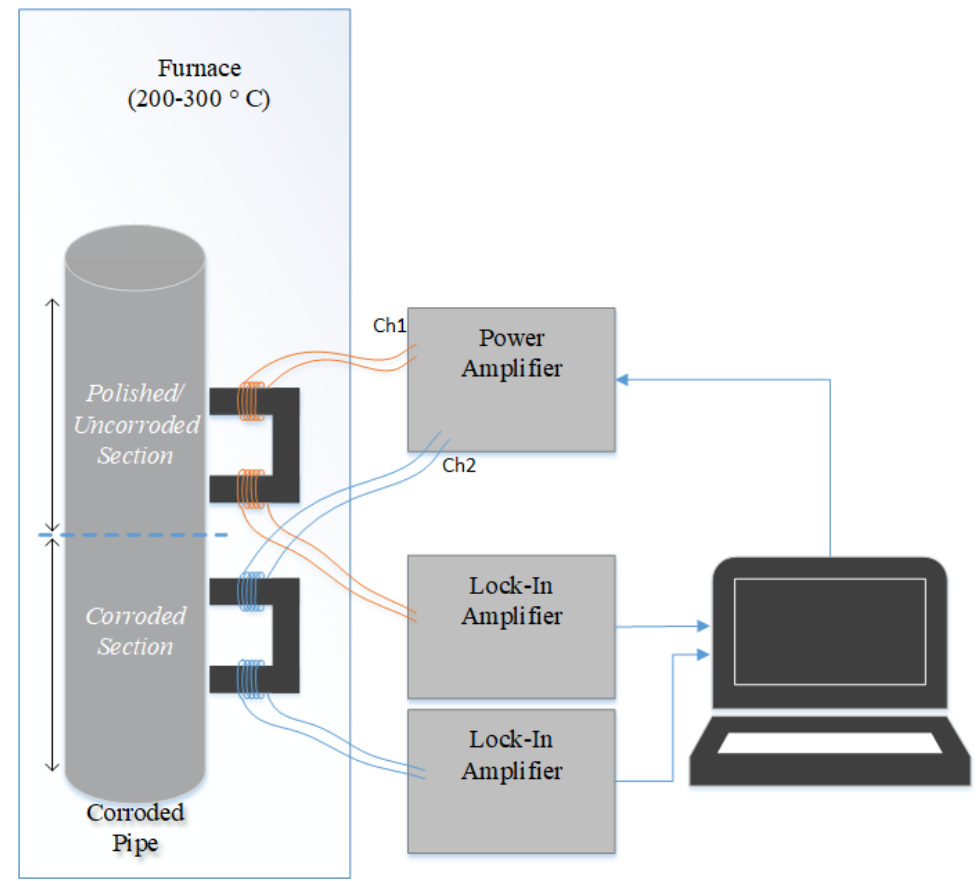

Figure 66. Furnace testing $\left(200-300{ }^{\circ} \mathrm{C}\right)$ of pipe using single sensor with TCR topology.

\subsubsection{CARTRIDGE HEATER TESTING}

A cartridge heater is used for extreme high temperature testing $\left(700-800^{\circ} \mathrm{C}\right)$ (Figure 67$)$. The electronics package and set-up is identical to the room temperature and furnace testing, except a cartridge heater is inserted inside the pipe being tested. The heater is controlled using a bench-top controller unit that monitors the the temperature via a thermocouple (Section 3.3). This test set-up is still under development. Since this is a bench-top experiment, a large amount of insulation is required to maintain a steady-state temperature profile. Also, the heating element has been custom built for this experiment, so bench-top testing is underway to ensure its performance. 


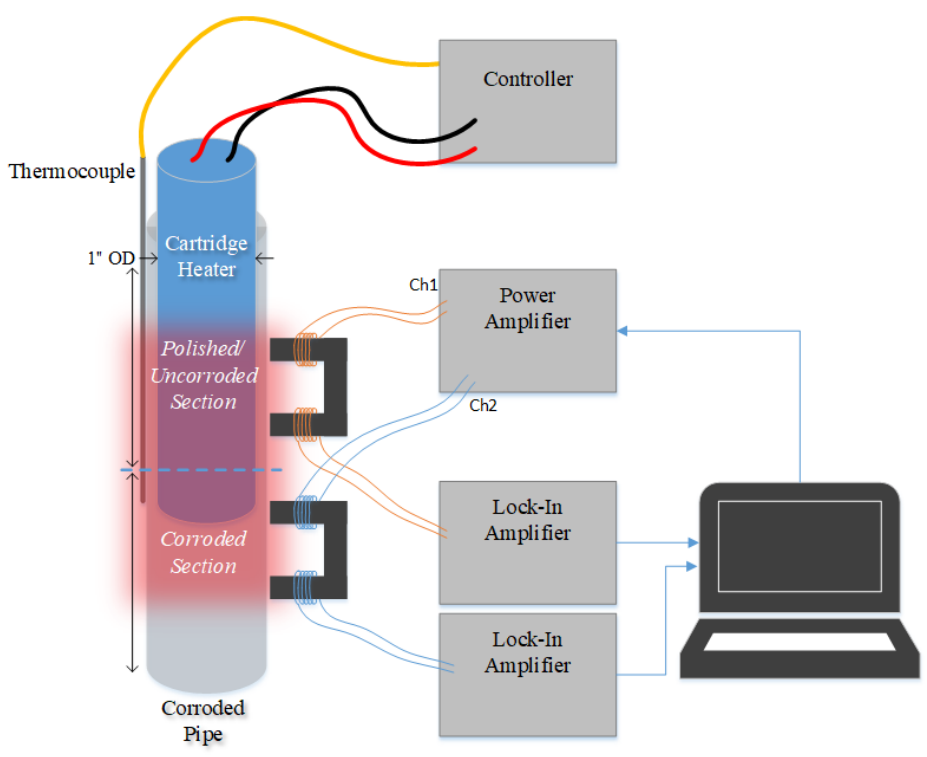

Figure 67. Cartridge heater testing $\left(700-800{ }^{\circ} \mathrm{C}\right)$ of pipe using a single sensor with TCR topology.

Thermal imaging and thermocouple monitoring are implemented on the initial bench-top testing of the cartridge heater. A FLIR camera with FLIR software are used to monitor the temperature visually, while a $\mathrm{k}$-type thermocouple is in physical contact with the pipe. 


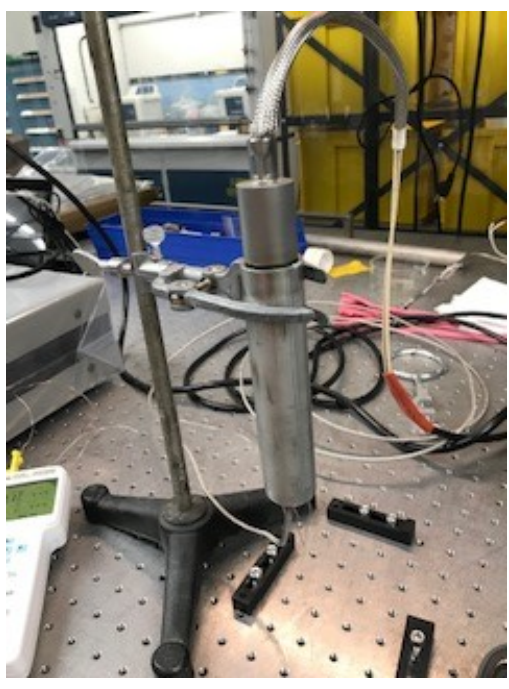

(a)

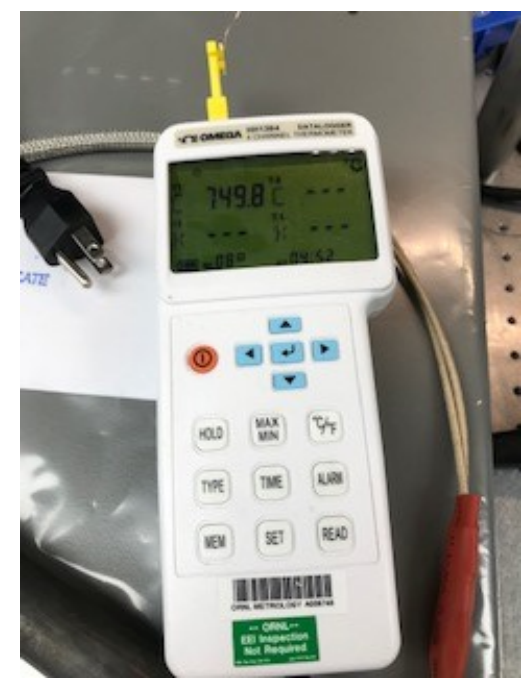

(b)

Figure 68. Cartridge heater bench-top evaluation of performance (a) and thermocouple readout (b).

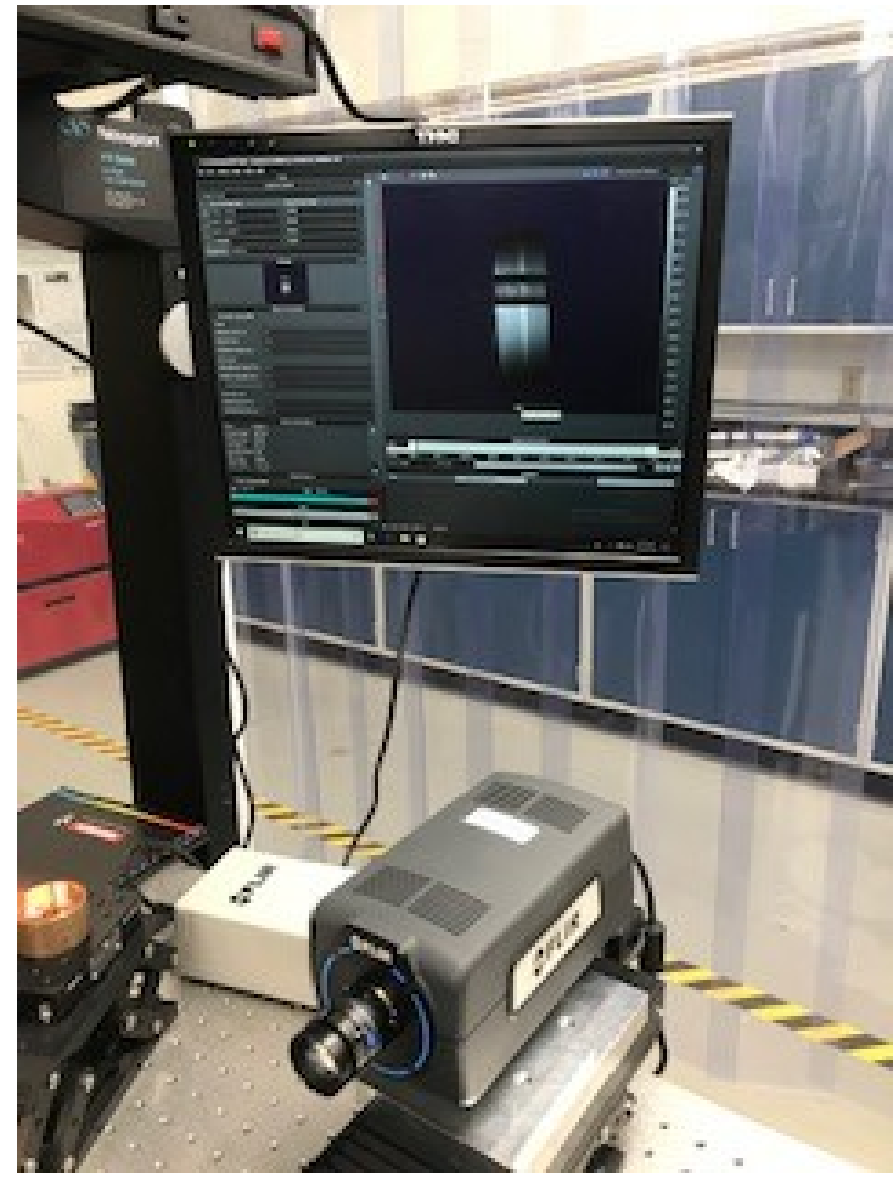

Figure 69. Thermal imaging system used as secondary performance monitoring system. 


\section{RESULTS/DESIGN CHANGES}

\subsection{ROOM TEMPERATURE TESTING}

\subsubsection{Comparing Annealed and Unannealed Hiperco ${ }^{\circledR} 50$ Core Materials}

A frequency sweep test was performed using 304L stainless steel corrosion samples with both the annealed and unannealed transducers. Transducers consisted of the laminated Hiperco ${ }^{\circledR} 50$ with boron nitride cores. The frequency was swept linearly from $100.0000 \mathrm{~Hz}$ to $10.0000 \mathrm{kHz}$ over a 30-second period with an AC input of $500 \mathrm{mV}$. The 150-turn coils were used on both sensors and were connected to the power amplifier and LIA. Tape was used to mark sensor and sample locations for consistent testing. The sensor configuration is depicted in Figure 70.

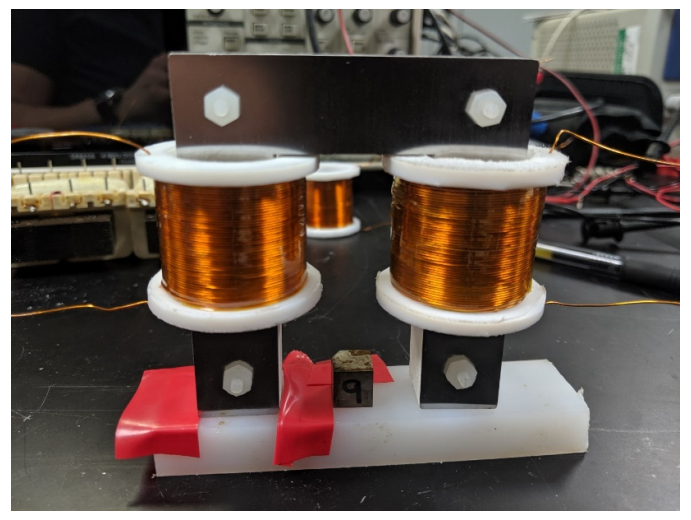

Figure 70. C-shaped Hiperco ${ }^{\circledR} 50$ core with transmit and receive coils.

The results of the test, as shown in Figures 71 and 72, indicate a diminishing gain in sensor performance above $500 \mathrm{~Hz}$. Moreover, the annealed sensor consistently demonstrated an improved performance over the unannealed sensor, with an average improvement of $250 \%$ by increasing the voltage.

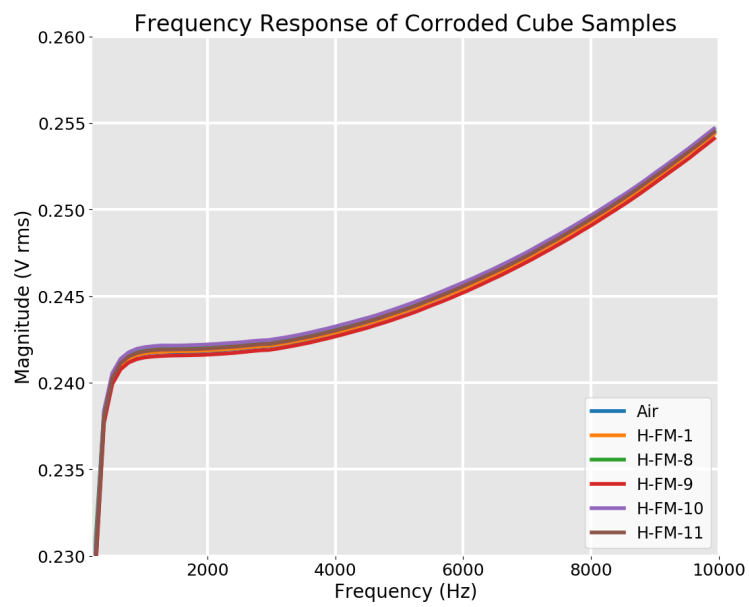

(a)

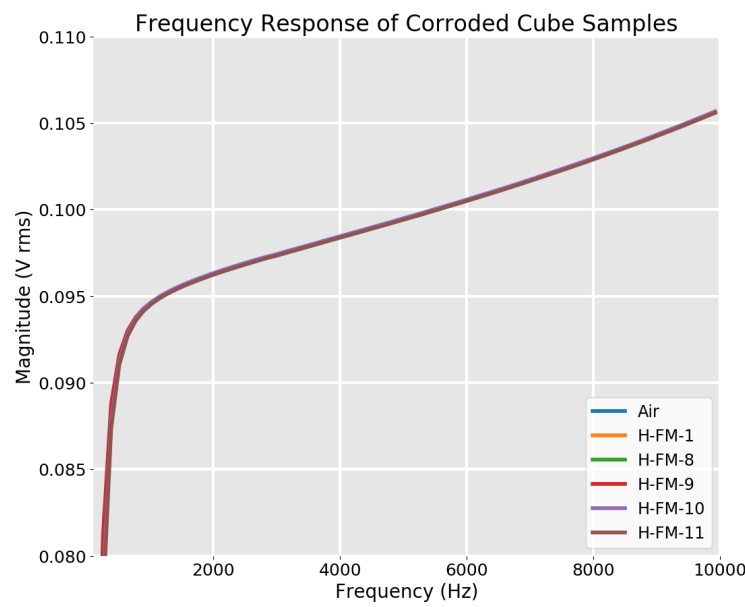

(b)

Figure 71. Magnitude response for cube samples with annealed core (a) and unannealed core (b). 


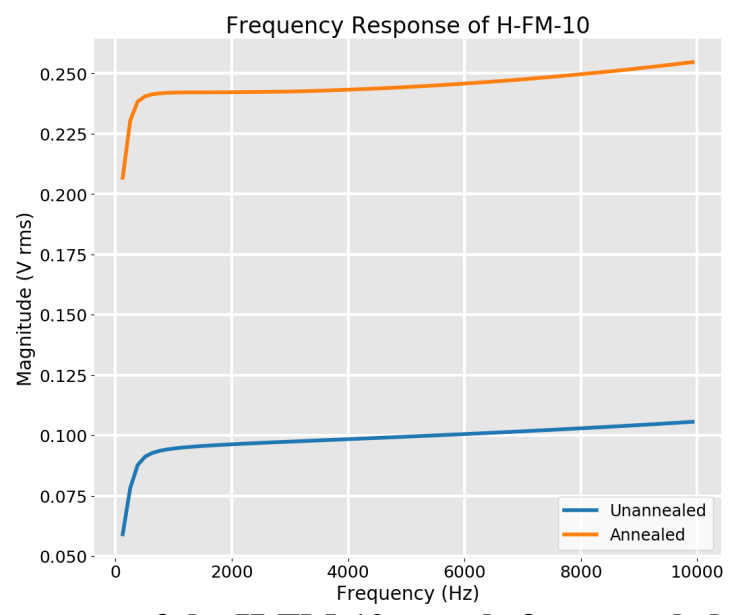

Figure 72. Magnitude response of the H-FM-10 sample for annealed and unannealed sensors.

\subsection{FURNACE TESTING}

\subsubsection{System Verification}

A heating test was performed to study the sensor performance at varying temperatures up to $250{ }^{\circ} \mathrm{C}$. A single sensor was tested consisting of the annealed Hiperco ${ }^{\circledR} 50$ core and two 150-turn bobbins. The Vulcan 3-550 was used for the system verification tests; the programmable controller includes a series of steps for autonomous operation. Each step includes a temperature ramp rate $\left(R_{i}\right)$, a temperature set-point $\left(T_{i}\right)$, and a hold time $\left(H_{i}\right)$. Figure 73 illustrates the programmed temperature profile.

The sensor was studied with and without a sample of polished, uncorroded 304L stainless steel pipe (see Figure 74). The pipe was laid flush with the open core side of the sensor. Various testing conditions were investigated (see Table 10).

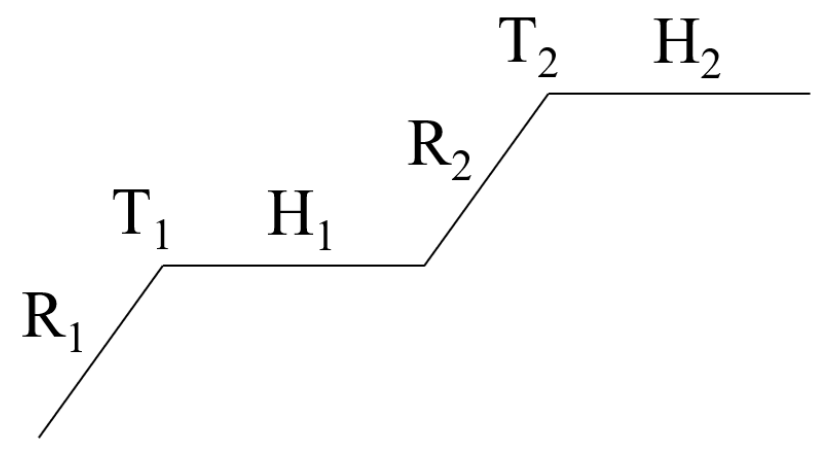

Figure 73. Furnace temperature step program diagram.

The results of the system verification tests are shown in Figure 75. All data were digitally filtered with a second-order Butterworth low-pass filter with a frequency cutoff of $0.05 \mathrm{~Hz}$. The temperature effects on the cores can be seen clearly in all tests. Both tests without the pipe are shown to have considerably lower voltage magnitudes than the tests with the pipe. Frequency dependence is reiterated by comparing the magnitude of sensor 1 with an air core test at $500 \mathrm{~Hz}$ (blue) and $300 \mathrm{~Hz}$ (orange). As $300 \mathrm{~Hz}$ is an integer 


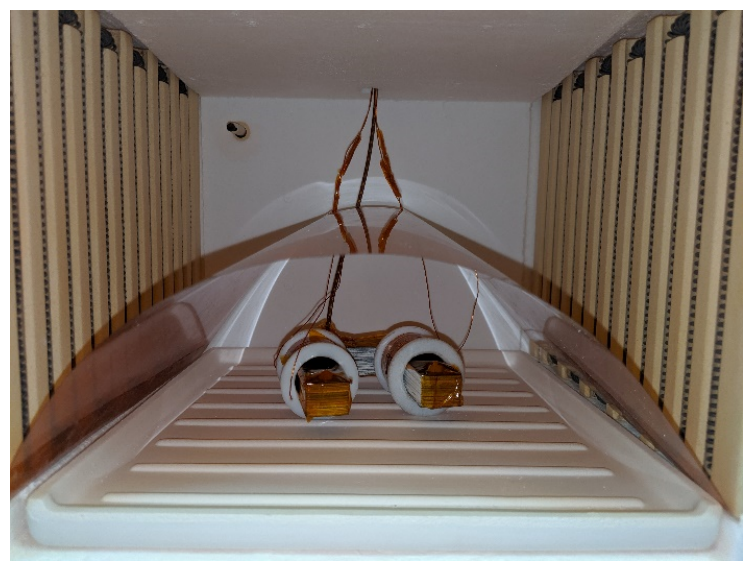

(a)

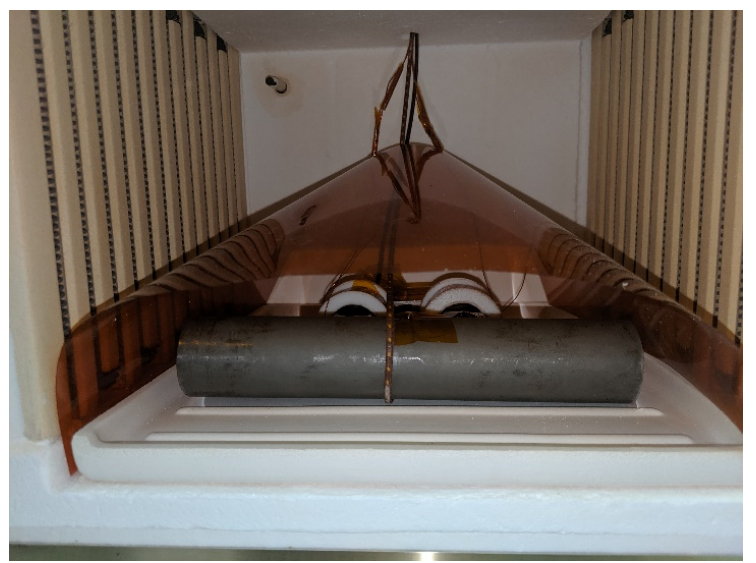

(b)

Figure 74. System verification placement without pipe (a) and with pipe (b).

Table 10. Experimental test parameters for system verification

\begin{tabular}{ccccccccc}
\hline Sensor & Sample & Frequency $(\mathbf{H z})$ & $R_{1}\left({ }^{\circ} \mathbf{C} / \mathbf{m i n}\right)$ & $T_{1}\left({ }^{\circ} \mathbf{C}\right)$ & $H_{1}(\mathbf{m i n})$ & $R_{2}\left({ }^{\circ} \mathbf{C} / \mathbf{m i n}\right)$ & $T_{2}\left({ }^{\circ} \mathbf{C}\right)$ & $H_{2}(\mathbf{m i n})$ \\
\hline 1 & Air & 500 & 2.0 & 125 & 30 & 2.0 & 250 & 30 \\
1 & Air & 300 & 3.0 & 125 & 60 & 3.0 & 250 & 60 \\
1 & Pipe & 500 & 3.0 & 125 & 60 & 3.0 & 250 & 60 \\
1 & Pipe & 500 & Natural Cooling & - & - & - & - & - \\
2 & Pipe & 500 & 3.0 & 125 & 60 & 3.0 & 250 & 60 \\
\hline
\end{tabular}

multiple of the $60 \mathrm{~Hz}$ line frequency used in the United States, more noise was introduced in the $300 \mathrm{~Hz}$ tests from the the power lines. Therefore, all subsequent tests were performed at $500 \mathrm{~Hz}$ for a better signal-to-noise ratio. Sensor 1 (green) and Sensor 2 (purple), each having a pipe sample at $500 \mathrm{~Hz}$ appear, to track each other with a voltage offset. The test with Sensor 1 has a pipe sample at $500 \mathrm{~Hz}$ at $60{ }^{\circ} \mathrm{C}$, whereas all the other tests (excluding cooldown) began at room temperature (approximately $22{ }^{\circ} \mathrm{C}$ ).

\subsubsection{Temperature Compensation Reference Verification}

Two annealed sensors were placed in the oven and connected as described in Section 3.3. Temperature probes were attached to each sensor using Kapton tape. The sensors were placed vertically in the same orientation, as shown in Figure 76. The coils were arranged so that the driving and sensing coils for each sensor were adjacent to each other. In Figure 76, the driving coils are the two coils closest to the camera. This arrangement was intended to reduce any cross-talk between the sensors, which was approximately $1 \%$ of the signal measurement. Furthermore, the gain on each audio amplifier was adjusted until the magnitudes matched on each sensor.

The plot of the sensors' magnitudes is shown in Figure 77a. Here the outputs align well for the lower temperatures, but they begin diverging at higher temperatures. A $2^{\text {nd }}$ order polynomial trend-line was generated in Python from the Numpy package for each sensor. The difference between the two trend-line magnitudes is shown in Figure 77b. Because small changes in temperature align better, this approach should be a reasonably way to compensate for temperature affects. 


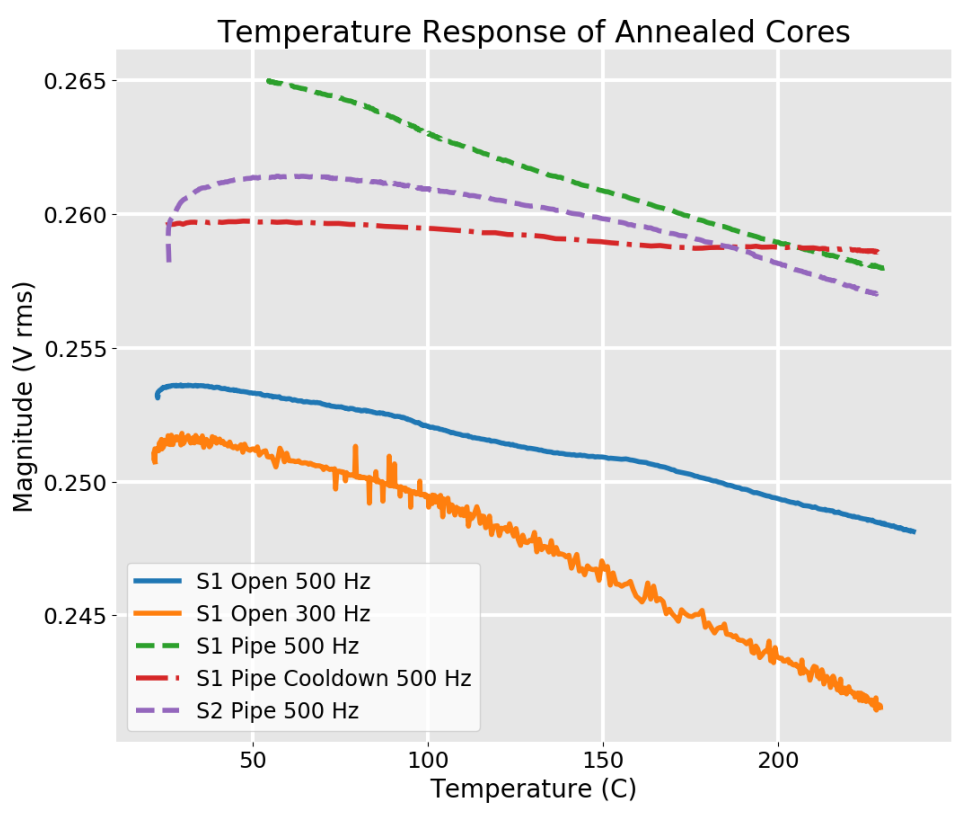

Figure 75. Temperature response of the system verification tests.

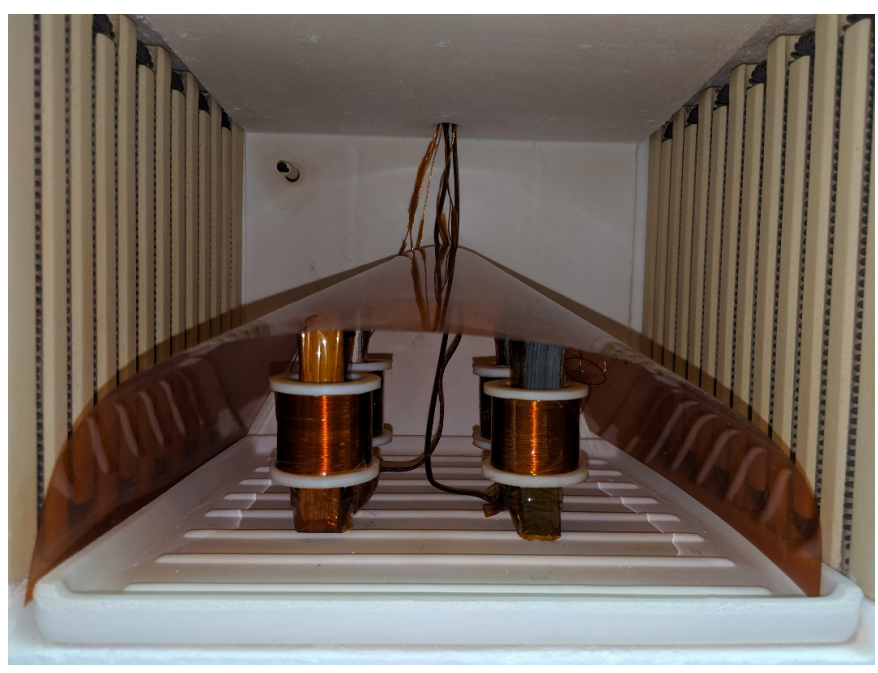

Figure 76. TCR placement within the furnace.

\subsubsection{Possible Current Drive Implementation}

Temperature dependence of the transducer is caused by three factors: (1) DC resistance of copper wire occurs at the rate of the temperature coefficient of copper $(0.004041 \Omega / K),(2)$ physical dimensions of the core and coil change with temperature, and (3) spacing of the magnetic domains changes at the atomic level as a function of temperature. Factors 2 and 3 cause the inductance to decrease as the temperature increases.

Currently, this system is implemented with a voltage-driven source with a current that generates the magnetic field. The magnetic field is proportional to the magnetic field for solenoids, as shown in 


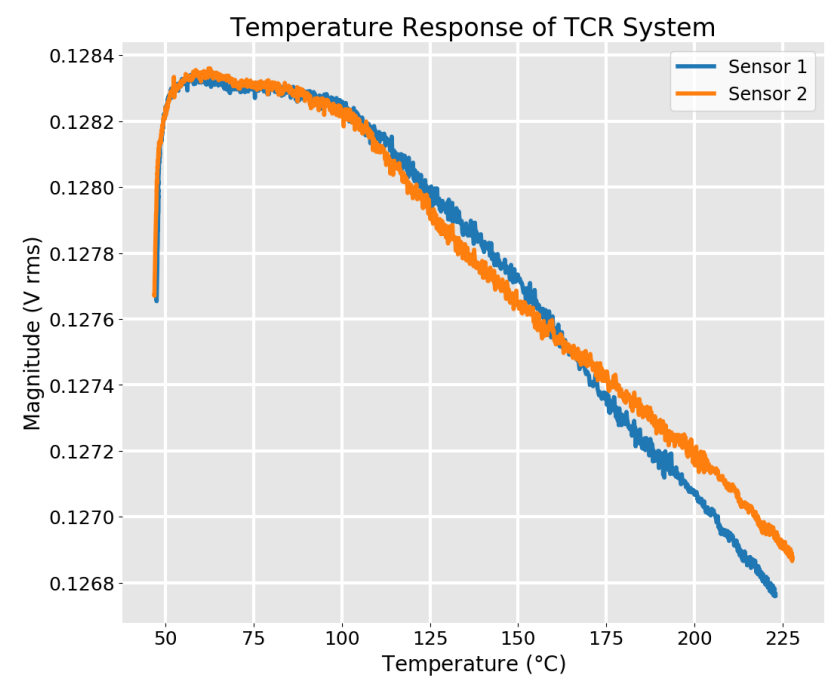

(a)

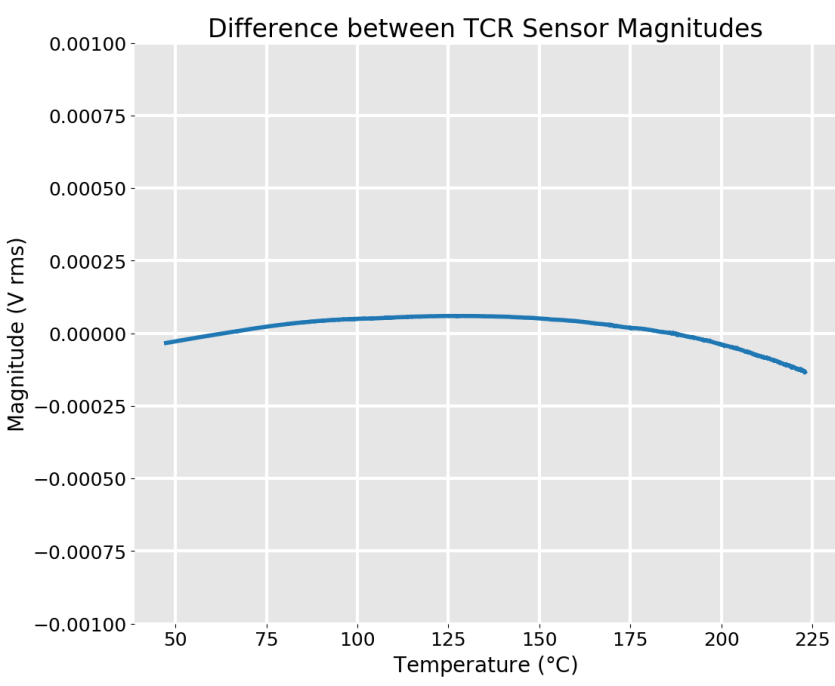

(b)

Figure 77. Temperature responses of all sensors in the TCR test (a) and the differences between their trendlines (b).

Equation 13:

$$
B=\mu N I
$$

The measured voltage on the second coil of the transducer is induced from Faraday's law, as in Equation 14:

$$
E M F_{\text {induced }}=-N A \frac{d B}{d t}
$$

It follows that the measure voltage is a function of the current in the loop. With a voltage-driven coil, the loop current is calculated from Equation 15:

$$
I=\frac{V}{Z}=\frac{V}{R+j \omega L}
$$

The receiver coil voltage is therefore dependent on the DC resistance coil $R$ and the inductance $L$ of the driving coil. In fact, as temperature varies, the resistance follows temperature proportionally, while inductance follows temperature as the inverse. The current through the driving coil with the discussed temperature dependence is shown in Equation 16, where $\Delta R_{T}$ is the change of resistance due to temperature, and $\Delta L_{T}$ it the change in inductance due to temperature (note that $\Delta R_{T}$ will be a positive quantity with an increase in temperature, and $\Delta L_{T}$ will be a negative quantity with an increase in temperature).

$$
I=\frac{V}{\left(R+\Delta R_{T}\right)+j \omega\left(L+\Delta L_{T}\right)}
$$


As shown in Figure 75 above, the inductance appears to drop quickly at lower temperatures, with their equivalent series resistors as the limiting factor for the remaining temperature increase. This is evidenced by a sharp increase in the magnitude response from 22 to $35^{\circ} \mathrm{C}$.

With a current-driven coil, the DR resistance is no longer a factor in setting the current, and measured voltage on the receiver coil becomes a function of the inductance only. This adaptation to the current mode will be made in the next series of experiments. 


\section{CONCLUSIONS / FUTURE WORK}

This document discusses the development and testing of a high temperature sensor that monitors for corrosion development in the structural materials of a molten salt reactor. While molten salt reactors have inherent advantages, the corrosive properties of the salt are a major disadvantage. Infrastructure can either be fabricated from expensive materials that withstand the corrosion for an extended period of time, or cheaper materials can be monitored for corrosion and replaced before failure.

While the Molten Salt Reactor Experiment sampled and monitored for leaching of chromium in the salt, this did not provide the information needed to understand the development of the corrosion. The sensor described herein monitors the increase in ferromagnetism of the corroding pipe and can be strategically placed on the reactor's infrastructure. In FY19, ORNL developed and demonstrated a high-temperature sensor that survives the harsh environment of an MSR. The sensor's electromagnetic and temperature performance was modeled and simulated to ensure an optimized design. An experiment testbed design at room temperature within a furnace $\left(200-300{ }^{\circ} \mathrm{C}\right)$ and with a cartridge heater $\left(700-800{ }^{\circ} \mathrm{C}\right)$ are discussed herein, as well as room temperature and furnace testing results.

Many lessons were learned about the materials selected for the high-temperature sensor. This led to some slight delays in development (annealing of core material). However, contingencies were taken into consideration, and allocated carryover funding allows for the cartridge heater testing to be preformed in FY20. Also, in FY20 the corrosion monitoring sensor will be installed on a flowing salt loop. 



\section{REFERENCES}

\section{References}

H. C. de Groh, S. M. Geng, J. M. Niedra, and R. R. Hofer. Magnetic Properties of Fe-49Co-2v Alloy and Pure Fe at Room and Elevated Temperatures. NASA Glenn Research Center: Cleveland, OH, 2018.

S. Delpech, E. Merle-Lucotte, D. Heuer, M. Allibert, V. Ghetta, C. Le-Brun, X. Doligez, and G. Picard. Reactor Physic and Reprocessing Scheme for Innovative Molten Salt Reactor System. Journal of Fluorine Chemistry, 130(1):11-17, 2009.

N. Dianne Bull Ezell, Joel McDuffee, Kurt Smith, and Stephen Raiman. Initial Irradiation Testing of Chloride Salts for Molten Salt Reactors. Proceedings of ANS Winter Meeting, 2018.

Charles W. Forsberg, Claude Renault, C. Le Brun, and V. Ignatiev. Liquid Salt Applications and Molten Salt Reactors. Revue Générale du Nucléaire, 4:63, 2007.

Charles W. Forsberg, Per F. Peterson, R. A. Kochendarfer, et al. Design Options for the Advanced High-Temperature Reactor. In Proceedings of ICAPP, volume 8, pages 8-12, 2008.

P. Guiraldeng and O. H. Duparc. The Genesis of the Schaeffler Diagram in the History of Stainless Steel. Metallurgical Research and Technology, 114(613), 2017.

David E. Holcomb, Roger A. Kisner, F. Kyle Reed, James Bates, and James R. Keiser. Development of an In-Situ Corrosion Monitor for Molten Salt Reactors. Proceedings of NPICEHMIT, 2019.

V. Ignatiev and A. Surenkov. Corrosion Phenomena Induced by Molten Salts in Generation IV Nuclear Reactors. In Structural Materials for Generation IV Nuclear Reactors, pages 153-189. Elsevier, 2017.

V. Ignatiev, O. Feynberg, I. Gnidoi, A. Merzlyakov, A. Surenkov, V. Uglov, A. Zagnitko, V. Subbotin, I. Sannikov, A. Toropov, et al. Molten Salt Actinide Recycler and Transforming System Without and With Th-U Support: Fuel Cycle Flexibility and Key Material Properties. Annals of Nuclear Energy, 64: 408-420, 2014.

Jérôme Serp, Michel Allibert, Ondřej Beneš, Sylvie Delpech, Olga Feynberg, Véronique Ghetta, Daniel Heuer, David Holcomb, Victor Ignatiev, Jan Leen Kloosterman, et al. The Molten Salt Reactor (MSR) in Generation IV: Overview and Perspectives. Progress in Nuclear Energy, 77:308-319, 2014.

Technical Datasheet. Hiperco ${ }^{\circledR} 50$ HS Alloy. Carpenter Technology Corporation, 2015. 